Florida International University FIU Digital Commons

\title{
Experimental Analysis of the Effects of Hydroscape Structure on Fishes in a Dynamic Wetland
}

Michael R. Bush

Florida International University, mbush002@fiu.edu

DOI: 10.25148 /etd.FIDC001755

Follow this and additional works at: https://digitalcommons.fiu.edu/etd

Part of the Aquaculture and Fisheries Commons, Behavior and Ethology Commons, and the Terrestrial and Aquatic Ecology Commons

\section{Recommended Citation}

Bush, Michael R., "Experimental Analysis of the Effects of Hydroscape Structure on Fishes in a Dynamic Wetland" (2017). FIU Electronic Theses and Dissertations. 3215.

https://digitalcommons.fiu.edu/etd/3215 


\section{FLORIDA INTERNATIONAL UNIVERSITY}

Miami, Florida

\section{EXPERIMENTAL ANALYSIS OF THE EFFECTS OF HYDROSCAPE STRUCTURE ON FISHES IN A DYNAMIC WETLAND}

A dissertation submitted in partial fulfillment of the requirements for the degree of

DOCTOR OF PHILOSOPHY

in

BIOLOGY

by

Michael Ross Bush 
To: Dean Michael R. Heithaus

College of Arts, Sciences and Education

This dissertation, written by Michael Ross Bush, and entitled Experimental Analysis of the Effects of Hydroscape Structure on Fishes in a Dynamic Wetland, having been approved in respect to style and intellectual content, is referred to you for judgment.

We have read this dissertation and recommend that it be approved.

William Anderson

Kevin Boswell

Michael Ross

John Withey

Joel C. Trexler, Major Professor

Date of Defense: March 20, 2017

The dissertation of Michael Ross Bush is approved.

Dean Michael R. Heithaus College of Arts, Sciences and Education

Andrés G. Gil

Vice President for Research and Economic Development and Dean of the University Graduate School

Florida International University, 2017 


\section{DEDICATION}

This dissertation is dedicated to my mom and dad. When all the other kids grew up, got real jobs, and started making money, I was still catching animals and playing in the woods. And my parents never questioned it for a second (or at least they did, they didn't tell me). 


\section{ACKNOWLEDGMENTS}

There are many that deserve credit for this dissertation. I wish to thank my advisor, Joel Trexler, who worked with me through my many various screw-ups, was always tough but fair, and taught me how to be a scientist. I wish to thank my committee members - Bill Anderson, Kevin Boswell, Mike Ross, and John Withey - for providing me with helpful comments throughout this process. I would like to thank Mike Ross again for generously providing excellent vegetation data of my study area, allowing me to include high quality maps in Chapters $1 \&$ 2. Thanks to Daniel Gann of the FIU GIS Center, who was instrumental in taking those vegetation data and making the maps. I wish to thank Florida Coastal Everglades Long-Term Ecological Research, USGS, and the Cristina Menendez Fellowship for funding. Franco Tobias and Sara Wilson were instrumental with nutrient analyses. Rafael Gonzalez-Collazo and Sergio Giglio were always there with vehicle help and rescuing when needed. Statistical help was provided and very welcomed by Jennifer Sweatman and Nathan Lemoine. Their patience in teaching me many matters of both stats and coding was key to this dissertation's success. Finally, I'd like to thank many, many members of Dr. Trexler's lab that provided me with assistance over the years. Joe Parkos, J-Matt Hoch, and Eric Sokol helped me with various aspects of experimental design, data collection, and analyses. Jessica Sanchez and John Gatto were kind enough to lend their time to my experiments, and Jessica also provided a lot of assistance with matters of nutrient quality and periphyton infauna for Chapter 3. Finally, I'd like to thank the dedicated and extremely hard-working field technicians and managers of the lab. Jim Easton, Eric Fortman, Chris Catano, Jake Bransky, Liz Huselid, Aaron Parker, and Sabrina Schneider helped make this dissertation possible and provided 
excellent field company. And finally, I wish to thank Justin Dummitt, who spent hundreds and hundreds of days out in the field with me, often in hot and stormy conditions. Of all the people who contributed to this dissertation, his role had the largest impact. Thank you. 


\title{
ABSTRACT OF THE DISSERTATION \\ EXPERIMENTAL ANALYSIS OF THE EFFECTS OF HYDROSCAPE STRUCTURE \\ ON FISHES IN A DYNAMIC WETLAND
}

\author{
by \\ Michael Ross Bush \\ Florida International University, 2017 \\ Miami, Florida \\ Professor Joel C. Trexler, Major Professor
}

Hydroscape structure can play a critical role in animal behavior, abundance, and community structure dynamics. Hydroscape configuration can be dynamic and can change quickly in ephemeral systems. However, ephemeral freshwater wetlands are among the most impacted systems in the world and restoration efforts often rely on incomplete information when establishing management objectives. Further understanding how alterations in hydroscape structure in dynamic systems affect animals is critical for conservation and management success.

To determine impacts that changing hydroscape conditions can have on consumers in freshwater wetlands, I examined the effects of a large-scale physical model on fish behavior, abundance, and community structure. The physical model incorporated the restoration of sheetflow, canal-fill treatments, and the removal of a decades-old levee that divided two water management areas in the central Everglades. Small fishes modified directional movement behaviors and speed of movement before and after alterations took place, though behavioral responses varied widely by species. Density and community structure of small fishes did change as a function of canal-fill and levee 
removal treatments. Behaviors of large fishes were also affected by hydroscape alterations, as well as hydroscape configuration beyond the limited footprint of the physical model. Large fish abundance was altered by hydroscape alteration, particularly among certain species. Composition of the large fish community changed before and after hydroscape alteration, though magnitude of responses were site-specific.

Effects of hydroscape structure proximity on trophic dynamics were examined using exclosure cages that excluded large predators but allowed access for small consumers. Exclosures were stratified according to proximity to a deep-water canal. Predator avoidance behaviors in small consumers were limited but present. Differences in behavior between sites may also be caused by differences in structure across sites and limited differences in nutrient quality.

Behavioral, population, and community responses to hydroscape alteration can be valuable metrics to assess the success of hydroscape restoration. While results can vary across individuals, species, and sampling sites, effects can still be detected even at the scale of the hydroscape. My research has detailed the potential effects of restoration plans across the greater Everglades and can be extended to other ephemeral wetland restoration programs. 


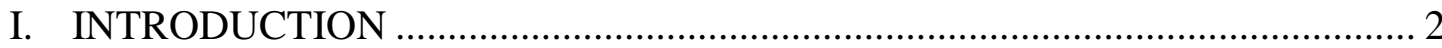

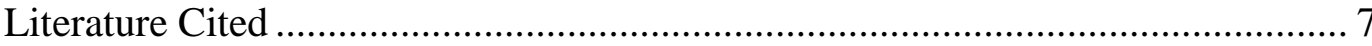

II. EXPERIMENTAL TEST OF EFFECTS OF HYDROSCAPE STRUCTURE ON WETLAND ANIMAL-SPACE INTERACTIONS .................................... 10

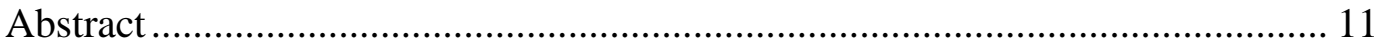

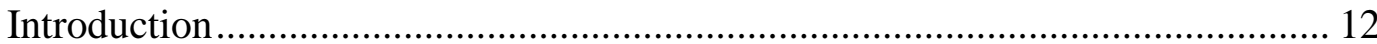

Materials and Methods............................................................................ 15

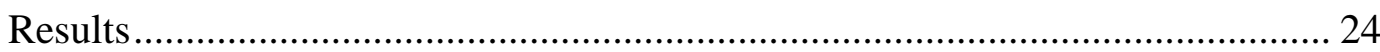

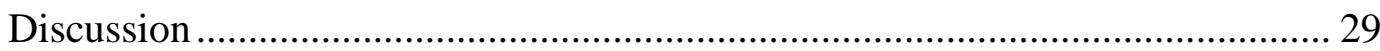

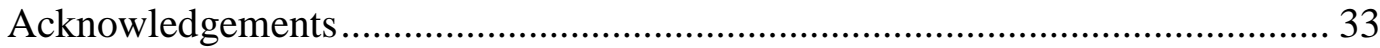

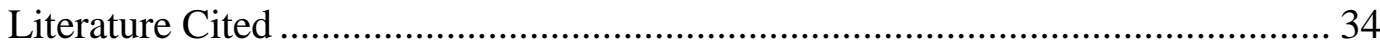

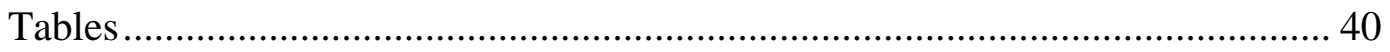

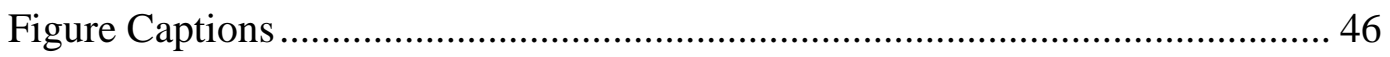

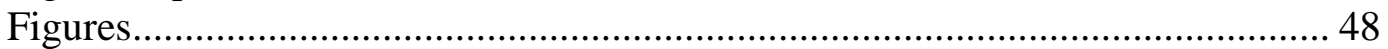

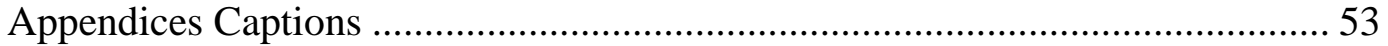

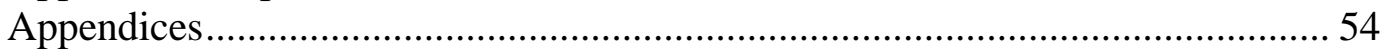

III. EFFECTS OF HYDROSCAPE ALTERATION ON LARGE FISH BEHAVIOR, DENSITY, AND COMMUNITIES IN A DYNAMIC

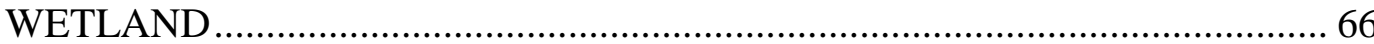

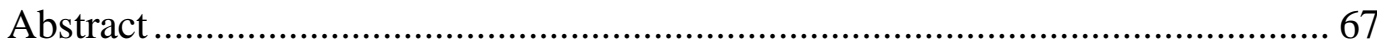

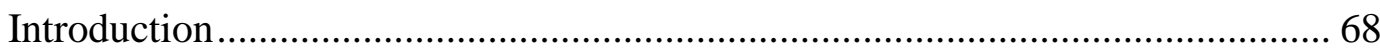

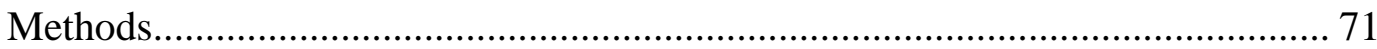

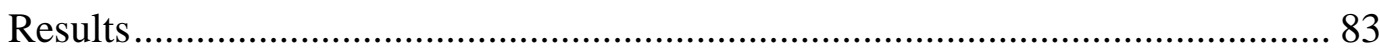

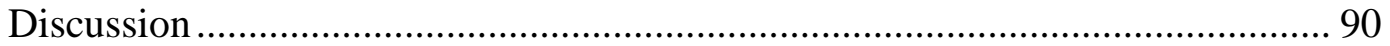

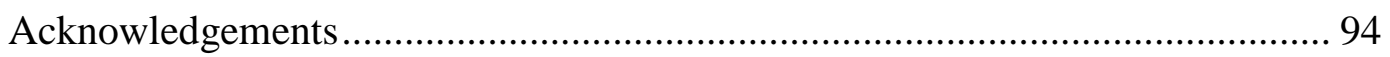

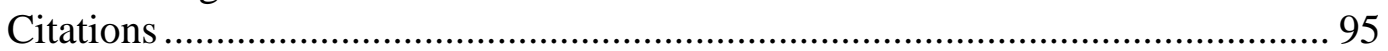

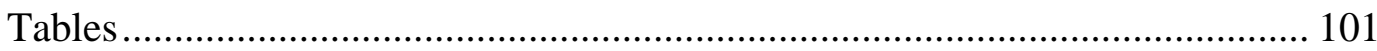

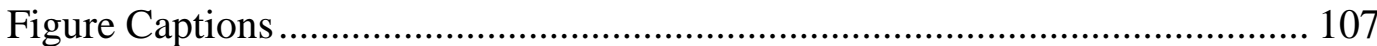

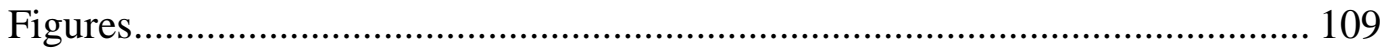

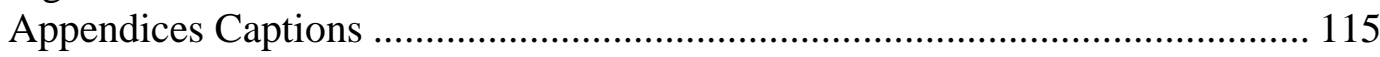

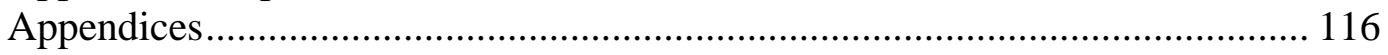

IV. ECOTONE PROXIMITY AND CONSUMER IN A DYNAMIC

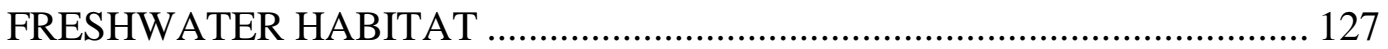

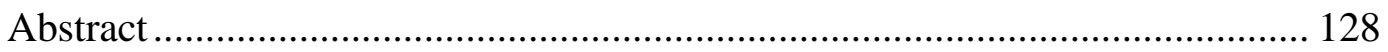

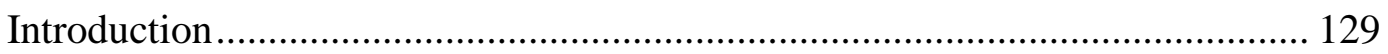

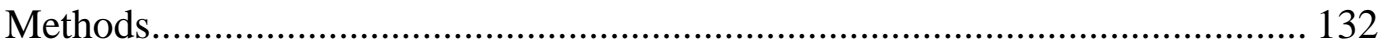




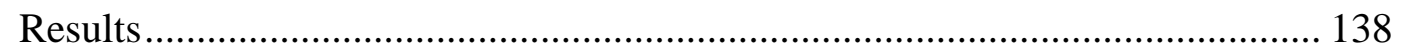

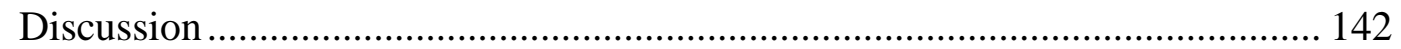

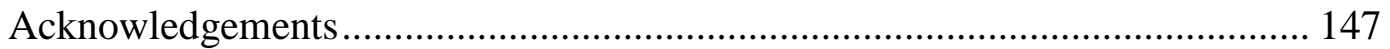

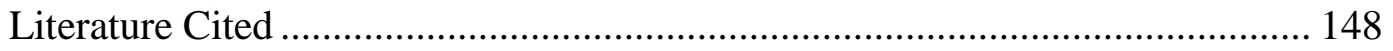

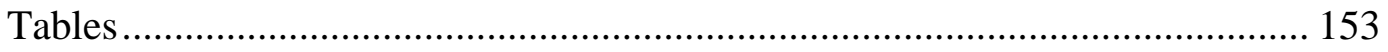

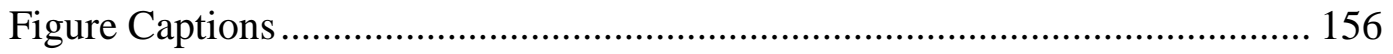

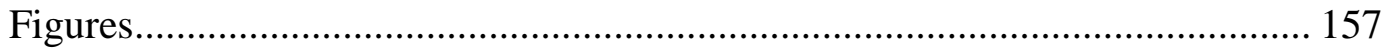

Appendices Captions ............................................................................. 161

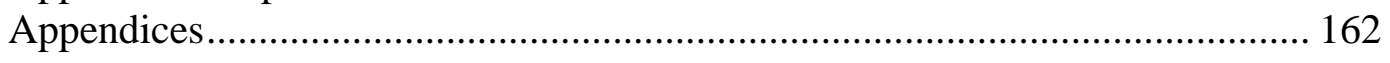

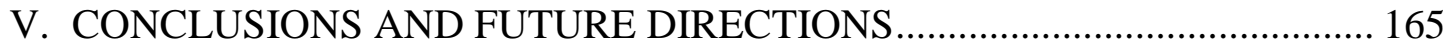

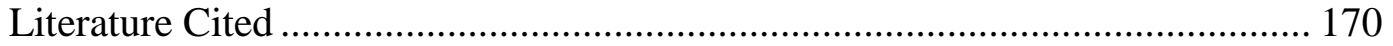

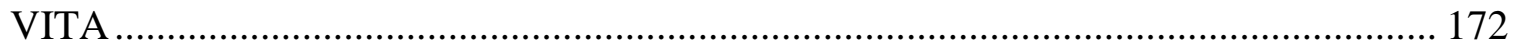




\section{LIST OF TABLES}

TABLE

PAGE

\section{CHAPTER II}

$1 \quad$ Sites and their abiotic and biotic parameters. Small fish density was estimated by throw traps and encounter rate was estimated by drift-fence captures. Error is one standard deviation. The FC and NC sites were sampled approximately 10 times before and after alteration. The EL sites were samples 9 times before and after alteration. The FC and NC Controls sites were sampled six times before alteration and the EL Control sites were sampled five times before alteration. All Control sites were sampled 10 times after alteration.

2 Species-specific relationship between drift fence CPUE (Y axis) and throw trap density ( $\mathrm{X}$ axis). $\mathrm{n}$ is the total number of throw trap and minnow trap sample pairs where species was captured. Slope equal to 1.0 was the null hypothesis. $\mathrm{R}^{2}$ is the coefficient of determination.

3 Model fit to A. density (\# fish $/ \mathrm{m}^{2}$ ) and B. encounter rate (CPUE) testing BACI hypothesis with three-way interaction accounting for water level fluctuation (WDC). $\mathrm{P}<0.10$ are in bold.

4 Results of PERMANOVA mobile community analyses for encounter rate data, including site data divided between before and after hydroscape alternation (Time). Permutations $=9999$.

5 Mantel's Test (PERMDISP) analyses, examining dispersion of communities within Sites and sample types that exhibited significant differences in community structure across Site $\times$ Time.

6 Parameters examined during hydroscape alteration. 'Yes' denotes that our BACI hypotheses were confirmed $(\mathrm{p}<0.10)$. NC-EL Convergence were test for convergence of fish communities on either side of the levee after removal....45

\section{CHAPTER III}

1 Abiotic and biotic conditions of our study area. Periphyton volume, emergent plant stem density, and fish density were estimated by use of a $1-\mathrm{m}^{2}$ throw trap (Bush and Trexler in review). Fish density includes all species captured in the throw trap, which are generally less than 5-cm standard length and are indicative of prey density for LMB and Bowfish at these sites. Error is 1 standard deviation. These metrics were not taken for sites within the L-67C canal. 
2 BACI distance from canal models. Only the most parsimonious models of best fit $(\triangle \mathrm{AIC}<2.0$ from the lowest scoring model) are shown, along with the null model.

3 Step length models for the all locations including fish moving outside the BACI area. Only the most parsimonious models of best fit $(\triangle \mathrm{AIC}<2.0$ from the lowest scoring model) are shown, along with the null model.....

4 Distance-from-Canal models. Only the most parsimonious models of best fit $(\triangle \mathrm{AIC}<2.0$ from the lowest scoring model) are shown, along with the null model.

5 PERMANOVA analyses from Time $\times$ Site $\times$ Hydroperiod. Number of permutations $=9999$.

\section{CHAPTER IV}

1 Overview of abiotic and biotic parameters of our study area. Data were grouped between periods of high water (October and December) and low water (March) samples

2 Models for small fish, grass shrimp, and algal cell densities, and edibility indices. Only the most parsimonious models of best fit $(\triangle \mathrm{AIC}<2.0$ from the lowest scoring model) are shown, along with the null model and the full model if necessary.

3 Dynamic effect sizes for small fishes $\left(\# / \mathrm{m}^{2}\right)$, grass shrimp $\left(\# / \mathrm{m}^{2}\right)$, edibility index, and cell count $\left(\# / \mathrm{mm}^{2}\right), \pm 95 \%$ confidence interval 


\section{LIST OF FIGURES}

FIGURE

PAGE

\section{CHAPTER II}

1 Map of Study Area. A. Region where the study was conducted, (southern Florida, USA). B. Study area showing area of control and impact plots. Polygons with diagonal lines are terrestrial tree islands. The water control structure that delivers the experimental flow pulse is at approximately the position of the arrow, which is pointing in the approximate direction of water flow during those periods. C. Experiment area with three plots at each site, FC, NC, EL. Control plots for each site are outside of this map. Sawgrass ridges are represented by dark gray. Open water sloughs are light gray........................48

2 Density of small fishes (individuals $\mathrm{m}^{-2}$ ) at the NC sites, divided by plot type. Error bars represent $95 \%$ confidence intervals. Densities were back-transformed from square-root +1 values.

3 A. Directionality of fish before and after hydroscape alteration with shaded area indicating 95\% confidence intervals. Solid lines represent Impact sites and dotted lines represent Control sites. Long-dashed line represents equal movement rates towards and away from canal. Minus and plus symbols along the $\mathrm{x}$-axis represent daily rising and falling water depths. A. Flagfish at EL sites. B. Golden Topminnow at NC sites.

$4 \quad$ Movement speed of fish before and after hydroscape alteration with shaded fill indicating 95\% confidence intervals. Speed values are back-transformed from natural-log or square root transformations. Water depth change is absolute values. Solid lines represent Impact sites and dotted lines represent Control sites. A. Flagfish at EL sites. B. Eastern Mosquitofish at FC sites (note different scale of y-axes). C. Bluefin Killifish at NC sites.

5 nMDS of communities at EL sites. Hollow shapes are before alteration. Filled shapes are after alteration. A.Mobile communities. B. Resident communities.....52

\section{CHAPTER III}

1 Map of Study Area. A. Regional location of the study in southern Florida, USA. B. The primary study area bounded by levees L67 A and C, the location of added water inflow (arrow) and the control and impact study areas (star). Polygons with diagonal lines are terrestrial tree islands. C. The primary experimental area with marsh and canal sampling sites. Sawgrass ridges are 
2 Bowfin (a) and LMB (b) step lengths (daily distance moved in meters) within and across marsh and canal habitats. Error bars represent $95 \%$ confidence intervals. Data are back-transformed from $\ln (\mathrm{x}+1)$.

3 Bowfin (a) and LMB (b) average distance from the canal. Error bars represent 95\% confidence intervals. Solid background line is the average marsh water depth. Data were not back-transformed because the model of best fit for Bowfin was Average Daily Depth + Average Daily Depth Change.

Bowfin (a) and LMB (b) predicted occupancy of the marsh. The solid line is when marsh water depth is increasing. The dotted line is when marsh water depth is decreasing. The shaded area around the lines represent $95 \%$ confidence intervals.

5 CPUE of total large fishes across all three site types with the Impact area before hydroscape alteration (a) and after hydroscape alteration (b), and in the Control areas before hydroscape alteration (c) and after hydroscape alteration (d). Solid lines represent Canal sites, dotted lines represent NC sites, and dot-dash lines represent FC sites. Shaded areas represent $95 \%$ confidence intervals. Data are back-transformed from $\ln (\mathrm{x}+1)($ graphs $\mathrm{a}$ and $\mathrm{b})$ and $\operatorname{sqrt}(\mathrm{x}+1)($ graphs $\mathrm{c}$ and $\mathrm{d}) . .113$

6 nMDS of community position and dispersion for Canal, NC, and FC sites for Impact (A) and Control (B) sites. nMDS was generated for all sites but graphically divided between Impact and Control for clarity. Dark shapes represent Before alteration and light gray shapes represent After alteration. Solid lines represent Canal or Canal Control. Long-dashed lines represent NC or NC Control. Dotted lines represent FC or FC Control. Stress $=0.21$.

\section{CHAPTER IV}

1 Hydrograph of marsh water depth at sites near canal. Filled circles indicate approximate period of exclosure experiments. Water depths were calculated using the Everglades Depth Estimation Network (EDEN; Telis 2006, Liu et al. 2009) and adjusted using period in situ measurements

2 Effect sizes across sampling months and habitat types. See Methods for descriptions of dynamic effect size and edibility index calculations

3 Stem density $\left(\mathrm{m}^{-2}\right)$ collected from throw-trap data during period of experiment termination across sampling months. Closed circles represent Canal sites and open circles represent Marsh sites. Error bars represent 95\% confidence 
intervals. Data were back-transformed from $\operatorname{sqrt}(\mathrm{x}+1)$.

4 Periphyton volume $\left(\mathrm{mL} \mathrm{m}^{-2}\right)$ collected from throw-trap data during period of experiment termination across sampling months. Closed circles represent Canal sites and open circles represent Marsh sites. Error bars represent 95\% confidence intervals. Data were back-transformed from sqrt $(x+1) \ldots \ldots \ldots \ldots \ldots \ldots \ldots . . . . .160$ 


\section{PREFACE}

The following chapters will be submitted for publication and are formatted according to journal specifications:

\section{CHAPTER II}

Bush, M.R., J.C. Trexler, C. Saunders, and F. Sklar Experimental test of effects of hydroscape structure on wetland animal-space interactions. Journal of Landscape Ecology.

\section{CHAPTER III}

Bush, M.R., H. Mallikarachchi, K. Boswell, C. Saunders, F. Sklar, B Rosen, and J.C. Trexler. Effects of hydroscape alteration on large fish behavior, density, and communities in a dynamic wetland. Transactions of the American Fisheries Society.

\section{CHAPTER IV}

Bush, M.R., S. Bornhoeft, and J.C. Trexler. Ecotone proximity and consumer in a dynamic freshwater habitat. Freshwater Science. 
CHAPTER I

INTRODUCTION 
Influences of landscape configuration on organismal dispersal can vary greatly across individuals, populations, and species (Kolasa and Romanuk 2005, Parkos et al. 2014, Hoch et al. 2015). Animals must adopt adaptive behaviors to successfully navigate landscape obstacles and the threats they represent (Roshier et al. 2008). Adaptive movement behaviors are necessary for survival in seasonally dynamic systems, where habitat quality can vary across spatiotemporal scales (Bell 2000). Effects of hydroscape structure on behavioral, population, and community dynamics have been relatively understudied in non-riverine wetlands when compared to advancements in terrestrial landscape ecology. However, management and restoration efforts often involve drastic alteration to the hydroscape that can influence behavioral and demographic processes (Cucherousset et al. 2007, Maloney et al. 2008, Hogg et al. 2015). Influences of the hydroscape can translate to differences across communities and form the basis of metacommunity theory (Leibold et al. 2004). While the metacommunity paradigm has been applied to aquatic macroinvertebrates (Cottennie et al. 2003), the field is still in its infancy with regard to vertebrate communities. With studies incorporating highly-mobile species, the possibilities of moving metacommunity studies to an applicable management framework become more realistic. Conservation and management programs often implicitly use metapopulation theory for species management (Marsh and Trenham 2001), but whole-system management could greatly benefit from the structural framework of metacommunity theory. As freshwater wetland conservation efforts expand to large and complicated management plans, understanding how hydroscape alteration effects aquatic animals is important for determining the efficacy of 
management programs (Poff et al. 1997, Poff and Zimmerman 2010) as well as furthering the understanding of vertebrate metacommunity function.

The Everglades of Florida, U.S.A., allows for the study of the confluence of animal behavior and hydroscape configuration, as well as how these behaviors influence population and community dynamics. Considerable structural modification proposed by restoration efforts are taking place throughout the Everglades ecosystem and provide opportunities to examine the role that large-scale hydroscape alteration has on aquatic vertebrates. My dissertation was conducted in support of these restoration efforts, using the Decomp Physical Model (DPM; DPMST 2010) to answer simple but powerful questions of fish behavior and community structure in a changing hydroscape.

Hydroscape modification from DPM included the filling of a deep-water canal to marsh or half-marsh depth over approximately 300 meter stretches, as well removal of an earthen levee near the modified canal that had two compartmentalized areas of the marsh that had not been hydrologically connected since the 1960s (Light and Dineen 1994). Findings from DPM-related research were then used to set up a research framework examining trophic interactions of two size classes of consumer and how they vary with location in the hydroscape.

The first chapter of this dissertation, titled "Experimental test of effects of hydroscape structure on wetland fish behavior, population, and community structure", examined impacts of hydroscape alteration from DPM on small fishes. Using $1 \mathrm{~m}^{2}$ throw traps and mobile drift fences embedded with minnow traps (Jordan et al. 1997, Obaza et al. 2011, Hoch et al. 2015), I examined the how hydroscape alterations influenced small fish community structures of both resident and mobile species, total fish density, total 
fish encounter rate, speed, and directional movement. The last two parameters were examined across the eight most common small fishes (standard length $<8 \mathrm{~cm}$ ) of the Everglades. Using a Before/After-Control/Impact (BACI) framework, three years of data were taken prior to DPM efforts, and approximately two years of data after those restoration efforts. Control sites were established to the north and south of the main study area. Sampling sites were established in a stratified fashion on both sides of the degraded levee, varying with distance from the impacted canal.

The second chapter, titled "Effects of hydroscape alteration on large fish behavior, abundance, and communities in a dynamic wetland", also relied on DPM alterations to examine community structure and behaviors of fishes, but applied these efforts to a larger size class of fishes (standard length $>8 \mathrm{~cm}$ ). These fishes differ from small fishes by having multi-year life spans and because large fishes are highly mobile and able to quickly move across the hydroscape. Two common piscivores, the Largemouth Bass (Micropterus salmoides) and Bowfin (Amia calva), were implanted with VHF radio transmitters and tracked weekly via airboat or fixed-wing aircraft before and after DPM construction efforts, allowing me to monitor the effects of major structural changes on large predator behavior and how they might have been influenced by hydroscape alteration. Over the course of my dissertation, the behaviors of approximately 100 individuals from each species were monitored for varying periods of time, from just a couple of weeks (dropped/failed transmitters) to over nine months. Using an airboat mounted electroshocker (Chick et al. 1999) and a dual-frequency identification sonar (DIDSON) (Tiffan et al. 2004) in a BACI design, I was able to determine the impacts of DPM on large fish abundance and community structure. Survey 
transects were stratified using their position relative to the modified canal and were located adjacent to the canal, in the marsh interior, and along the littoral edge of the canal itself.

My final data chapter, titled "Ecotone proximity and consumer behavior in a dynamic freshwater habitat", experimentally evaluated interactions between large and small-fish size classes and examined the role of hydroscape structure on large-fish predation risk for small fishes. One- $\mathrm{m}^{2}$ exclosure cages were deployed in 12 sites (six adjacent to the canal, six 150-300 meters away from the canal) for 13 days to evaluate behavioral responses of small fish and macroinvertebrates. Each site had a cage that excluded large predators, thus creating a refuge for small fishes and aquatic macroinvertebrates, and a control cage that permitted animals of all sizes to enter. The field experiment was run during three months representing the annual hydrological cycle, allowing me to determine if perceived predation risk of small fishes was dependent on proximity to a prominent hydroscape feature, the amount of water available, neither, or both. Fishes and macroinvertebrates from these cages were removed after each study period and the Dynamic Effect Size (Osenberg et al. 1997, Chick et al. 2008) was used to determine if perceived predation risks were altered on the basis of hydroscape proximity or water depth. Furthermore, effects of hydroscape proximity influence on periphyton forage quality, elemental abundance, and Chl- $\alpha$ abundance were also examined.

My dissertation builds on a robust body of work examining the role of hydroscape configuration and water depths of fish abundance, community structure, and behaviors in the seasonal marshes of the Everglades (Trexler et al. 2005, Parkos et al. 2011, Goss et al. 2014). By using the considerable efforts of DPM, I was able to experimentally study 
fishes in a long-hydroperiod marsh experiencing modifications of water flow and hydroscape configuration. These efforts permited me to detail the effects that hydroperiod alteration, configuration, and restoration efforts can have on the aquatic community of the Everglades. My dissertation provides a robust examination of hydroscape structure on the fish behaviors, populations, and metacommunity processes of the Everglades and of seasonal freshwater marshes in general.

Literature Cited

Bell CP (2000) Process in the evolution of bird migration and pattern in avian ecogeography. J Avian Biol 31:258-265

Chick JH, Coyne S, Trexler JC (1999) Effectiveness of airboat electroshocking for sampling fishes in shallow, vegetated habitats. N Am J Fish Manage 19:957-967

Chick JH, Geddes P, Trexler JC (2008) Periphyton mat structure mediates trophic interactions in a subtropical marsh. Wetlands 28:378-389

Cottenie K, Michels E, Nuytten N, De Meester L (2003) Zooplankton metacommunity structure: regional vs. local processes in highly interconnected ponds. Ecology 84:991-1000

Cucherousset J, Carpentier A, Paillisson JM (2007) How do fish exploit temporary water throughout a flooding episode? Fish Manag Ecol 14:269-276

Decomp Physical Model Science Team (DPMST) (2010) The Decomp Physical Model Science Plan. 52pp. Located in Documentum at: Cabinets/Project Teams/Decomp/Decomp Physical Model (DPM)/Environmental Assessment/Final - Dec 2009/Print/Science Plan

Goss CW, Loftus WF, Trexler JC (2014) Seasonal fish dispersal in ephemeral wetlands of the Florida Everglades. Wetlands 34:147-157

Hoch JM, Sokol ER, Parker AD, Trexler JC (2015) Migration strategies vary in space, time, and among species in the small-fish metacommunities of the Everglades. Copeia 103:157-169 
Hogg RS, Coghlan Jr. SM, Zydlewski J, Gardner C (2015) Fish community response to a small stream dam removal in a Maine coastal river tributary. Trans Am Fish Soc $144: 467-479$

Jordan F, Coyne S, Trexler JC (1997) Sampling fishes in vegetated habitats: effects of habitat structure on sampling characteristics of the 1-m2 throw trap. Trans Am Fish Soc 136:1012-1020

Kolasa J, Romanuk TN (2005) Assembly of unequals in the unequal world of a rock pool metacommunity. In: Holyoak M, Leibold MA, and RD Holt (eds)

Metacommunities: Spatial Dynamics and Ecological Communities. University of Chicago Press, Chicago, pp 212-232

Leibold MA, M Holyoak, Mouquet N et al. (2004) The metacommunity concept: a framework for multi-scale community ecology. Ecol Lett 7:601-613

Light SS, Dineen JW (1994) Water control in the Everglades: A historical perspective. In: Davis M and Ogden JC (eds) Everglades. The Ecosystem and Its Restoration. St. Lucie Press, Boca Raton, pp 47-84

Maloney KO, Dodd HR, Butler SE, Wahl DH (2008) Changes in macroinvertebrate and fish assemblages in a medium-sized river following a breach of a low-head dam. Freshwater Biol 53:1055-1068

Marsh DM, Trenham PC (2001) Metapopulation dynamics and amphibian conservation. Cons Biol 15:40-49

Obaza A, DeAngelis DL, Trexler JC (2011) Using data from an encounter sampler to model fish dispersal. J Fish Biol 78:495-513

Osenberg CW, Sarnelle O, Cooper SD (1997) Effect size in ecological experiments: the application of biological models in meta-analysis. Am Nat 150:798-812

Parkos JJ III, Ruetz CR III, Trexler JC (2011) Disturbance regime and limits on benefits of refuge use for fishes in a fluctuating hydroscape. Oikos 120:1519-1530

Poff NL, Allan JD, Bain MB, Karr JR, Prestegaard KL, Richter BD, Sparks RE, Stromberg JC (1997) The natural flow regime. BioScience 47:769-784

Poff NL, Zimmerman JKH (2010) Ecological responses to altered flow regimes: a literature review to inform the science and management of environmental flows. Freshw Biol 55:194-205

Roshier D, Asmus M, Klaasen M (2008) What drives long-distance movements in the nomadic grey teal Anas gracilis in Australia? Ibis 150:474-484 
Tiffan KF, Rondorf DW, Skalicky JJ (2004) Imaging fall Chinook Salmon redds in the Columbia River with a dual-frequency sonar. N Am J Fish Manage 24:1421-1426

Trexler JC, Loftus WF, Perry S (2005) Disturbance frequency and community structure in a twenty-five year intervention study. Oecologia 145:140-152 
CHAPTER II

EXPERIMENTAL TEST OF EFFECTS OF HYDROSCAPE STRUCTURE ON WETLAND ANIMAL-SPACE INTERACTIONS 


\begin{abstract}
Dispersal in response to environmental cues is a key survival trait for animals living in ephemeral habitats, but is difficult to study experimentally in nature. Canals added to wetlands provide permanent dry-season refuges for fishes in habitats where refuges may have been historically rare. We examined dispersal behavior, population density, and community responses of fishes before and after a canal was filled and an adjacent levee was removed, re-connecting marshes that had been hydrologically isolated for five decades. Canal filling was in three treatments: fill-to-marsh level, partial-fill, and no-fill. Control and impact sites were located three distances from the canal and were monitored for two years before and after hydroscape alteration. Hydroscape alteration changed either movement speed or directedness, or both, at one or more distances from the canal in five of eight species examined. Species most impacted by drought events outside of this study, such as Flagfish, were more likely to respond to hydroscape alteration than were species relatively unaffected by drought. At sites far from the canal, Eastern Mosquitofish reduced speed by almost $600 \%$ after alteration compared to a $50 \%$ decrease at control sites. Near the canal, fish density was up to $300 \%$ greater in plots adjacent to fill treatments after manipulation, compared to a 50\% increase at no-fill and control sites. Community composition changed after hydroscape alteration, but hydrologicallyreconnected communities did not become more similar. Hydroscape alteration can have strong but species-specific influences on members of the fish community, and these influences contribute to metacommunity dynamics. Keywords: Dispersal, landscape alteration, hydroscape, Everglades, metacommunity dynamics
\end{abstract}




\section{Introduction}

Seasonal environments present animals with a suite of challenges that vary across spatiotemporal scales (Bell 2000). To navigate seasonal change in the spatial distribution of habitats, animals employ physiological and behavioral coping mechanisms critical for survival of individuals and persistence of populations (Roshier et al. 2008). Behavioral strategies involving alteration of speed and directed movement are key adaptations for survival in ephemeral habitats (Bauer et al. 2011). Sink habitats may provide temporary opportunities for abundant food resources or refuge from predation for vulnerable life stages (Boughton and Pike 2013). However, failure to adopt adaptive migration strategies can trap individuals in sink habitats. Individuals can become stranded in sink habitats because of incorrect timing or direction of emigration (Inouye et al. 2000) or misidentification of habitat quality (Blondel et al. 1992).

Studies examining community assembly and dynamics commonly infer the mechanisms responsible for maintaining diversity from descriptive data (Thuiller et al. 2015). Competing models contrast the roles of environmental filters and dispersal in shaping community structure (Leibold et al. 2004). Documentation of movement dynamics among habitat patches is increasingly seen as a necessary complement to such analyses to validate processes inferred (Bouvier et al. 2009, Brown and Swan 2010). Interspecific and intraspecific variation in movement among habitats may underlie metacommunity dynamics (Kolasa and Romanuk 2005; Mari et al. 2014). While metacommunity dynamics have been described in many aquatic communities, experimental study of the underlying processes creating dynamics are rare. The dynamic spatial arrangement of aquatic habitats in wetlands resulting from a fluctuating water 
table provide an opportunity to experimentally evaluate the role of landscape structure in metacommunity dynamics.

Hydroscape features can affect the pattern and rate of habitat colonization and evacuation as waters rise and fall in seasonal aquatic habitats (Cucherousset et al. 2007; Bronmark et al 2008). In floodplain forests, fishes are constrained to river channels for a portion of the year. As the river floods, fishes can make lateral movements into newly accessible habitat (King et al. 2003). When rivers are channelized, relationships between ephemeral habitats and rivers become restricted (Arlinghaus et al. 2002). In some modified wetland and floodplain systems, canals substitute for deepwater areas. Fishes move from these controlled water bodies into the surrounding hydroscape when given the opportunity (Nishida et al. 2014, Parkos and Trexler 2014), though signals for a fish to move from deep to shallow water may be obscured by management actions leading to hydrological reversals, creating unsustainable population dynamics (Baumgartner et al. 2014). Fish response to dynamic water conditions in modified habitats, as well as how they respond in systems that are undergoing restoration efforts, are important for hydrologic management.

The Florida Everglades is characterized by seasonal hydrology with annual expansion and contraction of flooded habitats (Gaiser et al. 2012). Previous works have identified interspecific variation in recovery of fish populations after a drying event (Trexler et al. 2002, Trexler et al. 2005) and behaviors that promote recolonization (DeAngelis et al. 2010, Goss et al. 2014, Hoch et al. 2015) as contributors to community dynamics. The wet season typically begins around May, when water levels begin rising rapidly to depths around $80 \mathrm{~cm}$ where they remain through November; the dry season 
begins in December and water depth gradually decreases until May (Duever et al. 1994). In the dry season, fishes are restricted to deep sloughs that only rarely became dry (Loftus and Kushlan 1987) or are stranded in ephemeral pools where they are consumed by predators such as wading birds or succumb to desiccation (Trexler et al. 2005; Botson et al. 2016). As water levels rise, these fishes move laterally to newly inundated areas of the marsh (Goss et al. 2014). In the southern Everglades, fish move from freshwater marshes to ecotonal creeks for dry-season refuge, where they experience elevated risk of predation (Rehage and Loftus 2007; Boucek and Rehage 2013). Water control structures, such as levees and canals, have increased the frequency and severity of drying events, diminishing the function of sloughs as dry-season refuges for aquatic animals and in some areas replacing them with canals. While canals can present stable water conditions, there may also be a high abundance of piscivores within close proximity to the canal (Rehage and Trexler 2006; Ruehl and Trexler 2015). Thus, the Everglades provides an excellent system to study how the arrangement of habitats drive landscape behavioral ecology and shape metacommunity dynamics.

We used a field-scale Physical Model that experimentally removed canal and levee structures to evaluate their impact on fish movement and metacommunity dynamics after several years spent gathering baseline data. Our Physical Model reintroduced sheetflow at velocities that mimic historical flow conditions $(2-3 \mathrm{~cm} / \mathrm{sec})$, filled sections of a canal, and removed a levee that had isolated two areas of the Everglades since the mid-1960's (DPMST 2010). We used a Before-After-Control-Impact (BACI) design to evaluate the impact of these experimental changes of the hydroscape on fish behavior, population, and community dynamics. We hypothesized that movement behaviors 
(direction and speed) differ among fish species and at different proximities from deepwater refuges, promoting metacommunity dynamics. We further hypothesized that directional movement would reverse at the sites furthest from a canal after levee removal, as the newly accessible canal was in the opposite direction of the previously closest deepwater refuge. We also predicted that community composition and similarity would increase between formerly disconnected sites after levee removal, an indication that aquatic animals were moving into newly accessible areas. Furthermore, the communities at sites in closest proximity to hydroscape alteration were predicted to experience the largest shift.

\section{Materials and Methods}

\section{Study Design}

This study took place in the Everglades, Florida, USA (25 50'15'N $80^{\circ} 37^{\prime} 07^{\prime \prime} \mathrm{S}$, Figure 1). It was conducted within an area that has been bounded by earthen levees (the L-67C and L-67A levees) for over 50 years (Figure 1A, B; Light and Dineen 1994). Fifteen meters west of the L-67C levee is the L-67C canal, and Water Conservation Area 3B (WCA 3B) is to the east. The L-67C canal is approximately 4-m deep and 8-m wide, and is the only permanently flooded habitat in the area. The area west of the canal is a thickly-vegetated marsh (maximum water depth approximately $1 \mathrm{~m}$ ) with shallow ridges covered by sawgrass (Cladium jamaicense) and sloughs dominated by white waterlily (Nymphaea odarata), Gulf Coast spikerush (Eleocharis cellulosa), and bladderworts 
(Utricularia spp.), as typify the Everglades (Gunderson and Loftus 1993). While elevated tree islands dot the landscape of the marsh, water depth is relatively uniform. The area east of the L-67C levee is also characterized as shallow marsh, though slough vegetation and periphyton tend to be at lower densities than sites west of the levee (Table 1). Prior to our study, the nearest deepwater habitat in WCA 3B was a remnant canal $\sim 4.5$ kilometers to the south and southeast of the study area.

A BACI study design was employed with pre-manipulation data gathered for two years (Before: September 2010 - June 2012), and post-manipulation data for another two years (After: January 2013 - March 2015) and Control plots north and south of the manipulated marsh area (Impact). After the Before period, the canal in our study area was partially filled and the adjacent levee was degraded to marsh level (DPMST 2010).

We established three sites in sloughs experiencing experimental water deliveries positioned in relation to distance from the manipulated canal (Far-from-Canal (FC), Near-Canal (NC), and East-of-Levee (EL)), with three plots sampled for each site. The plots were arranged parallel to the canal, with control plots on either side and out of the experimental area (Figure 1B). The NC sites were immediately adjacent to the L67-C canal, along its western edge, while the FC sites were 150-300 meters away from the canal. The EL sites were in a separate water management unit east of the L67-C levee, WCA 3B (Figure 1C). The levee that separated these two regions was degraded in the study area during late 2012 and early 2013. After this period, the management units east and west of the L67-C levee were hydrologically connected and the closest deepwater habitat for the EL sites went from 4.5 kilometers away to only 40 meters away. Sections of the L67-C canal underwent filling (a no-fill control section, a partial-fill section, and a 
filled section approximately to marsh surface; each section was approximately 300 meters) during the same period. An experimental water release, designed to simulate sheetflow (McVoy et al. 2011), took place upstream of the study area during November December, 2013, and November 2014 - January 2015. The release came from 10 culverts that delivered $750 \mathrm{cfs}$ when opened (Figure 1B). The pulse had no measurable effect on water velocities in the study area, with average water velocities equal to 1.47 $\mathrm{cm} / \mathrm{sec}(\mathrm{SE}=0.26)$ during the pulse and $1.53 \mathrm{~cm} / \mathrm{sec}(\mathrm{SE}=0.21)$ when the pulse was not taking place (velocities estimated with a SonTek FlowTracker Acoustic Doppler Velocimeter), though $\mathrm{SF}_{6}$ tracers (Ho et al. 2009) indicated that that water introduced from the culverts moved through our study area (David Ho, University of Hawaii, personal communication).

Samples were grouped into Before (10 sampling events between September 2010 and June 2012 for NC and FC sites, 9 samples for EL sites) and After (10 sampling events between January 2013 and March 2015 for NC and FC sites, 9 samples for EL sites) time intervals for comparisons of temporal effects of the manipulation. Sampling periods were chosen to reflect changing water depths over the course of the year. When possible, sites were sampled four times per year. In March, 2011, and May, 2012, only two plots for NC were sampled because the third plot was dry. An additional sample was taken at NC Plot 3 in September, 2013. In August, 2011, control plots were added $\sim 3 \mathrm{~km}$ to the north and south of the main experimental area (Figure 1B). This distance was great enough for the control sites to be outside of the influence of any changes in structure or experimental flow pulse treatment. After their establishment, the control sites were sampled during the same time periods as the experimental sites. 
Fish density was estimated using a $1-\mathrm{m}^{2}$ throw trap (Jordan et al. 1997), with sampling by portable drift fences to assess speed and directionality of fish movement (Obaza et al. 2011, Hoch et al. 2015). Throw-trap catch estimates the density of small fishes in the area (\# individuals $\mathrm{m}^{-2}$ ), while drift fence catch-per-unit-effort (CPUE) is an encounter rate of fish moving across the marsh (Obaza et al. 2011), hereafter referred to as encounter rate. Drift fences consisted of landscape cloth (woven 47\% shade-cloth, B \& K Instillations, Homestead, FL, USA) forming an X pattern with 4-m wings, with four minnow traps (3-mm mesh, Gee's Minnow Traps, Tackle Factory, Fillmore, NY, USA) located at the intersection of the wings. The ends of the wings and each corner of the central box were supported by 1-m long PVC stakes. Each minnow trap was oriented in a different cardinal direction and the wings extended outwards at $45^{\circ}$ angles. Traps were left to soak for 24 hours. During each sampling period, three throw-trap samples and three drift-fence samples were taken. In a preliminary study, water velocity was not significantly different upstream versus downstream of the drift fences, suggesting minimal influence of the shade cloth on water movement (the $47 \%$ shade cloth was selected to minimize flow impedance after efforts with denser mesh blocked water flow and diverted high velocities through the traps). Throw-trap samples and drift-fence samples were taken within 3-8 days, depending on weather conditions. Fishes from all sampling types were euthanized in a tricaine methane sulfonate solution (MS-222; Argent Chemical Laboratories, Inc., Redmond, WA, USA), fixed in a 10\% formalin solution (UFR Committee, 2004), and processed after being moved into 70\% ethanol. Average throw-trap and minnow-trap values from each plot were treated as replicates for density, encounter rate, community, and behavioral analyses. 
We also analyzed all fish species combined (total fish) to determine if there were broad reactions to hydroscape alteration across all species. However, previous work has shown that marsh recolonization rates following droughts vary among the members of the Everglades aquatic communities (Trexler et al. 2002). Therefore, species contributing the most to community dissimilarity among sites and with enough non-zero catches for statistical analyses were analyzed separately for movement behavior. Eight species examined as part of the study were: Eastern Mosquitofish (Gambusia holbrooki), Bluefin Killifish (Lucania goodei), Flagfish (Jordanella floridae), Golden Topminnow (Fundulus chrysotus), Marsh Killifish (Fundulus confluentus), Blue-Spotted Sunfish (Enneacanthus gloriosus), Dollar Sunfish (Lepomis marginatus), and Sailfin Molly (Poecilia latipinna).

Data Analyses

We evaluated the effect of Time (pre- and post-alteration) and Site (EL vs EL control, FC vs FC control, and NC vs NC control) and Site $\times$ Time interaction to evaluate the impact of hydroscape alternation. We treated Water Depth Change (hereafter WDC) as a covariate that measured the rate of daily water depth change over the 15-day period preceding collection of a drift-fence sample. For some analyses, WDC was a categorical variable, coded as "increasing" or "decreasing". Daily water depth was estimated with the Everglades Depth Estimation Network (EDEN; Telis 2006; Liu et al. 2009), and was adjusted to local depth by comparison to in situ measured depth. The WDC rates were averaged across plots within site types. Dependent variables of all parametric tests were square-root or natural log transformed to meet assumptions of our statistical tests. 
Occasionally, outliers in Speed and Direction analyses involving very low catches (one or two fish) were removed to improve model fit. Some species were absent or rare from sites or time periods (e.g., Marsh Killifish were almost never captured at NC and FC sites); in these instances, species-specific analyses were restricted to sites where individuals were collected. Features of the landscape known to affect fish density such as periphyton volume $(\mathrm{mL})$, emergent vegetation stem density $\left(\mathrm{m}^{2}\right)$, and water depth $(\mathrm{cm})$, were analyzed across Site $\times$ Time to determine if hydroscape alteration affected them in ways that may influence results.

For every test examining the three-way interaction of Site $\times$ Time $\times$ WDC, Site $\times$ Time was also examined to determine if effects were present only with hydroscape alteration alone. If these interactions yielded $\mathrm{P}$ values less than 0.10 , pairwise comparisons were conducted using subsets of the data. If an interaction was significant $(\mathrm{P}<0.05)$ but no pairwise comparisons were, data were plotted and visually examined. Our inclusion of models with near-significant $(0.05<\mathrm{p}<0.10)$ interactions was justified by the complexity of these large field data sets. Relaxation of frequentist $\mathrm{P}=0.05$ cut-off for 'significance' is justified because alternative modeling frameworks demonstrate useful information is present in models with frequentist probability between 0.05 and 0.10 ; the information content (and usefulness) of statistical models should be treated as a gradient rather than a threshold (e.g., Burnham and Anderson 2010, Bolker 2008). We considered the variance explained (pseudo $\mathrm{R}^{2}$ ) and improvement in model fit compared to alternative models before interpreting these marginal models. As the NC sites were adjacent to the canal-fill treatments and each plot corresponded to a different treatment, we also examined density and encounter rate with the three-way interaction of WDC $\times$ 
Plot $\times$ Time to evaluate fill-treatment effects. Data from the two Control sites were averaged for these analyses and each site (FC and FC control, NC and NC control, EC and EC control) was analyzed separately to avoid difficult to interpret hypothesis tests (four-way interactions).

We regressed CPUE on density for each species to determine if encounter rate was determined primarily by density, activity, or both. We used a slope of 1.0 as the null hypothesis expected if encounter rate was mostly determined by fish density (i.e., activity rate or speed was constant over time and space); this assumes that variation from influences other than density and speed on trap captures are randomized across space and time (Obaza et al. 2011). Data were standardized after transformation. Samples where no fish were captured in throw traps or drift-fence minnow traps were excluded from the analysis. Dollar Sunfish and Marsh Killifish were excluded from this analysis because of their rarity in throw-trap samples.

We used data on the direction fish entered the drift fences to determine whether directional dispersal behavior of species was influenced by hydroscape structure. We grouped fishes captured in drift fences moving north or west as "Away" from the canal, and those moving east or south as "Towards" the canal. We adopted this approach because the L67-C canal is oriented at $34^{\circ}$ east of due north. The EL sites were $4.5 \mathrm{~km}$ to the north-northwest of a remnant canal, so movement toward it was approximately the same angle as the other sites. Directional movement was determined using the natural $\log$ of fish CPUE in the north (movement towards the south) and west (movement towards the east) minnow traps, directed towards the canal for the $\mathrm{NC}$ and FC and away from the levee before degradation at the EL sites, divided by natural log of total CPUE 
(ln(Towards/Total)). Plots within sites were replicates for each sampling period. A value of 0.1 was given to "Towards" if nothing was captured moving towards the canal, but the Total Fish captured was greater than 0 . We used a weighted analysis to standardize the influence of samples, notably those with relatively few fish captured. Weights equaled CPUE of a sample divided by the total CPUE of all samples. The interactions of WDC $\times$ Site $\times$ Time and Site $\times$ Time, and main effects, were examined.

Fish speed was estimated from drift fence CPUE with a modified equation for modeling prey encounter rate by a stationary predator (Obaza et al. 2011). Speed values were calculated for each plot from the average drift-fence CPUE and average density from the throw-trap samples collected at the same time. If a species was captured in throw trap samples for a sampling event, but not any drift fence samples, no speed could be calculated. If a species was present in a drift fence, but not a throw trap, the species was in the sampling area, but below detection density. For these cases, density was treated as 0.3 individuals $\mathrm{m}^{-2}$, approximately the maximum density undetectable by the replication of throw trapping we used. The model examined the interaction of Site $\times$ Time $\times$ WDC. The absolute value of WDC was used for analysis of speed. If changes in speed or directionality at the NC sites were detected, an examination of these behaviors at the plot was conducted to determine if specific canal-fill treatments were causing the behavioral shifts. Species-specific behaviors were also analyzed for Site $\times$ WDC to determine if dispersal behaviors would be like those seen in a study with similar hydroscape conditions (Hoch et al. 2015), and if dispersal behaviors apply at a regional scale. 
We used PERMANOVA to evaluate Morisita-Horn community composition similarity between Site $\times$ Time $\times$ WDC for each Site. Comparisons were also made between the FC and EL sites, to determine if levee removal led to an exchange of individuals that promoted community similarity. The Morisita-Horn index, selected for its property of density invariance (Jost et al. 2011), was calculated with square-root transformed data to preserve abundance differences for common species while still providing weight for rarer species (Clarke and Warwick 2001). Pairwise tests were conducted to determine which factors were driving differences, if present. Similarity-ofPercentage (SIMPER, two-way crossed between Site and Time) tests were then conducted to determine which species were contributing the most to dissimilarity between variables. If community structure changed across Site $\times$ Time, PERMDISP was used $($ number of permuations $=999)$ to evaluate the source of differences. PERMDISP is a permutational test comparing the dispersion of points between groups and is a complimentary test to the PERMANOVA (Anderson et al. 2008). A Mantel's Test (via the Relate option in Primer) with Spearman rank correlation (999 permutations) was used to compare density and encounter rate resemblance matrices for each site type. Matrices for these tests were of equal rank by limiting date $\times$ site combinations and species common to both datasets. All analyses regarding community structure were conducted with Primer (ver. 6.0). All other analyses were conducted with R ver. 3.2.2 (R Core Team 2015) using the Car (Fox and Weisberg 2011), GGThemes (Arnold 2015), and lmodel2 (Legendre 2014) packages. 


\section{Results}

Water depth, emergent plant stem density $\left(\mathrm{m}^{2}\right)$, and periphyton volume $(\mathrm{mL})$ were largely unaffected by the interaction of Site $\times$ Time (Table 1). However, stem density increased by more than $100 \%$ at the FC sites compared with an increase of $\sim 25 \%$ at the FC Control sites $($ Site $\times$ Time: $\mathrm{F}=6.24, \mathrm{df}=1,88, \mathrm{P}=0.01)$. Periphyton volume increased at the EL and EL Control sites, where it doubled at the EL sites in the After period and tripled at the EL Control sites (Table 1; Site $\times$ Time: $\mathrm{F}=3.16$, $\mathrm{df}=1,80, \mathrm{P}=0.08$ ).

Fish Movement Behavior

The relationship between fish density and encounter rate varied among species, but was generally weak (average $\mathrm{R}^{2}=0.21$; Table 2). Only Flagfish yielded a relationship of density and CPUE that was indistinguishable from $1: 1\left(\mathrm{R}^{2}=0.45\right)$. The slope was less than one for all other species with adequate data to evaluate, and near zero for Bluespotted Sunfish and Golden Topminows.

The BACI hypothesis (Site $\times$ Time) was significant for fish density (all species summed) at all three sites (FC, NC, and EL) (Table 3A; Appendix 1 for all results). Density of small fishes rose at all sites after alteration, though the magnitude of this increase varied among sites. For example, small-fish density increased more than $300 \%$ at the NC sites after hydroscape alteration, compared to a $25 \%$ increase in the NC Control sites in the same time (Figure 2). There was a $230 \%$ increase in density at the FC sites after canal alteration, but no change at the FC Control, and small fish density at both the 
EL and EL Control nearly tripled after hydroscape alteration, with a greater increase at the EL sites. In contrast, the BACI hypothesis for encounter rates of small fishes was significant for FC, but not for NC or EL (Table 3B). At FC control, the encounter rate dropped by almost $50 \%$ after alteration, from 12.7 before to 6.7 individuals/24 hour after, while the impact sites did not change (6.6 before to 7.3 individuals/24 hours after) (Table $1)$.

The BACI analysis indicated that three of the eight species examined displayed directed movement affected by the hydroscape alteration (Appendix 2). Bluefin Killifish exhibited directed movement affected by the change in hydroscape at the FC sites that was influenced by WDC $($ WDC $\times$ Site $\times$ Time: $\mathrm{F}=4.057, \mathrm{df}=1,76, \mathrm{p}<0.05)$. Prior to hydroscape alteration, when water levels were increasing, their movement was directed away from the canal at the FC sites and towards the canal at the FC Control sites. After alteration, no directed movement was detected. Flagfish movement was also affected by the hydroscape manipulation at the FC sites, marked by strong movement away from the canal after alteration and no change at the control sites (Site $\times$ Time: $\mathrm{F}=34.59$, df $=1,38$, $\mathrm{p}<0.05)$. Flagfish also changed directional movement in response to the hydroscape intervention at the EL sites (Figure 3A; Site $\times$ Time: $\mathrm{F}=5.60$, df =1,71, $\mathrm{P}=0.02$ ). Directed movement dependent upon direction of WDC was also revealed for Golden Topminnows at the NC Sites (Figure 3B; WDC $\times$ Site $\times$ Time: $F=3.62$, df $=1,61, P=$ $0.061)$.

Five of eight species examined revealed changes in speed associated with hydroscape alternation at some or all study sites (Appendix 3). Movement speed of Bluefin Killifish, Bluespotted Sunfish, Eastern Mosquitofish, Flagfish and Golden 
Topminnows were affected by the hydroscape intervention, while Dollar Sunfish, Marsh Killifish, and Sailfin Mollies were not. Speed was reduced after hydroscape alteration in most instances (Figure 4A-C). The effect of WDC on Flagfish speed changed at EL sites after the Intervention from increasing with rising water to decreasing (Figure 4A; Time $\times$ WDC: $\mathrm{F}=6.86, \mathrm{df}=1,72, \mathrm{P}=0.01$ ). Eastern Mosquitofish reduced speeds by nearly $600 \%$ after alteration $(0.17 \mathrm{~m} / \mathrm{sec}$ to $0.03 \mathrm{~m} / \mathrm{sec})$ at the $\mathrm{FC}$ site, compared to an approximate halving of speed values at the FC Control sites $(0.06 \mathrm{~m} / \mathrm{sec}$ to $0.03 \mathrm{~m} / \mathrm{sec})$ (Figure 4B; WDC $\times$ Site $\times$ Time: $F=3.31, d f=1,55, P=0.07$ ). The speed reduction was driven both by a substantial increase in mean Eastern Mosquitofish density (4.16 fish $/ \mathrm{m}^{2}$ before alteration to $9.38 \mathrm{fish} / \mathrm{m}^{2}$ after alteration) and a decrease in minnow trap CPUE (3.43 fishes/24 hours before alteration to 1.85 fishes/24 hours after alteration). Speed of Bluefin Killifish at FC Control sites decreased between the Before and After periods, while there was no change at the Intervention site (Figure 4C; Site $\times$ Time: F $=3.17$, df $=1,76, \mathrm{P}=0.07)$. No species exhibited behavioral differences between canal-fill treatments.

\section{Community Structure}

We observed moderate to weak correlation of fish community matrices obtained from drift fence and throw-trap sampling and the correlation depended on site. For the NC and FC sites, there was a moderate correlation between the throw-trap and drift-fence communities (NC Sites: Mantel $\rho=0.34, p<0.05$; FC Sites: Mantel $\rho=0.33, p<0.05$ ). 
The EL sites exhibited higher correlation between the sample types (Mantel $\rho=0.51, p<$ $0.05)$.

Structure of the small-fish community revealed by throw trapping at the FC sites was unaffected by hydroscape manipulation (Appendix 4; WDC $\times$ Time $\times$ Site, Time $\times$ Site all $\mathrm{ns}$ ). In contrast, the mobile fish community captured by drift fence differed before and after alteration for both the FC and FC Control sites. The FC and FC Control sites were different prior to alteration, but became more similar after alteration (Table 4).

At the NC sites, fish community structure measured by throw-trap-estimated density (resident community) was not altered by the interaction with covariates (Appendix 10), but community structure measured by CPUE (mobile community) was affected and varied with the direction of WDC. During periods of decreasing water depth, composition of mobile communities within the NC and NC Control sites changed across time (Table 4, NC sites: $\mathrm{t}=3.11, \mathrm{df}=40, \mathrm{p}<0.01$; $\mathrm{NC}$ Control sites: $\mathrm{t}=2.79$, $\mathrm{df}=$ 17, $\mathrm{p}<0.01)$. The NC and NC Control sites were different from each other after alteration during periods of falling water depth, but not before (Table 4; pre-alteration: $\mathrm{t}=1.32$, df $=18, \mathrm{p}=0.13$; post-alteration: $\mathrm{t}=1.79, \mathrm{df}=39, \mathrm{p}<0.05)$. When water depth was increasing, resident community structure of the NC sites was different before and after alteration and the $\mathrm{NC}$ and $\mathrm{NC}$ Control sites were different from each other prior to alteration, but not after alteration (Table 4: pre-alteration: $\mathrm{t}=1.45$, $\mathrm{df}=18, \mathrm{p}=0.06$; post-alteration: $\mathrm{t}=0.88, \mathrm{df}=8, \mathrm{p}=0.52$ ).

Both community sample types (resident and mobile) revealed effects of hydroscape alteration in the EL sites (Appendix 4 for resident fish data, Table 4 for mobile fish data). Community structure was different between the EL and EL Control 
sites both before and after alteration (resident communities: Pseudo-F: 2.10, df = 1,73, $\mathrm{p}=0.09$; mobile communities: Pseudo-F: $3.04, \mathrm{df}=1,83, \mathrm{p}=0.01$ ). Before alteration, the mobile communities at the EL and EL Control sites were not different from each other, but were after alteration (Table 4). Dispersion of communities between the EL and EL Control sites for the mobile communities was different after alteration, with the spread of community compositions greater in the EL sites compared to the EL control sites (Figure 5a, Table 5). A similar difference in dispersion after alteration was also seen for the EL fish communities, though for those communities EL and EL Control site differences and dispersion changed across Time (Figure 5b, Table 5). For the NC sites, dispersion of the mobile communities decreased after alteration, but were largely unchanged in the NC Control sites (Table 5).

Dissimilarity was often caused by the species with observed behavioral shifts, though differences in relative abundance between Impact and Control sites, separated by Time, varied greatly (Appendix 5). For example, Golden Topminnow, a species that displayed changes in directional movement, had an increase of $63 \%$ in relative abundance compared to the Control sites. At the same sites, Bluespotted Sunfish, a species that displayed an increase in speed, decreased by $39 \%$ in relative abundance, compared to the control sites. A comparison of the mobile (Table 4) and resident communities (Appendix 4) between the EL and NC sites revealed differences both before and after hydroscape alteration, but with no evidence of the EL and NC community structure convergence. 


\section{Discussion}

Our study showed that hydroscape alteration can affect adaptive behaviors, densities, and community structure of small fishes in a dynamic wetland (Table 6). Of the eight species considered, three changed directional behavior and five changed movement speed associated with our BACI design, and these differences were more likely in species that have independently been shown to respond strongly to hydrologic dynamics of the Everglades. Species exhibited directed movement behaviors in some sites but not others, suggesting that hydroscape context shapes how species were affected by experimental alternations. These differences resulted in effects on metacommunity structure and $\beta$ diversity determined by proximity to prominent hydroscape features. Composition of mobile fish communities (drift-fence collections) was often affected by hydroscape alteration while resident community structure (throw-trap collections) was not. Encounter rates and densities tended to increase across all sites after hydroscape alteration, with inter-specific variation in magnitude of the increase.

Animals move in response to stimuli and these responses can be temporally and spatially variable and adaptive (Chapman and Mackay 1984), but the magnitude of these behaviors can directly impact metacommunity dynamics and should be used to inform conservation programs. Several factors could be influencing fish dispersal in the Everglades, including predator avoidance and selection of spawning and feeding habitats. Behavioral strategies limiting predation would be advantageous, but must be weighed against the threat of becoming stranded in a drying marsh. Previous work has shown that areas immediately adjacent to canals exhibit increased density of fishes, both small and 
large, but with few effects on community structure (Rehage and Trexler 2006). Work from areas outside of the Everglades has shown that canals can serve as dry-season or thermal refuges, allowing population persistence for fishes in dynamic freshwater habitats (Cowley et al. 2007; but see Baumgartner et al. 2014). For example, the response of lotic fish communities to dam removal can vary greatly among river systems, ranging from few responses (Maloney et al. 2008) to very drastic responses (Hogg et al. 2015). Maloney et al. (2008) found that it took one year after dam removal for the physical conditions of the upstream and downstream stretches of the Fox River to become similar. Two years after levee removal, we could still detect a legacy effect of its presence, though the study area was becoming more homogeneous.

Accessibility of ephemeral habitats strongly influences fish dispersal behaviors in freshwater systems during critical periods of the year (Strauch et al. 2015). These areas act both as starting and ending points of annual flood cycles, and successful dispersal strategies may rely on directional movements, rapid life cycles to compensate for high annual mortality, or some combination of the two. In our study, species whose populations are strongly impacted by drying events, such as Bluefin Killifish (negatively) and Flagfish (positively) (Ruetz et al. 2005), are those that most often exhibited changes in behavior. Though our study area was dynamic over the period of study, our BACI sampling design revealed community changes associated with hydroscape manipulation resulting from interspecific differences in fish movement. Hydroscape manipulation affected interspecific patterns of fish behavior at the NC and EL sites. At the NC sites, but not at the EL sites, changes were also tied to the direction of water depth change. In turn, these species contributed to changes in both mobile and resident community 
structure, particularly in the EL sites. Contributions to community dissimilarity (greater than or equal to $6 \%$ of total dissimilarity) ranged from $50 \%$ at the EL sites, immediately adjacent to the degraded levee, to only $28 \%$ in the NC sites, adjacent to the canal-fill treatments. Differences in encounter rate (all species summed) from hydroscape alteration were only seen at the FC sites, where the encounter rate of fishes slightly increased from 6.1 to 7.3 fishes per 24 hours, in contrast to the FC Control sites, where encounter rate decreased from 12.7 fishes to 6.7 fishes per 24 hours. While changes in density were seen across all three sites, only the FC sites exhibited a pattern different from their respective controls sites (where small fish density increased from 8.4 fishes $\mathrm{m}^{-}$ ${ }^{2}$ to 19.8 fishes $\mathrm{m}^{-2}$ ), suggesting effects of alteration were not significant at the population level.

Hydroscape features, such as changing water depth and proximity to the canal, appeared to influence behaviors of small fishes, though not as much as did the alteration from the construction. For example, only two of five examples of altered behavior at the FC sites were caused by the interaction of WDC $\times$ Time $\times$ Site, suggesting that the canal fill treatments and degradation of the levee had a large effect on the small fishes of our study area. Previous work has noted widespread adaptive behaviors in a similar suite of species (Hoch et al. 2015; Appendices 6 and 7). However, that study was conducted in a short-hydroperiod area, where marsh drying events are frequent and severe. Our sites only dried twice during the study, a 12-week period in summer of 2011 and an approximately 14-day period in summer of 2014. While our study area featured seasonal fluctuation of water depth, the lessened severity of drying conditions may have been less 
stressful for aquatic animals than in other areas of the Everglades, necessitating fewer detectable adaptive behaviors.

Our results have important implications for metacommunity and population dynamics in a restored hydroscape, processes closely linked with dispersal behaviors (Moritz et al. 2013). The Natural Flow Regime Paradigm, a conceptual framework highlighting the influence of pulsed and connected conditions in flowing-water systems, highlights the importance of lateral connectivity between habitat patches reconnected by a conveyance of water (Poff et al. 1997). Behavior and community structure, particularly of the mobile community of fishes, were altered by hydroscape alteration, though we did not see formerly disconnected communities becoming more similar after alteration, suggesting our hypotheses were only partially correct. The alteration of behaviors changed at sites after hydroscape alteration, even after accounting for changes in physical parameters of our research sites such as the increased stem density of emergent vegetation at the FC sites following hydroscape alteration. These behavioral changes further contributed to changes in community structure. Changes occurred more frequently at the two site types nearest to alterations, the EL and NC sites (though canalfill treatments did not affect behavior at the NC sites). However, many examples were observed of behavioral and community changes further away from these alterations. While changes in water velocity during the experimental flow periods were at or below our detection limits, low velocity changes in water movement were documented that could have affected cues motivating fish movement orientation.

Previously, studies examining aquatic landscapes subject to strong anthropogenic modification often looked only at structural parameters, such as community composition 
(Maloney et al. 2008). To our knowledge, our study is the first to simultaneously examine behavioral, population, and community dynamics with an experimental manipulation of hydroscape structure. Our experimental study is robust to the diversity of environmental perturbations typical of wetlands. Behavioral strategies have shown to be dynamic across taxonomic boundaries and can vary greatly by abiotic factors such as water depth, proximity to deepwater canals, and alteration of water control structures. While directionality and speed have been recognized as the core elements of animal movement (Turchin 1998), movement studies often focus on one or the other without explicit examination of both. We have shown that these differences influence community structure across space. Our results, particularly the effects hydroscape alteration has on the mobile community versus the resident community, provide insight into how the structure of the aquatic landscape can influence community and metacommunity dynamics and promote $\beta$-diversity. Large-scale field studies that support restoration efforts can answer both fundamental and applied questions that are critical for planning and implementing effective management programs.

\section{Acknowledgements}

We wish to thank the technicians and graduate students of the Trexler lab for field and lab assistance,N. Lemoine for assistance with programming, and B. Rosen (USGS) for assistance with funding. We also wish to thank M. Ross for his vegetation data. Funding for this project came from Cooperative Agreement W32CS501185613 between FIU and the US Geological Survey. Collections were made under Florida state permit S-11-04 and in accordance with FIU IACUC (Protocol \#200246). This material was developed in 
collaboration with the Florida Coastal Everglades Long-Term Ecological Research program under National Science Foundation Grant No. DEB-1237517. This is publication xxx from the Southeast Environmental Center (SERC) at FIU.

\section{Literature Cited}

Anderson MJ, Gorley RN, Clarke KR (2008) PERMANOVA + for PRIMER: Guide to software and statistical methods. PRIMER-E, Plymouth

Arnold JB (2016) ggthemes: Extra Themes, Scales and Geoms for 'ggplot2'. (R package), URL https://CRAN.R-project.org/package=ggthemes

Arlinghaus R, Engelhardt C, Sukhodolov A, Wolter C (2002) Fish recruitment in a canal with intensive navigation: implications for ecosystem management. J Fish Biol 61:1386-1402

Bauer S, Nolet BA, Giske J, Chapman JW, Akesson S, Hedenstrom A, Fryxell JM (2011) Cues and decision rules in animal migration In: Animal Migration (Eds. Milner Gulland EJ, JM Fryxell, and Sinclair ARE), Oxford University Press, Oxford, pp 68-88

Baumgartner L, Zampatti B, Jones M, Stuart I, Mallen-Cooper M (2014) Fish passage in the Murray-Darling Basin, Australia: Not just an upstream battle. Ecol Manag and Rest 15:28-39

Belisle M (2005) Measuring landscape connectivity: the challenge of behavioral landscape ecology. Ecology 86:1988-1995

Bell CP (2000) Process in the evolution of bird migration and pattern in avian ecogeography. J Avian Biol 31:258-265

Bishop KA, Pidgeon RW, Walden DJ (1995) Studies on fish movement dynamics in a tropical floodplain river - prerequisites for a procedure to monitor the impacts of mining. Aust J Ecol 20:81-107

Blondel J, Perret P, Maistre M, Dias PC (1992) Do harlequin Mediterranean environments function as source sink for Blue Tits (Parus caeruleus L.)? Landscape Ecol 6:213-219

Bolker, BM (2008) Ecological Models and Data in R. Princeton University Press, Princeton, NJ 
Botson, BA, DE Gawlik, and JC Trexler. 2016. Mechanisms that generate resource pulses in a fluctuating wetland. PLoS ONE 11(7):e0158864.

doi:10.1371/journal.pone.0158864

Boucek RE, JS Rehage (2013) No free lunch: Displaced marsh consumers regulate a prey subsidy to an estuarine consumer. Oikos 122:1453-1464

Boughton DA, Pike AS (2013) Floodplain rehabilitation as a hedge against hydroclimatic uncertainty in a migration corridor of threatened steelhead. Conserv Biol 27:1158 1168

Bouvier LD, Cottenie K, Doka SE (2009) Aquatic connectivity and fish metacommunities in wetlands of the lower Great Lakes. Can J Fish Aquat Sci 66:933-948

Bronmark C, Skov C, Brodersen J, Nilsson PA, Hansson LA (2008) Seasonal migration determined by a trade-off between predator avoidance and growth. PloS One DOI: 10.1371/journal.pone.0001957

Brown BL Swan CM (2010) Dendritic network structure constrains metacommunity properties in reverine ecosystems. J Anim Ecol 79:571-580

Bruton MN, Boltt RE (1975) Aspects of the biology of Tilapia mossambica (Pisces, Cichlidae) in a natural freshwater lake (Lake Sibaya, South Africa). J Fish Biol $7: 423-445$

Burnham. K. P., and D. R. Anderson (2010) Model Selection and Multimodel Inference. A Practical Information-Theoretic Approach, Second Edition. Springer, NY

Chapman CA, Mackay WC (1984) Versatility in habitat use by a top aquatic predator, Esox lucius L. J Fish Biol 25:109-115

Clarke KR, Warwick RM (2001) Change in marine communities: an approach to statistical analysis and interpretation. Primer-E Ltd. Plymouth, UK

Cowley DE, Wissmar RC, Sallenave R (2007) Fish assemblages and seasonal movements of fish in irrigation canals and river reaches of the middle Rio Grande, New Mexico (USA). Ecol Freshw Fish 16:548-558

Cucherousset J, Carpentier A, Paillisson JM (2007) How do fish exploit temporary water throughout a flooding episode? Fish Manag Ecol 14:269-276

DeAngelis DL, Trexler JC, Cosner C, Obaza A, Jopp F (2010) Fish population dynamics in a seasonally varying wetland. Ecol Model 221:1131-1137 
Decomp Physical Model Science Team (DPMST) (2010) The Decomp Physical Model Science Plan. 52pp. Located in Documentum at: Cabinets/Project Teams/Decomp/Decomp Physical Model (DPM)/Environmental Assessment/Final - Dec 2009/Print/Science Plan

Duever MJ, Meeder JF, Meeder LC, McCollom JM (1994). The climate of South Florida and its role in shaping the Everglades ecosystem. In: Davis SM and Ogden JC (eds) Everglades: The Ecosystem and Its Restoration. St. Lucie Press, Boca Raton, pp 225-248

Gaiser EE, Trexler JC, Wetzel PR (2012) The Florida Everglades. In: Batzer DP and Baldwin AH (eds) Wetland Habitats of North America: Ecology and Conservation Concerns. University of California Press, Berkeley, pp 231-252

Goss CW, Loftus WF, Trexler JC (2014) Seasonal fish dispersal in ephemeral wetlands of the Florida Everglades. Wetlands 34:147-157

Gunderson LH, Loftus WF (1993) The Everglades. In: Martin WH, Boyce SG, and Echternacht AC (eds) Biodiversity of the Southeastern United States John Wiley \& Sons, New York City, pp 199-255

Ho DT, Engel VC, Variano EA, Schmieder PJ, and Condon ME (2009) Tracer studies of sheet flow in the Florida Everglades. Geophy. Res. Lett. 36, L09401, doi:10.1029/2009GL037355

Hoch JM, Sokol ER, Parker AD, Trexler JC (2015) Migration strategies vary in space, time, and among species in the small-fish metacommunities of the Everglades. Copeia 103:157-169

Hogg RS, Coghlan Jr. SM, Zydlewski J, Gardner C (2015) Fish community response to a small stream dam removal in a Maine coastal river tributary. Trans Am Fish Soc 144:467-479

Inouye DW, Barr B, Armitage KB, Inouye BD (2000) Climate change is affecting altitudinal migrants and hibernating species. PNAS 97:1630-1633

Jost L, Chao A, Chazdon RL (2011) Compositional similarity and $\beta$ (beta) diversity. In Magurran AE and McGill BJ (eds) Biological Diversity. Oxford University Press, Oxford, pp 66-84

King AJ, P Humphries, and PS Lake (2003) Fish recruitment on floodplains: the roles of patterns of flooding and life history characteristics. Can J Fish Aquat Sci 60:773 786 
Kolasa J, Romanuk TN (2005) Assembly of unequals in the unequal world of a rock pool metacommunity. In: Holyoak M, Leibold MA, and RD Holt (eds)

Metacommunities: Spatial Dynamics and Ecological Communities. University of Chicago Press, Chicago, pp 212-232

Legendre P (2014) lmodel2: Model II Regression (R package), URL http://cran.rproject.org/web/packages/lmodel2/index.html

Leibold MA, M Holyoak, Mouquet N et al. (2004) The metacommunity concept: a framework for multi-scale community ecology. Ecol Lett 7:601-613

Light SS, Dineen JW (1994) Water control in the Everglades: A historical perspective. In: Davis M and Ogden JC (eds) Everglades. The Ecosystem and Its Restoration. St. Lucie Press, Boca Raton, pp 47-84

Liu Z, Volin JC, Owen VD, Pearlstine LG, Allen JR, Mazzotti FJ, Higer AL (2009) Validation and ecosystem applications of the EDEN water-surface model for the Florida Everglades. Ecohydrology 2:182-194

Loftus WF, Kushlan JA (1987) Freshwater fishes of southern Florida. Bull FL State Mus: Biol Sci 31:147-344

Maloney KO, Dodd HR, Butler SE, Wahl DH (2008) Changes in macroinvertebrate and fis assemblages in a medium-sized river following a breach of a low-head dam. Freshwater Biol 53:1055-1068

Mari L, Casagrandi R, Bertuzzo E, Rinaldo A, Gatto M (2014) Metapopulation persistence and species spread in river networks. Ecol Lett 17:426-434

McVoy CW, Said WP, Obeysekera J, VanArman J, Dreschel T (2011) Landscapes and hydrology of the pre-drainage Everglades. University Press of Florida, Gainesville

Moritz C, Meynard CN, Devictor V, Guizien K, Labrune C, Guarini JM, Mouquet N (2013) Disentangling the role of connectivity, environmental filtering, and spatial structure on metacommunity dynamics. Oikos 122:1401-1410

Nishida K, Ohira M, Senga Y (2014) Movement and assemblage of fish in an artificial wetland and canal in a paddy fields areas, in eastern Japan. Landscape Ecol Eng $10: 309321$

Obaza A, DeAngelis DL, Trexler JC (2011) Using data form an encounter sampler to model fish dispersal. J Fish Biol 78:495-513 
Parkos JJ III, Trexler JC (2014) Origins of functional connectivity in a human-modified wetland landscape. Can J Fish Aquat Sci 71:1-12

Poff NL, Allan JD, Bain MB et al. (1997) The natural flow regime: a paradigm for river conservation and restoration. BioScience 47:769-784

R Development Core Team (2011) R: A language and environment for statistical computing. R Foundation for Statistical Computing, Vienna, Austria. ISBN 3900051-07-0, URL http://www.R-project.org/

Rehage JS, Loftus WF (2007) Seasonal fish community variation in headwater mangrove creeks in the southwestern Everglades: An examination of their role as dry-down refuges. Bulletin of Marine Science 80:625-645

Rehage JS, Trexler JC (2006) Assessing the net effect of anthropogenic disturbance on aquatic communities in wetlands: Community structure relative to distance from canals. Hydrobiologia 569:359-373

Roshier D, Asmus M, Klaasen M (2008) What drives long-distance movements in the nomadic grey teal Anas gracilis in Australia? Ibis 150:474-484

Ruetz CR III, Trexler JC, Jordan F, Loftus WF, Perry SA (2005) Population dynamics of wetland fishes: spatio-temporal patterns synchronized by hydrological disturbance? J Anim Ecol 74:322-332

Strauch AM, Kapust AR, Jost CC (2015) Composition and health of fish in refugia habitat of ephemeral tributaries to the lower Zambezi in southern Africa. Mar Freshwater Res 66:343-351

Telis PA (2006). The Everglades Depth Estimation Network (EDEN) for support of ecological and biological assessments. U.S. Geological Survey Fact Sheet 20063087

Thuiller W, Pollock LJ, Gueguen M, Münkemüller T (2015) From species distributions to meta-communities. Ecol Lett 12:1321-1328

Trexler, J. C., W. F. Loftus, and J. Chick (2003) Setting and monitoring restoration goals in the absence of historical data: The case of fishes in the Florida Everglades, pp 351-376. In D. Busch and J. C. Trexler. Monitoring Ecoregional Initiatives: Interdisciplinary Approaches for Determining Status and Trends of Ecosystems. Island Press, Washington, DC 
Trexler JC, Loftus WF, Jordan F, Chick JH, Kandl KL, McElroy TC, Bass Jr. OL (2002) Ecological scale and its implications for freshwater fishes in the Florida Everglades In: Porter JW and Porter KG (eds) The Everglades, Florida Bay, and Coral Reefs of the Florida Keys: An Ecosystem Sourcebook. CRC Press, Boca Raton

Trexler JC, Loftus WF, Perry S (2005) Disturbance frequency and community structure in a twenty-five year intervention study. Oecologia 145:140-152

Turchin, P. 1998. Quantitative Analysis of Movement. Sinauer Associates, Sunderland, MA

Yurek S, DeAngelis DL, Trexler JC, Jopp F, Donalson DL (2013) Spatially explicit mechanistic model of dynamic hydrology driving small fish biomass dispersal and stranding. Ecol Model 250:391-401 


\section{Tables}

Table 1 - Sites and their abiotic and biotic parameters. Small fish density was estimated by throw traps and encounter rate was estimated by drift-fence captures. Error is one standard deviation. The FC and NC sites were sampled approximately 10 times before and after alteration. The EL sites were samples 9 times before and after alteration. The FC and NC Controls sites were sampled six times before alteration and the EL Control sites were sampled five times before alteration. All Control sites were sampled 10 times after alteration.

\begin{tabular}{|c|c|c|c|c|c|c|}
\hline SITE & ALTERATION & DEPTH (cm) & $\begin{array}{c}\text { PERIPHYTON (mL } \\
\left.\mathbf{m}^{-2}\right)\end{array}$ & $\begin{array}{c}\text { STEM DENSITY } \\
\left(\text { stem m}^{-2}\right)\end{array}$ & $\begin{array}{c}\text { FISH DENSITY (ind } \\
\mathbf{m}^{-2} \text { ) }\end{array}$ & $\begin{array}{c}\text { FISH ENCOUNTER } \\
\text { RATE }(24 \mathrm{hrs})\end{array}$ \\
\hline \multirow{2}{*}{$\mathrm{EL}$} & Pre & $32.9 \pm 10.1$ & $1028.3 \pm 867.1$ & $60.9 \pm 40.6$ & $24.3 \pm 17.8$ & $51.1 \pm 37.4$ \\
\hline & Post & $46.6 \pm 12.6$ & $2266.9 \pm 1249.6$ & $60.4 \pm 56.6$ & $70.8 \pm 37.9$ & $40.7 \pm 29.8$ \\
\hline \multirow{2}{*}{ EL Control } & Pre & $26.7 \pm 6.9$ & $1140.6 \pm 1137.2$ & $118.8 \pm 41.8$ & $15.9 \pm 15.9$ & $46.5 \pm 29.1$ \\
\hline & Post & $37.8 \pm 8.1$ & $3346.6 \pm 1333.5$ & $152.1 \pm 114.6$ & $37.6 \pm 17.3$ & $39.7 \pm 18.8$ \\
\hline \multirow{2}{*}{$\mathrm{FC}$} & Pre & $53.2 \pm 12.6$ & $3314.0 \pm 2285.2$ & $185.5 \pm 112.9$ & $8.4 \pm 5.5$ & $6.6 \pm 7.4$ \\
\hline & Post & $61.8 \pm 8.4$ & $3251.1 \pm 1906.2$ & $491.8 \pm 314.6$ & $19.8 \pm 9.9$ & $7.3 \pm 7.4$ \\
\hline \multirow{2}{*}{ FC Control } & Pre & $46.4 \pm 11.2$ & $4032.6 \pm 3105.17$ & $340.8 \pm 354.6$ & $12.0 \pm 4.3$ & $12.7 \pm 7.6$ \\
\hline & Post & $57.2 \pm 9.7$ & $5170.3 \pm 1638.6$ & $460.4 \pm 721.8$ & $14.2 \pm 6.7$ & $6.7 \pm 4.7$ \\
\hline \multirow{2}{*}{$\mathrm{NC}$} & Pre & $40.9 \pm 11.8$ & $773.9 \pm 780.0$ & $563.6 \pm 1176.0$ & $14.6 \pm 10.7$ & $14.4 \pm 14.8$ \\
\hline & Post & $51.2 \pm 10.6$ & $1631.7 \pm 1276.23$ & $739.4 \pm 1459.2$ & $47.1 \pm 25.7$ & $16.4 \pm 12.3$ \\
\hline \multirow{2}{*}{ NC Control } & Pre & $45.1 \pm 9.8$ & $1242.2 \pm 1744.6$ & $437.7 \pm 759.7$ & $20.9 \pm 13.6$ & $17.9 \pm 9.0$ \\
\hline & Post & $55.0 \pm 9.8$ & $2021.6 \pm 982.1$ & $514.8 \pm 492.9$ & $28.3 \pm 10.9$ & $11.7 \pm 9.7$ \\
\hline
\end{tabular}


Table 2 - Species-specific relationship between drift fence CPUE (Y axis) and throw trap density ( $\mathrm{X}$ axis). $\mathrm{n}$ is the total number of throw trap and minnow trap sample pairs where species was captured. Slope equal to 1.0 was the null hypothesis. $\mathrm{R}^{2}$ is the coefficient of determination.

\begin{tabular}{lcccc}
\hline \multicolumn{1}{c}{ SPECIES } & n & Slope & $\mathbf{R}^{\mathbf{2}}$ & $\mathbf{P}$ \\
\hline Bluefin Killifish & 254 & 0.51 & 0.29 & $<<0.05$ \\
Bluespotted Sunfish & 185 & 0.08 & 0.001 & $<<0.05$ \\
Dollar Sunfish & - & - & - & - \\
Eastern Mosquitofish & 255 & 0.65 & 0.2 & $<<0.05$ \\
Flagfish & 203 & 1.04 & 0.45 & 0.64 \\
Golden Topminnow & 245 & 0.06 & -0.002 & $<<0.05$ \\
Marsh Killifish & - & - & - & - \\
Sailfin Molly & 75 & 0.57 & 0.35 & $<<0.05$ \\
\hline
\end{tabular}


Table 3 - Model fit to A. density (\# fish $/ \mathrm{m}^{3}$ ) and B. encounter rate (CPUE) testing BACI hypothesis with three-way interaction accounting for water level fluctuation (WDC). P < 0.10 are in bold.

\begin{tabular}{|c|c|c|c|c|c|}
\hline DATA TYPE & SITE & FACTORS & $\mathrm{F}$ & $\mathrm{DF}$ & P-VALUE \\
\hline \multirow[t]{12}{*}{ A. Density } & \multirow[t]{4}{*}{$\mathrm{FC}$} & DepthChange $\times$ Time $\times$ Site & 2.15 & 1,84 & 0.14 \\
\hline & & Time $\times$ Site & 10.39 & 1,84 & $<0.01$ \\
\hline & & DepthChange $\times$ Site & 0.03 & 1,84 & 0.85 \\
\hline & & DepthChange $\times$ Time & 4.42 & 1,84 & $\mathbf{0 . 0 3}$ \\
\hline & \multirow[t]{4}{*}{$\mathrm{NC}$} & DepthChange $\times$ Time $\times$ Site & $<0.01$ & 1,83 & 0.98 \\
\hline & & Time $\times$ Site & 6.77 & 1,83 & 0.01 \\
\hline & & DepthChange $\times$ Site & 0.55 & 1,83 & 0.45 \\
\hline & & DepthChange $\times$ Time & 9.30 & 1,83 & $<0.01$ \\
\hline & \multirow[t]{4}{*}{ EL } & DepthChange $\times$ Time $\times$ Site & 0.37 & 1,76 & 0.54 \\
\hline & & Time $\times$ Site & 2.88 & 1,76 & 0.09 \\
\hline & & DepthChange $\times$ Site & 0.15 & 1,76 & 0.69 \\
\hline & & DepthChange $\times$ Time & 3.00 & 1,76 & 0.08 \\
\hline \multirow[t]{12}{*}{ B. Encounter Rate } & \multirow[t]{4}{*}{$\mathrm{FC}$} & DepthChange $\times$ Time $\times$ Site & 0.03 & 1,84 & 0.84 \\
\hline & & Time $\times$ Site & 4.74 & 1,84 & $\mathbf{0 . 0 3}$ \\
\hline & & DepthChange $\times$ Site & 0.22 & 1,84 & 0.63 \\
\hline & & DepthChange $\times$ Time & 2.66 & 1,84 & 0.11 \\
\hline & \multirow[t]{4}{*}{$\mathrm{NC}$} & DepthChange $\times$ Time $\times$ Site & 1.25 & 1,83 & 0.26 \\
\hline & & Time $\times$ Site & 2.23 & 1,83 & 0.13 \\
\hline & & DepthChange $\times$ Site & 0.66 & 1,83 & 0.41 \\
\hline & & DepthChange $\times$ Time & $<0.01$ & 1,83 & 0.99 \\
\hline & \multirow[t]{4}{*}{ EL } & DepthChange $\times$ Time $\times$ Site & $<0.01$ & 1,76 & 0.99 \\
\hline & & Time $\times$ Site & $<0.01$ & 1,76 & 0.94 \\
\hline & & DepthChange $\times$ Site & 0.08 & 1,76 & 0.77 \\
\hline & & DepthChange $\times$ Time & 0.76 & 1,76 & 0.38 \\
\hline
\end{tabular}


Table 4 - Results of PERMANOVA mobile community analyses for encounter rate data, including site data divided between before and after hydroscape alternation (Time).

Permutations $=9999$.

\begin{tabular}{|c|c|c|c|c|}
\hline SITE & FACTORS & TEST STATISTIC & DF & P-VALUE \\
\hline \multirow[t]{5}{*}{$\overline{\mathrm{FC}}$} & & Pseudo-F & $D F$ & \\
\hline & DepthChange $\times$ Time $\times$ Site & 0.58 & 1,84 & 0.72 \\
\hline & Time $\times$ Site & 3.09 & 1,84 & 0.01 \\
\hline & DepthChange $\times$ Site & 0.45 & 1,84 & 0.82 \\
\hline & DepthChange $\times$ Time & 1.03 & 1,84 & 0.39 \\
\hline FC Pairwise & & $t$-statistic & DenominatorDF & \\
\hline For Site FC & Time & 2.42 & 56 & $<0.01$ \\
\hline For Site FC Control & Time & 2.24 & 28 & $<0.01$ \\
\hline For Time Pre & Site & 2.36 & 38 & $<0.01$ \\
\hline For Time Post & Site & 0.34 & 46 & 0.97 \\
\hline \multirow[t]{5}{*}{$\mathrm{NC}$} & & Pseudo-F & $D F$ & \\
\hline & DepthChange $\times$ Time $\times$ Site & 1.97 & 1,83 & 0.07 \\
\hline & Time $\times$ Site & 3.04 & 1,83 & 0.01 \\
\hline & DepthChange $\times$ Site & 0.82 & 1,83 & 0.53 \\
\hline & DepthChange $\times$ Time & 1.07 & 1,83 & 0.36 \\
\hline $\mathrm{NC}$ & & $t$-statistic & DenominatorDF & \\
\hline For Decreasing Water and Site NC & Time & 3.11 & 40 & $<0.01$ \\
\hline \multicolumn{5}{|l|}{ For Decreasing Water and Site NC } \\
\hline Control & Time & 2.79 & 17 & $<0.01$ \\
\hline For Increasing Water and Site NC & Time & 1.97 & 15 & $<0.01$ \\
\hline \multicolumn{5}{|l|}{ For Increasing Water and Site NC } \\
\hline Control & Time & 1.22 & 11 & 0.20 \\
\hline For Decreasing Water and Time Pre & Site & 1.32 & 18 & 0.13 \\
\hline For Decreasing Water and Time Post & Site & 1.79 & 39 & 0.02 \\
\hline For Increasing Water and Time Pre & Site & 1.45 & 18 & 0.06 \\
\hline For Increasing Water and Time Post & Site & 0.88 & 8 & 0.52 \\
\hline \multirow[t]{5}{*}{$\overline{\mathrm{EL}}$} & & Pseudo-F & $D F$ & \\
\hline & DepthChange $\times$ Time $\times$ Site & 0.57 & 1,74 & 0.68 \\
\hline & Time $\times$ Site & 4.71 & 1,74 & $<0.01$ \\
\hline & DepthChange $\times$ Site & 0.31 & 1,74 & 0.87 \\
\hline & DepthChange $\times$ Time & 1.03 & 1,74 & 0.40 \\
\hline EL Pairwise & & $t$-statistic & $D F$ & \\
\hline For Site EL & Time & 3.83 & 49 & $<0.01$ \\
\hline For Site EL Control & Time & 5.11 & 25 & $<0.01$ \\
\hline For Time Pre & Site & 1.25 & 31 & 0.19 \\
\hline For Time Post & Site & 2.85 & 43 & $<0.01$ \\
\hline \multirow[t]{6}{*}{ EL vs NC } & & Pseudo-F & $D F$ & \\
\hline & DepthChange $\times$ Time $\times$ Site & 1.4 & 3,157 & 0.13 \\
\hline & Time $\times$ Site & 2.35 & 3,157 & $<0.01$ \\
\hline & DepthChange $\times$ Site & 0.66 & 3,157 & 0.81 \\
\hline & DepthChange $\times$ Time & 0.72 & 1,157 & 0.62 \\
\hline & & $t$-statistic & $D F$ & \\
\hline \multirow[t]{2}{*}{ Pre Pairwise } & EL vs NC & 4.04 & 50 & $<0.01$ \\
\hline & EL Control vs NC Control & 3.45 & 17 & $<0.01$ \\
\hline \multirow[t]{2}{*}{ Post Pairwise } & EL vs NC & 3.01 & 54 & $<0.01$ \\
\hline & EL Control vs NC Control & 6.06 & 36 & $<0.01$ \\
\hline
\end{tabular}


Table 5 -Mantel's Test (PERMDISP) analyses, examining dispersion of communities within Sites and sample types that exhibited significant differences in community structure across Site $\times$ Time.

\begin{tabular}{|c|c|c|c|}
\hline \multirow{3}{*}{$\frac{\text { SITE }}{\text { EL Mobile Community Main Test }}$} & TEST STATISTIC & \multicolumn{2}{|c|}{ DF P-VALUE } \\
\hline & F Statistic & & \\
\hline & 4.34 & 3,78 & 0.01 \\
\hline EL Mobile Community Pairwise & t Statistic & & \\
\hline Pre EL vs Post EL & 0.85 & 51 & 0.43 \\
\hline Pre EL vs Pre EL Control & 1.46 & 33 & 0.20 \\
\hline Pre EL Control vs Post EL Control & 0.55 & 27 & 0.63 \\
\hline Post EL vs Post EL Control & 1.82 & 45 & $<<0.01$ \\
\hline \multirow[t]{2}{*}{ EL Resident Main Test } & F Statistic & & \\
\hline & 12.08 & 3,77 & $<<0.01$ \\
\hline EL Resident Pairwise & t Statistic & & \\
\hline Pre EL vs Post EL & 2.99 & 51 & $<<0.01$ \\
\hline Pre EL vs Pre EL Control & 1.91 & 32 & 0.11 \\
\hline Pre EL Control vs Post EL Control & 3.20 & 26 & $<<0.01$ \\
\hline Post EL vs Post EL Control & 3.94 & 45 & $<<0.01$ \\
\hline \multirow[t]{2}{*}{ NC Mobile Community Main Test } & F Statistic & & \\
\hline & 6.14 & 3,87 & $<<0.01$ \\
\hline NC Mobile Community Pairwise & t Statistic & & \\
\hline Pre $\mathrm{NC}$ vs Post $\mathrm{NC}$ & 3.80 & 57 & $<<0.01$ \\
\hline Pre NC vs Pre NC Control & 2.13 & 38 & $<<0.01$ \\
\hline Pre NC Control vs Post NC Control & $<<0.01$ & 30 & 0.99 \\
\hline Post NC vs Post NC Control & 0.44 & 49 & 0.65 \\
\hline \multirow[t]{2}{*}{ FC Mobile Community Main Test } & F Statistic & & \\
\hline & 3.89 & 3,88 & 0.03 \\
\hline FC Mobile Community Pairwise & t Statistic & & \\
\hline Pre FC vs Post FC & 1.71 & 58 & 0.13 \\
\hline Pre FC vs Pre FC Control & 3.04 & 40 & $<<0.01$ \\
\hline Pre FC Control vs Post FC Control & 1.53 & 30 & 0.18 \\
\hline Post FC vs Post FC Control & 0.45 & 48 & 0.68 \\
\hline
\end{tabular}


Table 6 - Parameters examined during hydroscape alteration. 'Yes' denotes that our BACI hypotheses were confirmed ( $\mathrm{p}<0.10)$.

NC-EL Convergence were test for convergence of fish communities on either side of the levee after removal.

\begin{tabular}{|c|c|c|c|c|c|c|c|c|}
\hline Site & EL Sites & $\begin{array}{c}\text { EL Control } \\
\text { Sites }\end{array}$ & FC Sites & $\begin{array}{c}\text { FC } \\
\text { Control } \\
\text { Sites } \\
\end{array}$ & $\begin{array}{c}\mathrm{NC} \\
\text { Sites }\end{array}$ & $\begin{array}{c}\text { NC Control } \\
\text { Sites }\end{array}$ & $\begin{array}{c}\text { NC } \\
\text { Plots }\end{array}$ & $\begin{array}{c}\text { NC-EL } \\
\text { Convergence }\end{array}$ \\
\hline Density & Yes & No & Yes & No & Yes & Yes & Yes & - \\
\hline Encounter Rate & No & No & No & Yes & No & No & No & - \\
\hline Resident Community Structure & Yes & Yes & No & No & No & No & - & No \\
\hline Mobile Community Structure & Yes & Yes & Yes & Yes & Yes & Yes & - & No \\
\hline Bluefin Killifish Speed & Yes & Yes & Yes & Yes & No & No & No & - \\
\hline Bluefin Killifish Directionality & No & No & Yes & No & No & No & No & - \\
\hline Bluespotted Sunfish Speed & - & - & No & No & Yes & No & No & - \\
\hline Bluespotted Sunfish Directionality & - & - & No & No & No & No & No & - \\
\hline Dollar Sunfish Speed & No & No & No & No & No & No & No & - \\
\hline Dollar Sunfish Directionality & No & No & No & No & No & No & No & - \\
\hline Eastern Mosquitofish Speed & No & No & Yes & Yes & No & No & No & - \\
\hline Eastern Mosquitofish Directionality & No & No & No & No & No & No & No & - \\
\hline Flagfish Speed & Yes & No & No & No & No & No & No & - \\
\hline Flagfish Directionality & Yes & No & Yes & No & No & No & No & - \\
\hline Golden Topminnow Speed & No & Yes & No & No & No & No & No & - \\
\hline Golden Topminnow Directionality & No & No & No & No & Yes & Yes & No & - \\
\hline Marsh Killifish Speed & No & No & No & No & No & No & No & - \\
\hline Marsh Killifish Directionality & No & No & - & - & - & - & - & - \\
\hline Sailfin Molly Speed & No & No & - & - & - & - & - & - \\
\hline Sailfin Molly Directionality & No & No & - & - & - & - & - & - \\
\hline
\end{tabular}




\section{Figure Captions}

Figure 1. Map of Study Area. A. Region where the study was conducted, (southern Florida, USA). B. Study area showing area of control and impact plots. Polygons with diagonal lines are terrestrial tree islands. The water control structure that delivers the experimental flow pulse is at approximately the position of the arrow, which is pointing in the approximate direction of water flow during those periods. C. Experiment area with three plots at each site, FC, NC, EL. Control plots for each site are outside of this map. Sawgrass ridges are represented by dark gray. Open water sloughs are light gray.

Figure 2 - Density of small fishes (individuals $\mathrm{m}^{-2}$ ) at the NC sites, divided by plot type. Error bars represent $95 \%$ confidence intervals. Densities were back-transformed from square-root +1 values.

Figure 3 - A. Directionality of fish before and after hydroscape alteration with shaded area indicating 95\% confidence intervals. Solid lines represent Impact sites and dotted lines represent Control sites. Long-dashed line represents equal movement rates towards and away from canal. Minus and plus symbols along the x-axis represent daily rising and falling water depths. A. Flagfish at EL sites. B. Golden Topminnow at NC sites. 
Figure 4 - Movement speed of fish before and after hydroscape alteration with shaded fill indicating 95\% confidence intervals. Speed values are back-transformed from natural$\log$ or square root transformations. Water depth change is absolute values. Solid lines represent Impact sites and dotted lines represent Control sites. A. Flagfish at EL sites. B. Eastern Mosquitofish at FC sites (note different scale of y-axes). C. Bluefin Killifish at NC sites.

Figure 5 -nMDS of communities at EL sites. Hollow shapes are before alteration. Filled shapes are after alteration. A.Mobile communities. B. Resident communities. 
Figures

Figure 1
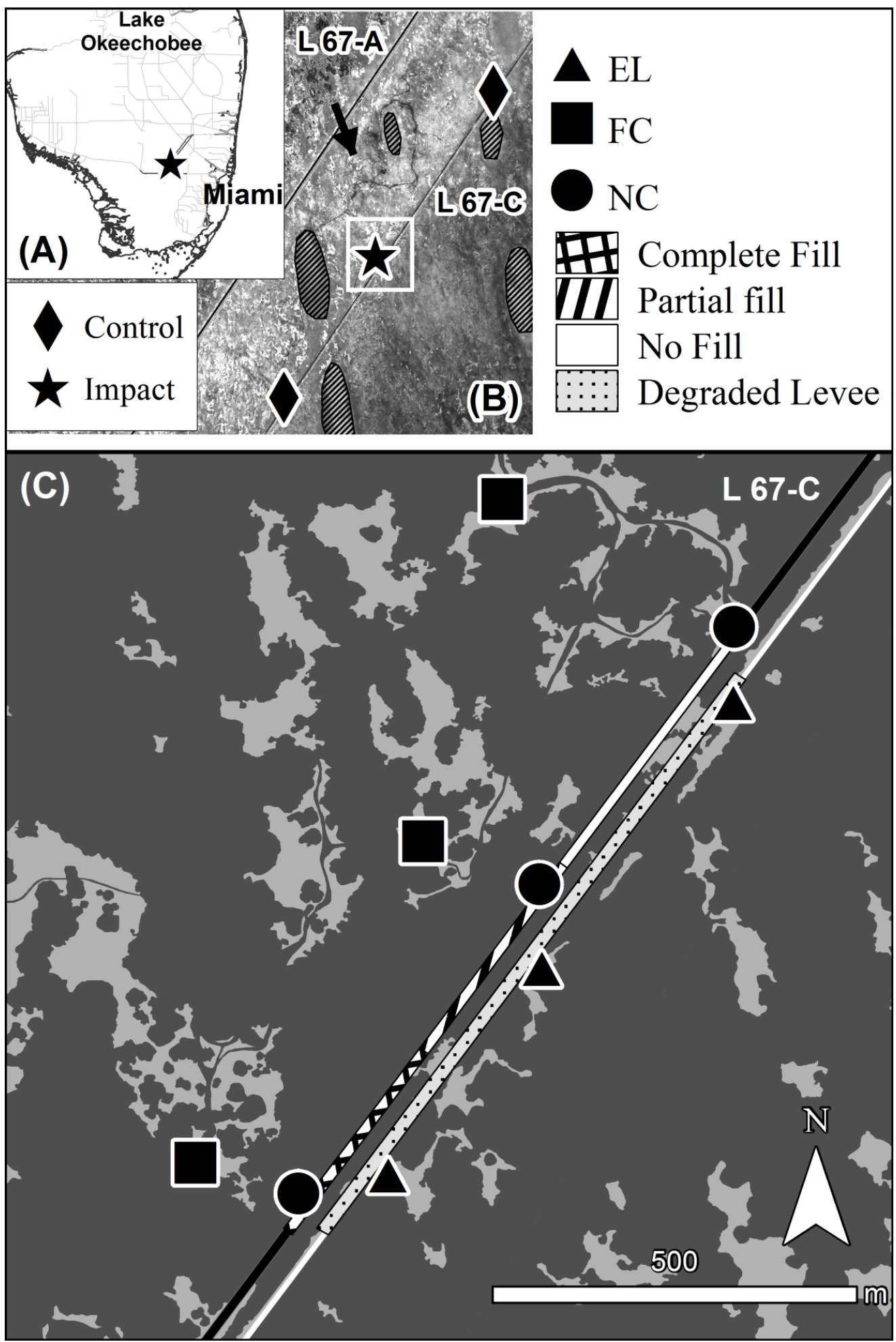
Figure 2

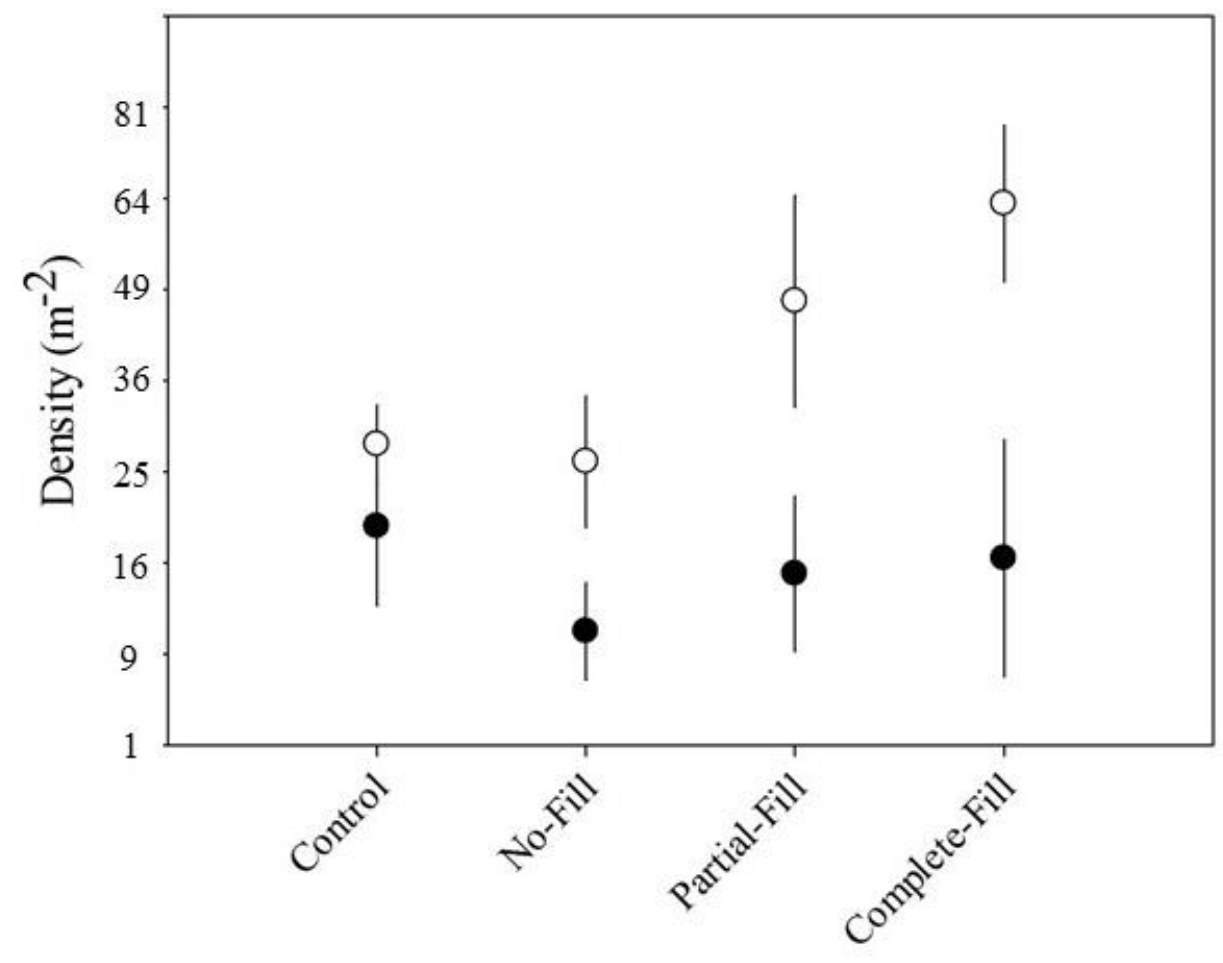


Figure 3
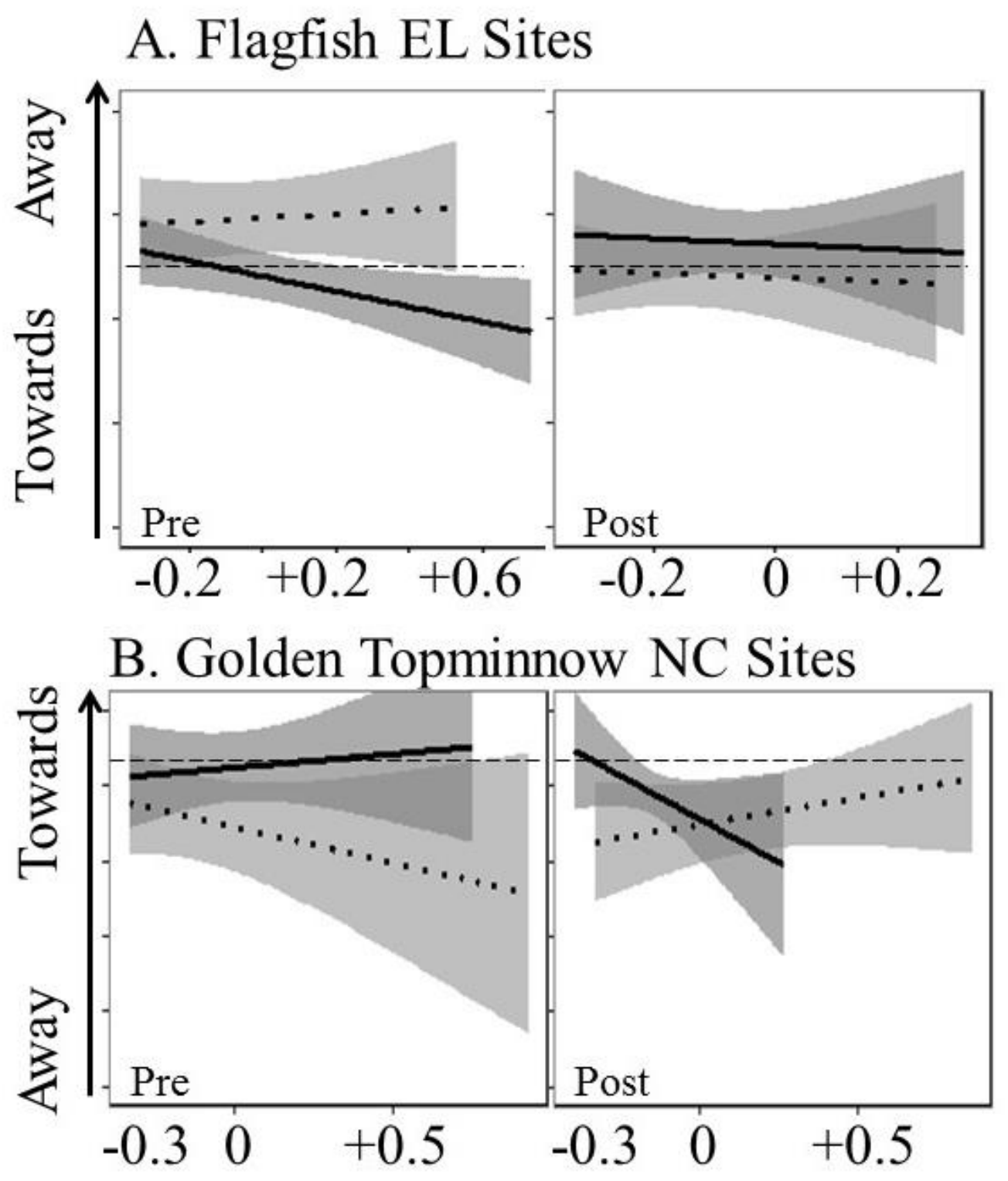

Daily Water Depth Change (cm/day) 
Figure 4

\section{A. Flagfish EL Sites}

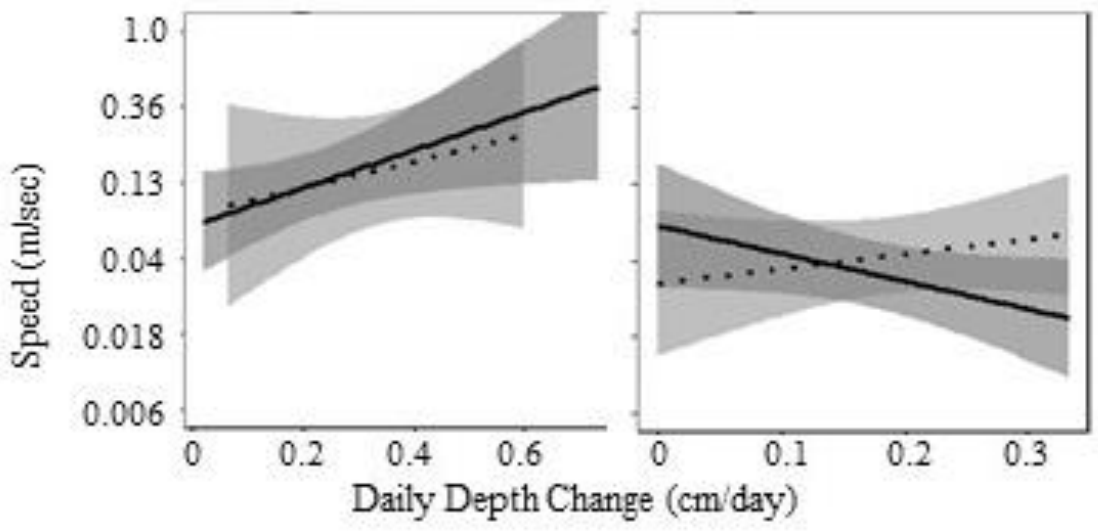

\section{B. Eastern Mosquitofish FC Sites}

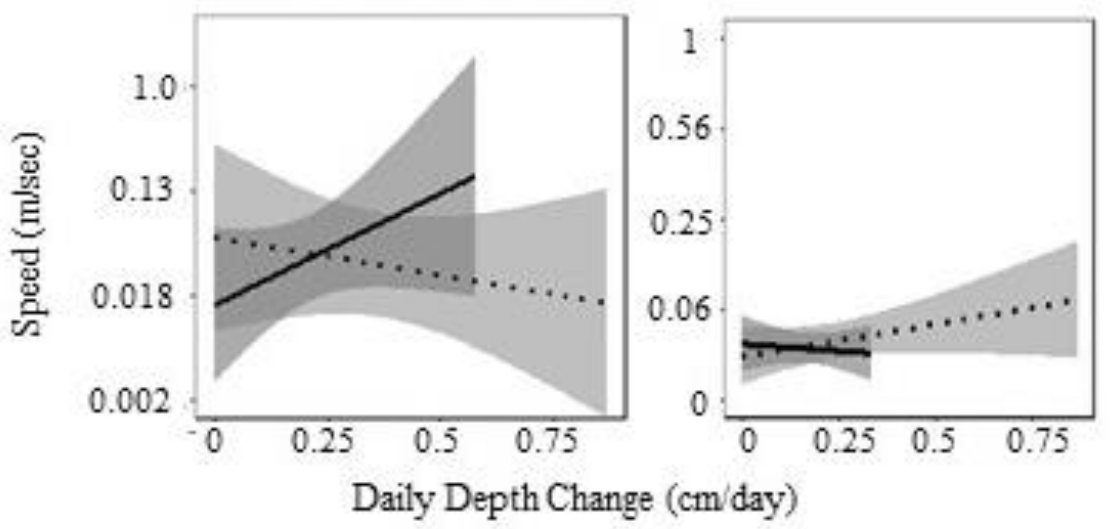

\section{Bluefin Killifish FC Sites}

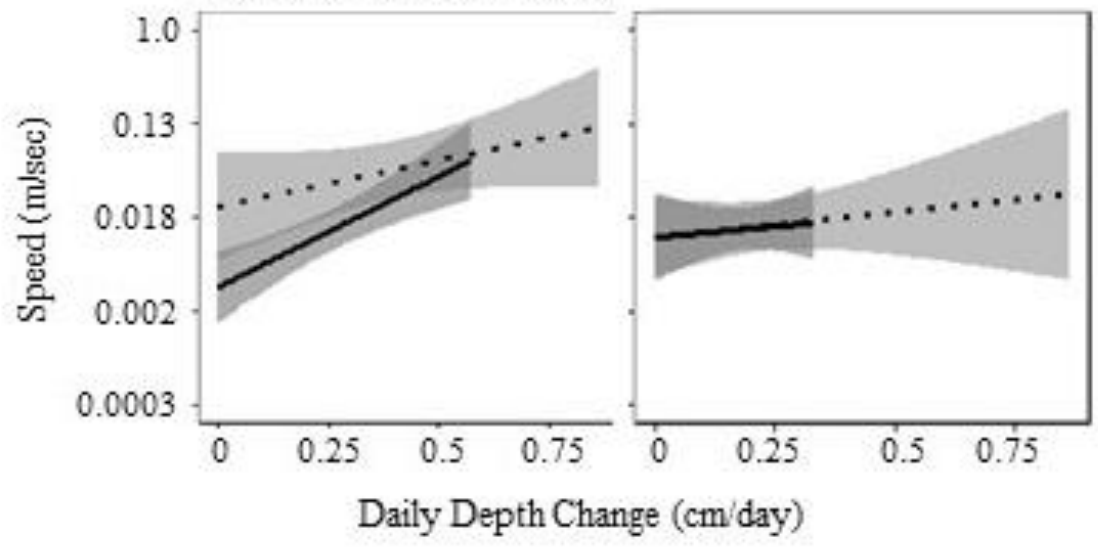


Figure 5
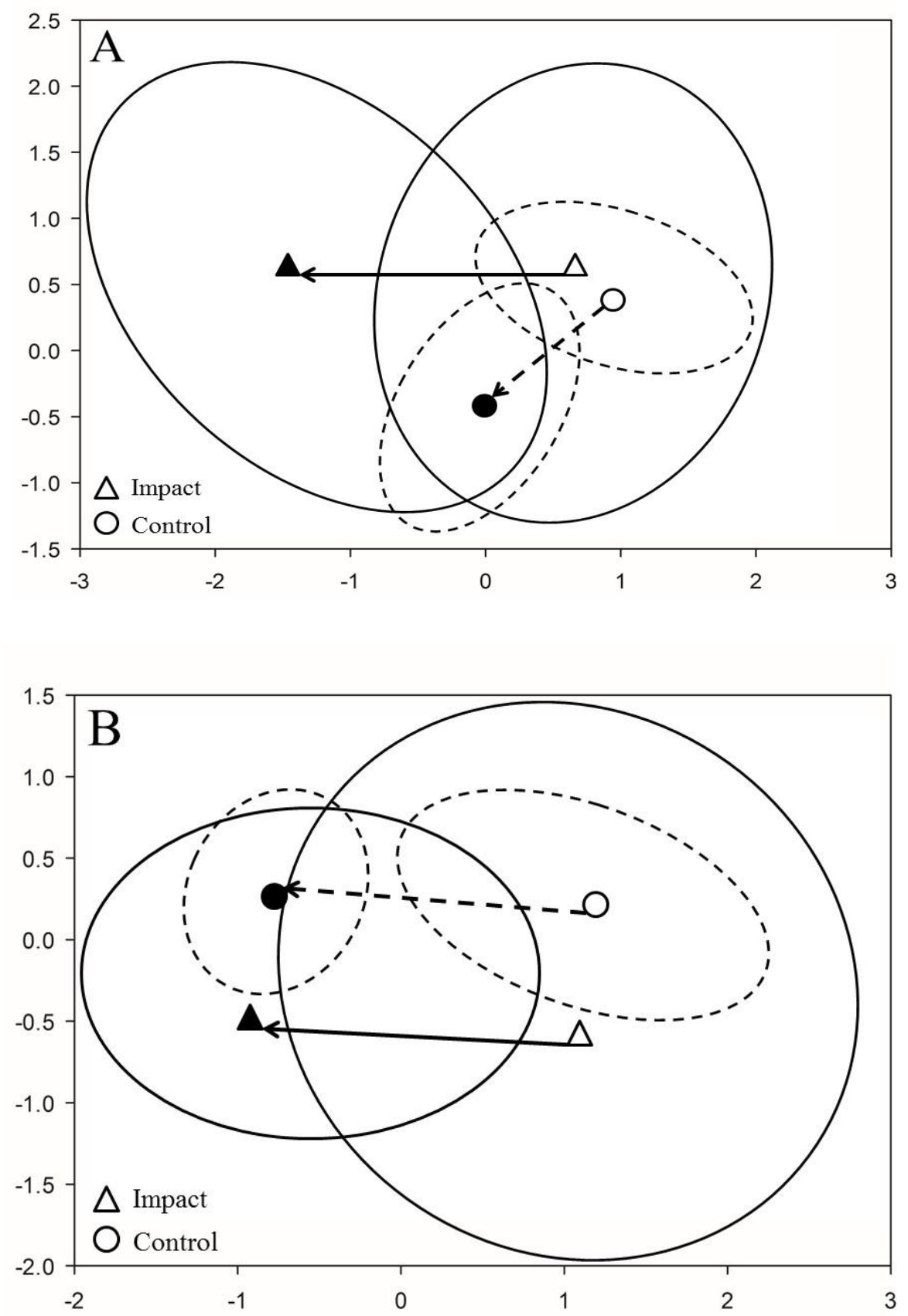


\section{Appendices Captions}

Appendix 1: Results of density and encounter rate analyses across the different sampling sites. Test statistic for main model interactions was an F-value. Test statistic for pairwise interactions was a t-value.

Appendix 2: Directionality results of eight fishes examined. Test statistic for main model interactions was an F-value. Test statistic for pairwise interactions was a t-value.

Appendix 3: Speed results of eight fishes examined. Test statistic for main model interactions was an F-value. Test statistic for pairwise interactions was a t-value.

Appendix 4: Results of PERMANOVA community analyses for resident community data, including site data divided between pre and post levee removal (Time).

Permutations $=9999$.

Appendix 5: SIMPER analyses for mobile and resident communities where community composition was altered by Water Depth Change $\times$ Site $\times$ Time or Site $\times$ Time. Data are divided by Before and After alteration. Species that exhibited changes in speed or directionality are shaded in grey. Sailfin Mollies contributed less than 5\% of community dissimilarity between the NC and NC Control sites for the mobile community before alteration, so were not included.

Appendix 6: Results of behavioral analyses across Site $\times$ WDC. Bluespotted killifish were excluded from these analyses as they were not included in the analyses of Hoch et al. (2015).

Appendix 7: Comparisons of the behavioral analyses of this study in Hoch et al. (2015). The authors in that study used encounter rate as a proxy for speed and differentiated between rising and falling water levels for encounter rate analyses, whereas we used absolute values for water depth changes. Sites mentioned under individual species and behaviors were cases where patterns observed were similar to those observed in Hoch et al. (2015). Our analyses used ANCOVA models (Site $\times$ Water Depth Change) to determine significance $(p<0.05)$ or near-significance $(p=0.05-0.10)$. Results were significant if directed movements or speed were different between treatment groups. 


\section{Appendices}

\section{Appendix 1}

\begin{tabular}{|c|c|c|c|c|c|}
\hline DATA TYPE & SITE \& TEST & FACTORS & TEST STATISTIC & DF & P-VALUE \\
\hline \multirow[t]{31}{*}{$\overline{\text { Density }}$} & FC Main Test & DepthChange $\times$ Time $\times$ Site & 2.15 & 1,84 & 0.14 \\
\hline & & Time $\times$ Site & 10.39 & 1,84 & $<0.01$ \\
\hline & & DepthChange $\times$ Site & 0.53 & 1,84 & 0.46 \\
\hline & & DepthChange $\times$ Time & 11.09 & 1,84 & $<0.01$ \\
\hline & FC Pairwise Tests & & & & \\
\hline & For Time Pre & DepthChange $\times$ Site & 2.58 & 1,38 & 0.11 \\
\hline & For Time Post & DepthChange $\times$ Site & 0.60 & 1,46 & 0.44 \\
\hline & For Site FC & DepthChange $\times$ Time & 9.63 & 1,56 & $<0.01$ \\
\hline & For Site FC Control & DepthChange $\times$ Time & 0.20 & 1,28 & 0.65 \\
\hline & NC Main Test & DepthChange $\times$ Time $\times$ Site & $<0.01$ & 1,83 & 0.98 \\
\hline & & Time $\times$ Site & 6.77 & 1,83 & 0.01 \\
\hline & & DepthChange $\times$ Site & 0.20 & 1,83 & 0.65 \\
\hline & & DepthChange $\times$ Time & 5.61 & 1,83 & 0.02 \\
\hline & NC Pairwise Tests & & & & \\
\hline & For Time Pre & DepthChange $\times$ Site & 0.32 & 1,36 & 0.57 \\
\hline & For Time Post & DepthChange $\times$ Site & 0.28 & 1,47 & 0.59 \\
\hline & For Site NC & DepthChange $\times$ Time & 4.91 & 1,55 & 0.03 \\
\hline & $\begin{array}{l}\text { For Site NC Control } \\
\text { NC by Plot }\end{array}$ & DepthChange $\times$ Time & 5.54 & 1,28 & 0.02 \\
\hline & & DepthChange $\times$ Time $\times$ Plot & 0.31 & 3,75 & 0.81 \\
\hline & & Time $\times$ Plot & 4.34 & 3,75 & $<0.01$ \\
\hline & & DepthChange $\times$ Plot & 0.69 & 3,75 & 0.56 \\
\hline & & DepthChange $\times$ Time & 2.96 & 1,75 & 0.08 \\
\hline & EL Main Test & DepthChange $\times$ Time $\times$ Site & 0.37 & 1,76 & 0.54 \\
\hline & & Time $\times$ Site & 2.88 & 1,76 & 0.09 \\
\hline & & DepthChange $\times$ Site & 0.37 & 1,76 & 0.54 \\
\hline & & DepthChange $\times$ Time & 3.37 & 1,76 & 0.06 \\
\hline & EL Pairwise Tests & & & & \\
\hline & For Time Pre & DepthChange $\times$ Site & 0.05 & 1,33 & 0.81 \\
\hline & For Time Post & DepthChange $\times$ Site & 0.29 & 1,43 & 0.58 \\
\hline & For Site EL & DepthChange $\times$ Time & 2.68 & 1,50 & 0.10 \\
\hline & For Site EL Control & DepthChange $\times$ Time & 1.04 & 1,26 & 0.31 \\
\hline \multirow[t]{22}{*}{ Encounter Rate } & FC Main Test & DepthChange $\times$ Time $\times$ Site & 0.34 & 1,84 & 0.55 \\
\hline & & Time $\times$ Site & 5.31 & 1,84 & 0.02 \\
\hline & & DepthChange $\times$ Site & 0.14 & 1,84 & 0.70 \\
\hline & & DepthChange $\times$ Time & 1.91 & 1,84 & 0.17 \\
\hline & FC Pairwise Tests & & & & \\
\hline & For Time Pre & DepthChange $\times$ Site & 0.19 & 1,38 & 0.66 \\
\hline & For Time Post & DepthChange $\times$ Site & 0.17 & 1,46 & 0.67 \\
\hline & For Site FC & DepthChange $\times$ Time & 1.69 & 1,56 & 0.19 \\
\hline & For Site FC Control & DepthChange $\times$ Time & 1.41 & 1,28 & 0.24 \\
\hline & NC Main Test & DepthChange $\times$ Time $\times$ Site & 1.25 & 1,83 & 0.26 \\
\hline & & Time $\times$ Site & 2.23 & 1,83 & 0.13 \\
\hline & & DepthChange $\times$ Site & 1.27 & 1,83 & 0.26 \\
\hline & & DepthChange $\times$ Time & 0.50 & 1,83 & 0.47 \\
\hline & NC by Plot & & & & \\
\hline & & DepthChange $\times$ Time $\times$ Plot & 0.62 & 3,74 & 0.60 \\
\hline & & Time $\times$ Plot & 0.93 & 3,74 & 0.42 \\
\hline & & DepthChange $\times$ Plot & 0.60 & 3,74 & 0.61 \\
\hline & & DepthChange $\times$ Time & $<0.01$ & 1,74 & 0.95 \\
\hline & EL Main Test & DepthChange $\times$ Time $\times$ Site & $<0.01$ & 1,76 & 0.99 \\
\hline & & Time $\times$ Site & $<0.01$ & 1,76 & 0.94 \\
\hline & & DepthChange $\times$ Site & 0.02 & 1,76 & 0.86 \\
\hline & & DepthChange $\times$ Time & 0.47 & 1,76 & 0.49 \\
\hline
\end{tabular}




\section{Appendix 2}

\begin{tabular}{|c|c|c|c|c|c|}
\hline SPECIES & SITE \& TEST & FACTORS & TEST STATISTIC & $\mathrm{DF}$ & P-VALUE \\
\hline \multirow[t]{17}{*}{ Bluefin Killifish } & \multirow[t]{4}{*}{ FC Main Test } & DepthChange $\times$ Time $\times$ Site & 4.05 & 1,76 & 0.04 \\
\hline & & Time $\times$ Site & 0.16 & 1,76 & 0.68 \\
\hline & & DepthChange $\times$ Site & 2.31 & 1,76 & 0.13 \\
\hline & & DepthChange $\times$ Time & 1.31 & 1,76 & 0.25 \\
\hline & \multicolumn{5}{|l|}{ FC Pairwise Tests } \\
\hline & For Time Pre & DepthChange $\times$ Site & 9.50 & 1,31 & $<0.01$ \\
\hline & For Time Post & DepthChange $\times$ Site & 0.08 & 1,45 & 0.76 \\
\hline & For Site FC & DepthChange $\times$ Time & 4.30 & 1,48 & 0.04 \\
\hline & For Site FC Control & DepthChange $\times$ Time & 0.49 & 1,28 & 0.48 \\
\hline & \multirow[t]{4}{*}{ NC Main Test } & DepthChange $\times$ Time $\times$ Site & 0.02 & 1,74 & 0.88 \\
\hline & & Time $\times$ Site & 0.22 & 1,74 & 0.63 \\
\hline & & DepthChange $\times$ Site & 1.91 & 1,74 & 0.17 \\
\hline & & DepthChange $\times$ Time & $<0.01$ & 1,74 & 0.93 \\
\hline & \multirow[t]{4}{*}{ EL Main Test } & DepthChange $\times$ Time $\times$ Site & 0.21 & 1,71 & 0.64 \\
\hline & & Time $\times$ Site & 0.14 & 1,71 & 0.70 \\
\hline & & DepthChange $\times$ Site & 0.01 & 1,71 & 0.91 \\
\hline & & DepthChange $\times$ Time & 0.35 & 1,71 & 0.55 \\
\hline \multirow[t]{8}{*}{ Bluespotted Sunfish } & \multirow[t]{4}{*}{ FC Main Test } & DepthChange $\times$ Time $\times$ Site & 1.02 & 1,78 & 0.31 \\
\hline & & Time $\times$ Site & 0.01 & 1,78 & 0.90 \\
\hline & & DepthChange $\times$ Site & 0.13 & 1,78 & 0.71 \\
\hline & & DepthChange $\times$ Time & 0.42 & 1,78 & 0.51 \\
\hline & \multirow[t]{4}{*}{ NC Main Test } & DepthChange $\times$ Time $\times$ Site & $<0.01$ & 1,79 & 0.92 \\
\hline & & Time $\times$ Site & 0.24 & 1,79 & 0.61 \\
\hline & & DepthChange $\times$ Site & 0.52 & 1,79 & 0.46 \\
\hline & & DepthChange $\times$ Time & 0.17 & 1,79 & 0.67 \\
\hline \multirow[t]{12}{*}{ Dollar Sunfish } & \multirow[t]{4}{*}{ FC Main Test } & DepthChange $\times$ Time $\times$ Site & 0.39 & 1,62 & 0.53 \\
\hline & & Time $\times$ Site & 2.16 & 1,62 & 0.14 \\
\hline & & DepthChange $\times$ Site & 0.07 & 1,62 & 0.78 \\
\hline & & DepthChange $\times$ Time & 0.22 & 1,62 & 0.63 \\
\hline & \multirow[t]{4}{*}{ NC Main Test } & DepthChange $\times$ Time $\times$ Site & 1.32 & 1,62 & 0.25 \\
\hline & & Time $\times$ Site & 0.17 & 1,62 & 0.67 \\
\hline & & DepthChange $\times$ Site & 0.55 & 1,62 & 0.45 \\
\hline & & DepthChange $\times$ Time & 1.01 & 1,62 & 0.31 \\
\hline & \multirow[t]{4}{*}{ EL Main Test } & DepthChange $\times$ Time $\times$ Site & - & - & - \\
\hline & & Time $\times$ Site & - & - & - \\
\hline & & DepthChange $\times$ Site & - & - & - \\
\hline & & DepthChange $\times$ Time & $<0.01$ & 1,36 & 0.97 \\
\hline
\end{tabular}


Appendix 2 cntd.

\begin{tabular}{|c|c|c|c|c|c|}
\hline \multirow[t]{12}{*}{ Eastern Mosquitofish } & \multirow[t]{4}{*}{ FC Main Test } & DepthChange $\times$ Time $\times$ Site & 0.12 & 1,55 & 0.72 \\
\hline & & Time $\times$ Site & 1.98 & 1,55 & 0.16 \\
\hline & & DepthChange $\times$ Site & 3.21 & 1,55 & 0.07 \\
\hline & & DepthChange $\times$ Time & 0.96 & 1,55 & 0.33 \\
\hline & \multirow[t]{4}{*}{ NC Main Test } & DepthChange $\times$ Time $\times$ Site & 0.13 & 1,68 & 0.71 \\
\hline & & Time $\times$ Site & 0.38 & 1,68 & 0.53 \\
\hline & & DepthChange $\times$ Site & 0.12 & 1,68 & 0.72 \\
\hline & & DepthChange $\times$ Time & 0.51 & 1,68 & 0.47 \\
\hline & \multirow[t]{4}{*}{ EL Main Test } & DepthChange $\times$ Time $\times$ Site & $<0.01$ & 1,73 & 0.96 \\
\hline & & Time $\times$ Site & 0.25 & 1,73 & 0.61 \\
\hline & & DepthChange $\times$ Site & 0.29 & 1,73 & 0.58 \\
\hline & & DepthChange $\times$ Time & 1.20 & 1,73 & 0.27 \\
\hline \multirow[t]{22}{*}{ Flagfish } & \multirow[t]{4}{*}{ FC Main Test } & DepthChange $\times$ Time $\times$ Site & 2.15 & 1,38 & 0.15 \\
\hline & & Time $\times$ Site & 34.59 & 1,38 & $<0.01$ \\
\hline & & DepthChange $\times$ Site & 2.29 & 1,38 & 0.13 \\
\hline & & DepthChange $\times$ Time & 3.16 & 1,38 & 0.08 \\
\hline & \multicolumn{5}{|l|}{ FC Pairwise Tests } \\
\hline & For Time Pre & DepthChange $\times$ Site & 0.02 & 1,22 & 0.87 \\
\hline & For Time Post & DepthChange $\times$ Site & 1.54 & 1,16 & 0.23 \\
\hline & For Site FC & DepthChange $\times$ Time & 6.07 & 1,20 & 0.02 \\
\hline & For Site FC Control & DepthChange $\times$ Time & 0.09 & 1,18 & 0.76 \\
\hline & \multirow[t]{4}{*}{ NC Main Test } & DepthChange $\times$ Time $\times$ Site & 0.13 & 1,47 & 0.71 \\
\hline & & Time $\times$ Site & 0.51 & 1,47 & 0.47 \\
\hline & & DepthChange $\times$ Site & $<0.01$ & 1,47 & 0.94 \\
\hline & & DepthChange $\times$ Time & 3.62 & 1,47 & 0.06 \\
\hline & \multirow[t]{4}{*}{ EL Main Test } & DepthChange $\times$ Time $\times$ Site & 0.24 & 1,71 & 0.62 \\
\hline & & Time $\times$ Site & 5.60 & 1,71 & 0.02 \\
\hline & & DepthChange $\times$ Site & 0.31 & 1,71 & 0.57 \\
\hline & & DepthChange $\times$ Time & $<0.01$ & 1,71 & 0.97 \\
\hline & \multicolumn{5}{|l|}{ EL Pairwise Tests } \\
\hline & For Time Pre & DepthChange $\times$ Site & 2.5 & 1,30 & 0.12 \\
\hline & For Time Post & DepthChange $\times$ Site & $<0.01$ & 1,41 & 0.96 \\
\hline & For Site EL & DepthChange $\times$ Time & 0.10 & 1,46 & 0.74 \\
\hline & For Site EL Control & DepthChange $\times$ Time & 0.16 & 1,25 & 0.68 \\
\hline
\end{tabular}


Appendix 2 cntd.

\begin{tabular}{|c|c|c|c|c|c|}
\hline \multirow[t]{17}{*}{ Golden Topminnow } & \multirow[t]{4}{*}{ FC Main Test } & DepthChange $\times$ Time $\times$ Site & 1.16 & 1,43 & 0.28 \\
\hline & & Time $\times$ Site & 0.58 & 1,43 & 0.44 \\
\hline & & DepthChange $\times$ Site & 1.36 & 1,43 & 0.24 \\
\hline & & DepthChange $\times$ Time & 0.17 & 1,43 & 0.67 \\
\hline & \multirow[t]{4}{*}{ NC Main Test } & DepthChange $\times$ Time $\times$ Site & 3.62 & 1,61 & 0.06 \\
\hline & & Time $\times$ Site & 1.57 & 1,61 & 0.21 \\
\hline & & DepthChange $\times$ Site & 0.55 & 1,61 & 0.45 \\
\hline & & DepthChange $\times$ Time & 0.19 & 1,61 & 0.66 \\
\hline & \multicolumn{5}{|l|}{ NC Pairwise Tests } \\
\hline & For Time Pre & DepthChange $\times$ Site & 1.23 & 1,27 & 0.27 \\
\hline & For Time Post & DepthChange $\times$ Site & 3.47 & 1,34 & 0.07 \\
\hline & For Site NC & DepthChange $\times$ Time & 1.78 & 1,43 & 0.18 \\
\hline & For Site NC Control & DepthChange $\times$ Time & 2.31 & 1,18 & 0.14 \\
\hline & EL Main Test & DepthChange $\times$ Time $\times$ Site & 1.55 & 1,61 & 0.21 \\
\hline & & Time $\times$ Site & 0.58 & 1,61 & 0.44 \\
\hline & & DepthChange $\times$ Site & 0.41 & 1,61 & 0.41 \\
\hline & & DepthChange $\times$ Time & 0.59 & 1,61 & 0.45 \\
\hline \multirow[t]{4}{*}{ Marsh Killifish } & EL Main Test & DepthChange $\times$ Time $\times$ Site & 0.15 & 1,47 & 0.69 \\
\hline & & Time $\times$ Site & 0.07 & 1,47 & 0.78 \\
\hline & & DepthChange $\times$ Site & 1.07 & 1,47 & 0.30 \\
\hline & & DepthChange $\times$ Time & 0.60 & 1,47 & 0.44 \\
\hline \multirow[t]{4}{*}{ Sailfin Molly } & EL Main Test & DepthChange $\times$ Time $\times$ Site & 0.25 & 1,67 & 0.61 \\
\hline & & Time $\times$ Site & 0.02 & 1,67 & 0.88 \\
\hline & & DepthChange $\times$ Site & 0.08 & 1,67 & 0.77 \\
\hline & & DepthChange $\times$ Time & 0.08 & 1,67 & 0.77 \\
\hline
\end{tabular}




\section{Appendix 3}

\begin{tabular}{|c|c|c|c|c|c|}
\hline SPECIES & SITE \& TEST & FACTORS & TEST STATISTIC & DF & P-VALUE \\
\hline \multirow[t]{22}{*}{ Bluefin Killifish } & \multirow[t]{4}{*}{ FC Main Test } & DepthChange $\times$ Time $\times$ Site & 0.84 & 1,76 & 0.35 \\
\hline & & Time $\times$ Site & 3.17 & 1,76 & 0.07 \\
\hline & & DepthChange $\times$ Site & 0.69 & 1,76 & 0.40 \\
\hline & & DepthChange $\times$ Time & 2.21 & 1,76 & 0.14 \\
\hline & \multicolumn{5}{|l|}{ FC Pairwise Tests } \\
\hline & For Time Pre & DepthChange $\times$ Site & 2.62 & 1,31 & 0.11 \\
\hline & For Time Post & DepthChange $\times$ Site & $<0.01$ & 1,45 & 0.92 \\
\hline & For Site FC & DepthChange $\times$ Time & 2.05 & 1,48 & 0.15 \\
\hline & For Site FC Control & DepthChange $\times$ Time & 0.27 & 1,28 & 0.60 \\
\hline & \multirow[t]{4}{*}{ NC Main Test } & DepthChange $\times$ Time $\times$ Site & 1.46 & 1,74 & 0.23 \\
\hline & & Time $\times$ Site & 1.29 & 1,74 & 0.25 \\
\hline & & DepthChange $\times$ Site & 0.15 & 1,74 & 0.69 \\
\hline & & DepthChange $\times$ Time & 3.83 & 1,74 & 0.05 \\
\hline & \multirow[t]{4}{*}{ EL Main Test } & DepthChange $\times$ Time $\times$ Site & 10.67 & 1,71 & $<0.01$ \\
\hline & & Time $\times$ Site & 4.02 & 1,71 & 0.04 \\
\hline & & DepthChange $\times$ Site & 3.86 & 1,71 & 0.05 \\
\hline & & DepthChange $\times$ Time & 1.85 & 1,71 & 0.17 \\
\hline & \multicolumn{5}{|l|}{ EL Pairwise Tests } \\
\hline & For Time Pre & DepthChange $\times$ Site & 7.86 & 1,28 & $<0.01$ \\
\hline & For Time Post & DepthChange $\times$ Site & 0.70 & 1,43 & 0.40 \\
\hline & For Site EL & DepthChange $\times$ Time & 3.58 & 1,47 & 0.06 \\
\hline & For Site EL Control & DepthChange $\times$ Time & 11.18 & 1,24 & $<0.01$ \\
\hline \multirow[t]{13}{*}{ Bluespotted Sunfish } & \multirow[t]{4}{*}{ FC Main Test } & DepthChange $\times$ Time $\times$ Site & 2.02 & 1,78 & 0.15 \\
\hline & & Time $\times$ Site & 1.56 & 1,78 & 0.21 \\
\hline & & DepthChange $\times$ Site & 1.61 & 1,78 & 0.21 \\
\hline & & DepthChange $\times$ Time & 5.03 & 1,78 & 0.02 \\
\hline & \multirow[t]{4}{*}{ NC Main Test } & DepthChange $\times$ Time $\times$ Site & 2.82 & 1,79 & 0.09 \\
\hline & & Time $\times$ Site & 0.71 & 1,79 & 0.40 \\
\hline & & DepthChange $\times$ Site & 3.71 & 1,79 & 0.05 \\
\hline & & DepthChange $\times$ Time & 0.87 & 1,79 & 0.35 \\
\hline & \multicolumn{5}{|l|}{ NC Pairwise Tests } \\
\hline & For Time Pre & DepthChange $\times$ Site & 0.34 & 1,33 & 0.56 \\
\hline & For Time Post & DepthChange $\times$ Site & 13.02 & 1,46 & $<0.01$ \\
\hline & For Site NC & DepthChange $\times$ Time & 3.90 & 1,53 & 0.05 \\
\hline & For Site NC Control & DepthChange $\times$ Time & 0.47 & 1,26 & 0.49 \\
\hline
\end{tabular}


Appendix 3 cntd.

\begin{tabular}{|c|c|c|c|c|c|}
\hline \multirow[t]{12}{*}{ Dollar Sunfish } & \multirow[t]{4}{*}{ FC Main Test } & DepthChange $\times$ Time $\times$ Site & $<0.01$ & 1,62 & 0.93 \\
\hline & & Time $\times$ Site & 0.80 & 1,62 & 0.37 \\
\hline & & DepthChange $\times$ Site & 0.31 & 1,62 & 0.58 \\
\hline & & DepthChange $\times$ Time & 4.08 & 1,62 & 0.05 \\
\hline & \multirow[t]{4}{*}{ NC Main Test } & DepthChange $\times$ Time $\times$ Site & 0.75 & 1,62 & 0.38 \\
\hline & & Time $\times$ Site & 0.23 & 1,62 & 0.63 \\
\hline & & DepthChange $\times$ Site & 0.13 & 1,62 & 0.72 \\
\hline & & DepthChange $\times$ Time & 1.41 & 1,62 & 0.24 \\
\hline & \multirow[t]{4}{*}{ EL Main Test } & DepthChange $\times$ Time $\times$ Site & - & - & \\
\hline & & Time $\times$ Site & - & - & \\
\hline & & DepthChange $\times$ Site & 0.31 & 1,36 & 0.57 \\
\hline & & DepthChange $\times$ Time & - & - & \\
\hline \multirow[t]{17}{*}{ Eastern Mosquitofish } & \multirow[t]{4}{*}{ FC Main Test } & DepthChange $\times$ Time $\times$ Site & 3.31 & 1,55 & 0.07 \\
\hline & & Time $\times$ Site & 1.01 & 1,55 & 0.31 \\
\hline & & DepthChange $\times$ Site & 0.11 & 1,55 & 0.73 \\
\hline & & DepthChange $\times$ Time & 0.26 & 1,55 & 0.61 \\
\hline & \multicolumn{5}{|l|}{ FC Pairwise Tests } \\
\hline & For Time Pre & DepthChange $\times$ Site & 2.52 & 1,23 & 0.12 \\
\hline & For Time Post & DepthChange $\times$ Site & 1.01 & 1,32 & 0.32 \\
\hline & For Site FC & DepthChange $\times$ Time & 1.52 & 1,33 & 0.22 \\
\hline & For Site FC Control & DepthChange $\times$ Time & 2.43 & 1,22 & 0.13 \\
\hline & \multirow[t]{4}{*}{ NC Main Test } & DepthChange $\times$ Time $\times$ Site & 0.63 & 1,68 & 0.42 \\
\hline & & Time $\times$ Site & 0.72 & 1,68 & 0.39 \\
\hline & & DepthChange $\times$ Site & 0.56 & 1,68 & 0.45 \\
\hline & & DepthChange $\times$ Time & 0.05 & 1,68 & 0.81 \\
\hline & \multirow{4}{*}{ EL Main Test } & DepthChange $\times$ Time $\times$ Site & 1.32 & 1,73 & 0.25 \\
\hline & & Time $\times$ Site & $<0.01$ & 1,73 & 0.98 \\
\hline & & DepthChange $\times$ Site & $<0.01$ & 1,73 & 0.97 \\
\hline & & DepthChange $\times$ Time & 3.26 & 1,73 & 0.07 \\
\hline \multirow[t]{17}{*}{ Flagfish } & \multirow[t]{4}{*}{ FC Main Test } & DepthChange $\times$ Time $\times$ Site & 1.28 & 1,40 & 0.26 \\
\hline & & Time $\times$ Site & $<0.01$ & 1,40 & 0.92 \\
\hline & & DepthChange $\times$ Site & 1.48 & 1,40 & 0.23 \\
\hline & & DepthChange $\times$ Time & 5.37 & 1,40 & 0.03 \\
\hline & \multirow[t]{4}{*}{ NC Main Test } & DepthChange $\times$ Time $\times$ Site & 0.16 & 1,47 & 0.68 \\
\hline & & Time $\times$ Site & 0.12 & 1,47 & 0.72 \\
\hline & & DepthChange $\times$ Site & $<0.01$ & 1,47 & 0.97 \\
\hline & & DepthChange $\times$ Time & $<0.01$ & 1,47 & 0.99 \\
\hline & \multirow[t]{4}{*}{ EL Main Test } & DepthChange $\times$ Time $\times$ Site & 2.78 & 1,72 & 0.09 \\
\hline & & Time $\times$ Site & 0.70 & 1,72 & 0.4 \\
\hline & & DepthChange $\times$ Site & 1.59 & 1,72 & 0.21 \\
\hline & & DepthChange $\times$ Time & 2.44 & 1,72 & 0.12 \\
\hline & \multicolumn{4}{|l|}{ EL Pairwise Tests } & 0.07 \\
\hline & For Time Pre & DepthChange $\times$ Site & 0.10 & 1,30 & 0.74 \\
\hline & For Time Post & DepthChange $\times$ Site & 3.47 & 1,42 & 0.06 \\
\hline & For Site EL & DepthChange $\times$ Time & 5.83 & 1,47 & 0.01 \\
\hline & For Site EL Control & DepthChange $\times$ Time & $<0.01$ & 1,25 & 0.93 \\
\hline
\end{tabular}


Appendix 3 cntd.

\begin{tabular}{|c|c|c|c|c|c|}
\hline \multirow[t]{17}{*}{ Golden Topminnow } & FC Main Test & DepthChange $\times$ Time $\times$ Site & $<0.01$ & 1,43 & 0.96 \\
\hline & & Time $\times$ Site & 0.49 & 1,43 & 0.48 \\
\hline & & DepthChange $\times$ Site & $<0.01$ & 1,43 & 0.94 \\
\hline & & DepthChange $\times$ Time & 6.69 & 1,43 & 0.01 \\
\hline & NC Main Test & DepthChange $\times$ Time $\times$ Site & 1.45 & 1,61 & 0.23 \\
\hline & & Time $\times$ Site & 0.72 & 1,61 & 0.39 \\
\hline & & DepthChange $\times$ Site & 0.48 & 1,61 & 0.48 \\
\hline & & DepthChange $\times$ Time & 1.40 & 1,61 & 0.24 \\
\hline & EL Main Test & DepthChange $\times$ Time $\times$ Site & 3.20 & 1,61 & 0.07 \\
\hline & & Time $\times$ Site & 1.92 & 1,61 & 0.17 \\
\hline & & DepthChange $\times$ Site & 1.06 & 1,61 & 0.31 \\
\hline & & DepthChange $\times$ Time & 0.32 & 1,61 & 0.57 \\
\hline & EL Pairwise Tests & & & & \\
\hline & For Time Pre & DepthChange $\times$ Site & 1.97 & 1,23 & 0.17 \\
\hline & For Time Post & DepthChange $\times$ Site & 0.76 & 1,38 & 0.38 \\
\hline & For Site EL & DepthChange $\times$ Time & 0.78 & 1,39 & 0.38 \\
\hline & For Site EL Control & DepthChange $\times$ Time & 3.55 & 1,22 & 0.07 \\
\hline \multirow[t]{4}{*}{ Marsh Killifish } & EL Main Test & DepthChange $\times$ Time $\times$ Site & 1.10 & 1,47 & 0.29 \\
\hline & & Time $\times$ Site & 0.30 & 1,47 & 0.58 \\
\hline & & DepthChange $\times$ Site & $<0.01$ & 1,47 & 0.97 \\
\hline & & DepthChange $\times$ Time & 0.98 & 1,47 & 0.32 \\
\hline \multirow[t]{4}{*}{ Sailfin Molly } & EL Main Test & DepthChange $\times$ Time $\times$ Site & 0.35 & 1,67 & 0.55 \\
\hline & & Time $\times$ Site & 0.93 & 1,67 & 0.33 \\
\hline & & DepthChange $\times$ Site & 0.32 & 1,67 & 0.56 \\
\hline & & DepthChange $\times$ Time & 3.87 & 1,67 & 0.05 \\
\hline
\end{tabular}




\section{Appendix 4}

\begin{tabular}{|c|c|c|c|c|}
\hline SITE & FACTORS & TEST STATISTIC & DF & P-VALUE \\
\hline \multirow[t]{5}{*}{$\overline{\mathrm{FC}}$} & & Pseudo-F & $D F$ & \\
\hline & DepthChange $\times$ Time $\times$ Site & 0.43 & 1,82 & 0.84 \\
\hline & Time $\times$ Site & 1.63 & 1,82 & 0.14 \\
\hline & DepthChange $\times$ Site & 1.14 & 1,82 & 0.33 \\
\hline & DepthChange $\times$ Time & 0.82 & 1,82 & 0.54 \\
\hline \multirow[t]{5}{*}{$\overline{\mathrm{NC}}$} & & Pseudo-F & $D F$ & \\
\hline & DepthChange $\times$ Time $\times$ Site & 1.66 & 1,82 & 0.12 \\
\hline & Time $\times$ Site & 1.22 & 1,82 & 0.29 \\
\hline & DepthChange $\times$ Site & 1.39 & 1,82 & 0.21 \\
\hline & DepthChange $\times$ Time & 1.51 & 1,82 & 0.17 \\
\hline \multirow[t]{5}{*}{$\overline{\mathrm{EL}}$} & & Pseudo-F & $D F$ & \\
\hline & DepthChange $\times$ Time $\times$ Site & 0.60 & 1,73 & 0.66 \\
\hline & Time $\times$ Site & 2.10 & 1,73 & 0.09 \\
\hline & DepthChange $\times$ Site & 1.01 & 1,73 & 0.40 \\
\hline & DepthChange $\times$ Time & 2.78 & 1,73 & 0.03 \\
\hline EL Pairwise & & $t$-statistic & $D F$ & \\
\hline For Site EL & Time & 3.01 & 49 & $<0.01$ \\
\hline For Site EL Control & Time & 5.91 & 24 & $<0.01$ \\
\hline For Time Pre & Site & 1.49 & 30 & 0.09 \\
\hline For Time Post & Site & 1.97 & 43 & $<0.01$ \\
\hline \multirow[t]{6}{*}{ EL vs NC } & & Pseudo-F & $D F$ & \\
\hline & DepthChange $\times$ Time $\times$ Site & 1.41 & 3,155 & 0.12 \\
\hline & Time $\times$ Site & 2.79 & 3,155 & $<0.01$ \\
\hline & DepthChange $\times$ Site & 1.26 & 3,155 & 0.21 \\
\hline & DepthChange $\times$ Time & 2.20 & 1,155 & 0.04 \\
\hline & & $t$-statistic & DenominatorDF & \\
\hline \multirow[t]{2}{*}{ Pre Pairwise } & EL vs NC & 3.55 & 49 & $<0.01$ \\
\hline & EL Control vs NC Control & 2.90 & 16 & $<0.01$ \\
\hline \multirow[t]{2}{*}{ Post Pairwise } & EL vs NC & 2.40 & 54 & $<0.01$ \\
\hline & EL Control vs NC Control & 3.76 & 36 & $<0.01$ \\
\hline
\end{tabular}




\section{Appendix 5}

\begin{tabular}{|c|c|c|c|c|c|c|}
\hline \multicolumn{7}{|l|}{ EL Mobile Community } \\
\hline Species & $\begin{array}{l}\text { Before Rel Abund } \\
\text { (EL/EL Control) }\end{array}$ & $\begin{array}{l}\text { Actual } \\
\text { Change }\end{array}$ & $\begin{array}{c}\% \\
\text { Change }\end{array}$ & $\begin{array}{l}\text { After Rel Abund } \\
\text { (EL/EL Control) }\end{array}$ & $\begin{array}{l}\text { Actual } \\
\text { Change }\end{array}$ & $\%$ Change \\
\hline Bluefin Killifish & $1.84 / 0.97$ & 0.87 & +89.69 & $4.87 / 1.74$ & 3.13 & +179.89 \\
\hline Eastern Mosquitofish & $7.01 / 7.17$ & -0.16 & -0.02 & $5.26 / 6.02$ & -0.76 & -12.60 \\
\hline Flagfish & $5.03 / 6.03$ & -1 & -16.58 & $2.61 / 3.22$ & -0.61 & -18.90 \\
\hline Sailfin Molly & $2.14 / 1.01$ & 1.13 & +111.88 & $4.19 / 5.59$ & -1.4 & -25.00 \\
\hline Goldent Topminnow & $1.23 / 0.81$ & 0.42 & +51.85 & $0.96 / 2.19$ & -1.23 & -56.20 \\
\hline Marsh Killifish & $0.87 / 0.28$ & 0.59 & +210.71 & $0.80 / 1.95$ & -1.15 & -59.00 \\
\hline \multicolumn{7}{|l|}{ EL Resident Community } \\
\hline Species & $\begin{array}{l}\text { Before Rel Abund } \\
\text { (EL/EL Control) }\end{array}$ & $\begin{array}{l}\text { Actual } \\
\text { Change }\end{array}$ & $\begin{array}{c}\% \\
\text { Change }\end{array}$ & $\begin{array}{l}\text { After Rel Abund } \\
\text { (EL/EL Control) }\end{array}$ & $\begin{array}{l}\text { Actual } \\
\text { Change }\end{array}$ & $\%$ Change \\
\hline Golden Topminnow & $1.50 / 1.55$ & -0.05 & -3.20 & $0.96 / 2.18$ & -1.22 & +56.00 \\
\hline Eastern Mosquitofish & $6.31 / 7.19$ & -13.5 & -12.20 & $5.21 / 3.84$ & 1.37 & +35.68 \\
\hline Bluefin Killifish & $2.91 / 1.37$ & -4.28 & +112.41 & $4.81 / 3.66$ & 1.15 & +31.42 \\
\hline Least Killifish & $3.07 / 2.88$ & 0.19 & +6.60 & $4.18 / 4.74$ & -0.56 & -11.80 \\
\hline Sailfin Molly & $2.07 / 0.90$ & 1.17 & +130.00 & $3.95 / 5.45$ & -1.5 & -27.50 \\
\hline Flagfish & $3.88 / 4.94$ & -1.06 & -21.50 & $1.85 / 2.8$ & -0.95 & -33.90 \\
\hline \multicolumn{7}{|l|}{ NC Mobile Community } \\
\hline Species & $\begin{array}{l}\text { Before Rel Abund } \\
\text { (NC/NC Control) }\end{array}$ & $\begin{array}{r}\text { Actual } \\
\text { Change }\end{array}$ & $\begin{array}{c}\% \\
\text { Change }\end{array}$ & $\begin{array}{l}\text { After Rel Abund } \\
\text { (NC/NC Control) }\end{array}$ & $\begin{array}{r}\text { Actual } \\
\text { Change }\end{array}$ & $\%$ Change \\
\hline Flagfish & $2.20 / 3.74$ & -1.54 & -41.18 & $1.19 / 0.45$ & 0.74 & +164.44 \\
\hline Goldent Topminnow & $2.33 / 2.27$ & 0.06 & +2.64 & $1.92 / 1.18$ & 0.74 & +62.71 \\
\hline Eastern Mosquitofish & $5 / 4.09$ & 0.91 & +22.25 & $3.58 / 2.59$ & 0.99 & +38.22 \\
\hline Sailfin Molly & - & - & - & $2.83 / 2.58$ & 0.25 & +9.69 \\
\hline Dollar Sunfish & $2.23 / 2.24$ & -0.01 & -0.45 & $1.81 / 1.84$ & -0.03 & -1.63 \\
\hline Bluefin Killifish & $2.69 / 5.05$ & -2.36 & -46.73 & $6.71 / 7.09$ & -0.38 & -5.36 \\
\hline Bluespotted Sunfish & $3.16 / 1.52$ & 1.64 & +107.89 & $1.49 / 2.44$ & -0.95 & -38.93 \\
\hline \multicolumn{7}{|l|}{ FC Mobile Community } \\
\hline Species & $\begin{array}{l}\text { Before Rel Abund } \\
\text { (FC/FC Control) }\end{array}$ & $\begin{array}{l}\text { Actual } \\
\text { Change }\end{array}$ & $\begin{array}{c}\% \\
\text { Change }\end{array}$ & $\begin{array}{l}\text { After Rel Abund } \\
\text { (FC/FC Control) }\end{array}$ & $\begin{array}{l}\text { Actual } \\
\text { Change }\end{array}$ & $\%$ Change \\
\hline Spotted Sunfish & $0.95 / 1.15$ & -0.2 & -17.39 & $1.22 / 0.63$ & 0.59 & +93.65 \\
\hline Dollar Sunfish & $3.42 / 3.01$ & 0.41 & +13.62 & $1.94 / 1.60$ & 0.34 & +21.25 \\
\hline Bluefin Killifish & $3.55 / 5.20$ & -1.65 & -31.73 & $6.34 / 6.27$ & 0.07 & +1.12 \\
\hline Sailfin Molly & $0.48 / 0$ & 0.48 & - & $1.85 / 1.89$ & -0.04 & -2.12 \\
\hline Golden Topminnow & $1.67 / 2.81$ & -1.14 & -40.57 & $0.98 / 1.03$ & -0.05 & -4.85 \\
\hline Bluespotted Sunfish & $4.94 / 1.53$ & 3.41 & +222.88 & $3.37 / 3.61$ & -0.24 & -6.65 \\
\hline Eastern Mosquitofish & $2.20 / 3.79$ & -1.59 & -41.95 & $2.34 / 2.86$ & -0.52 & -18.18 \\
\hline Flagfish & $1.56 / 3.50$ & -1.94 & -55.43 & $0.60 / 1.18$ & -0.58 & -49.15 \\
\hline
\end{tabular}




\section{Appendix 6}

\begin{tabular}{|c|c|c|c|c|c|}
\hline SPECIES & SITE \& TEST & FACTORS & TEST STATISTIC & $\mathrm{DF}$ & P-VALUE \\
\hline \multirow[t]{12}{*}{ Bluefin Killifish } & \multirow[t]{3}{*}{ Speed } & DepthChange $\times$ Site & 0.62 & 5,233 & 0.67 \\
\hline & & Site & 0.33 & 5,233 & 0.89 \\
\hline & & DepthChange & $<0.01$ & 1,233 & 0.95 \\
\hline & \multirow[t]{3}{*}{ Directionality } & DepthChange $\times$ Site & 2.23 & 5,233 & 0.05 \\
\hline & & Site & 1.58 & 5,233 & 0.16 \\
\hline & & DepthChange & 10.17 & 1,233 & $<0.01$ \\
\hline & For Site FC & DepthChange & 7.01 & 1,50 & 0.01 \\
\hline & For Site FC Control & DepthChange & 1.05 & 1,30 & 0.31 \\
\hline & For Site NC & DepthChange & 0.49 & 1,48 & 0.48 \\
\hline & For Site NC Control & DepthChange & 3.30 & 1,30 & 0.07 \\
\hline & For Site EL & DepthChange & 3.37 & 1,49 & 0.07 \\
\hline & For Site EL Control & DepthChange & 2.20 & 1,26 & 0.14 \\
\hline \multirow[t]{12}{*}{ Dollar Sunfish } & \multirow[t]{3}{*}{ Speed } & DepthChange $\times$ Site & 1.88 & 5,171 & 0.09 \\
\hline & & Site & 0.56 & 5,171 & 0.72 \\
\hline & & DepthChange & 1.68 & 1,171 & 0.19 \\
\hline & For Site FC & DepthChange & 3.87 & 1,44 & 0.05 \\
\hline & For Site FC Control & DepthChange & 2.14 & 1,22 & 0.15 \\
\hline & For Site NC & DepthChange & 5.54 & 1,44 & 0.02 \\
\hline & For Site NC Control & DepthChange & 5.59 & 1,22 & 0.02 \\
\hline & For Site EL & DepthChange & 1.22 & 1,30 & 0.27 \\
\hline & For Site EL Control & DepthChange & 0.56 & 1,9 & 0.47 \\
\hline & \multirow{3}{*}{ Directionality } & DepthChange $\times$ Site & 0.61 & 5,171 & 0.68 \\
\hline & & Site & 1.81 & 5,171 & 0.11 \\
\hline & & DepthChange & 0.51 & 1,171 & 0.47 \\
\hline \multirow[t]{6}{*}{ EasternMosquitofish } & \multirow[t]{3}{*}{ Speed } & DepthChange $\times$ Site & 0.08 & 5,208 & 0.99 \\
\hline & & Site & 0.68 & 5,208 & 0.63 \\
\hline & & DepthChange & 0.19 & 1,208 & 0.66 \\
\hline & \multirow[t]{3}{*}{ Directionality } & DepthChange $\times$ Site & 0.77 & 5,208 & 0.56 \\
\hline & & Site & 4.81 & 5,208 & $<0.01$ \\
\hline & & Depth Change & 0.01 & 1,208 & 0.89 \\
\hline
\end{tabular}


Appendix 6 cntd.

\begin{tabular}{|c|c|c|c|c|c|}
\hline \multirow[t]{18}{*}{ Flagfish } & \multirow[t]{3}{*}{ Speed } & DepthChange $\times$ Site & 2.32 & 5,171 & 0.04 \\
\hline & & Site & 0.32 & 5,171 & 0.89 \\
\hline & & DepthChange & 9.76 & 1,171 & $<0.01$ \\
\hline & For Site FC & DepthChange & 0.01 & 1,24 & 0.91 \\
\hline & For Site FC Control & DepthChange & 0.85 & 1,20 & 0.36 \\
\hline & For Site NC & DepthChange & 14.24 & 1,36 & $<0.01$ \\
\hline & For Site NC Control & DepthChange & 9.11 & 1,15 & $<0.01$ \\
\hline & For Site EL & DepthChange & 4.03 & 1,49 & 0.05 \\
\hline & For Site EL Control & DepthChange & 12.70 & 1,27 & $<0.01$ \\
\hline & \multirow[t]{3}{*}{ Directionality } & DepthChange $\times$ Site & 1.96 & 5,171 & 0.08 \\
\hline & & Site & 3.97 & 5,171 & $<0.01$ \\
\hline & & DepthChange & 9.16 & 1,171 & $<0.01$ \\
\hline & For Site FC & DepthChange & 0.01 & 1,24 & 0.94 \\
\hline & For Site FC Control & DepthChange & 0.14 & 1,20 & 0.70 \\
\hline & For Site NC & DepthChange & 2.24 & 1,36 & 0.14 \\
\hline & For Site NC Control & DepthChange & 0.56 & 1,15 & 0.46 \\
\hline & For Site EL & DepthChange & 7.31 & 1,49 & $<0.01$ \\
\hline & For Site EL Control & DepthChange & 0.73 & 1,27 & 0.40 \\
\hline \multirow[t]{6}{*}{ Golden Topminnow } & \multirow[t]{3}{*}{ Speed } & DepthChange $\times$ Site & 0.53 & 5,177 & 0.75 \\
\hline & & Site & 0.80 & 5,177 & 0.54 \\
\hline & & DepthChange & 0.29 & 1,77 & 0.58 \\
\hline & \multirow[t]{3}{*}{ Directionality } & DepthChange $\times$ Site & 0.32 & 5,177 & 0.89 \\
\hline & & Site & 1.79 & 5,177 & 0.11 \\
\hline & & DepthChange & 0.80 & 1,177 & 0.37 \\
\hline \multirow[t]{6}{*}{ Marsh Killifish } & \multirow[t]{3}{*}{ Speed } & DepthChange $\times$ Site & 0.24 & 1,51 & 0.62 \\
\hline & & Site & 0.01 & 1,51 & 0.93 \\
\hline & & DepthChange & 0.78 & 1,51 & 0.37 \\
\hline & \multirow[t]{3}{*}{ Directionality } & DepthChange $\times$ Site & 2.49 & 1,51 & 0.12 \\
\hline & & Site & 4.07 & 1,51 & 0.04 \\
\hline & & DepthChange & 2.06 & 1,51 & 0.15 \\
\hline \multirow[t]{6}{*}{ Sailfin Molly } & \multirow[t]{3}{*}{ Speed } & DepthChange $\times$ Site & 2.31 & 1,71 & 0.13 \\
\hline & & Site & 0.85 & 1,71 & 0.35 \\
\hline & & DepthChange & 2.14 & 1,71 & 0.14 \\
\hline & \multirow[t]{3}{*}{ Directionality } & DepthChange $\times$ Site & 0.13 & 1,71 & 0.71 \\
\hline & & Site & 0.01 & 1,71 & 0.99 \\
\hline & & DepthChange & 0.60 & 1,71 & 0.43 \\
\hline
\end{tabular}




\section{Appendix 7}

\begin{tabular}{|c|c|c|c|}
\hline Species & Hoch et al. 2015 & This study (Speed) & This study (Directionality) \\
\hline Bluefin Killifish & $\begin{array}{l}\text { Directed movement; high encounter } \\
\text { rate, especially as water levels rise }\end{array}$ & All sites ns & $\begin{array}{l}\text { Increased directed movement as } \\
\text { water levels rise at FC, EL, and NC } \\
\text { Control sites }\end{array}$ \\
\hline Dollar Sunfish & $\begin{array}{l}\text { Directed movement; high encounter } \\
\text { rate, especially as water levels fall }\end{array}$ & $\begin{array}{l}\text { Increased speed as water levels } \\
\text { rise at } \mathrm{FC}, \mathrm{NC} \text {, and } \mathrm{NC} \text { Control } \\
\text { sites }\end{array}$ & All sites ns \\
\hline Eastern Mosquitofish & $\begin{array}{l}\text { Directed movement; high encounter rate } \\
\text { during changes in water levels }\end{array}$ & All sites ns & $\begin{array}{l}\text { Significant differences across sites, } \\
\text { but not water depth change }\end{array}$ \\
\hline Flagfish & $\begin{array}{l}\text { Directed movement; high encounter } \\
\text { rate, especially as water levels rise }\end{array}$ & $\begin{array}{l}\text { Increased speed as water levels } \\
\text { rise at NC, NC Control, EL, and } \\
\text { EL Control sites }\end{array}$ & $\begin{array}{l}\text { Increased directed movement as } \\
\text { water levels rise at EL sites }\end{array}$ \\
\hline Golden Topminnow & $\begin{array}{l}\text { Directed movement; high encounter } \\
\text { rate, especially as water levels rise }\end{array}$ & All sites ns & All sites ns \\
\hline Marsh Killifish & $\begin{array}{l}\text { Directed movement; high encounter } \\
\text { rate, especially as water levels rise }\end{array}$ & All sites ns & $\begin{array}{l}\text { Significant differences across sites, } \\
\text { but not water depth change }\end{array}$ \\
\hline Sailfin Molly & $\begin{array}{l}\text { No directed movement; high encounter } \\
\text { rate during changes in water levels }\end{array}$ & All sites ns & All sites ns \\
\hline
\end{tabular}


CHAPTER III

EFFECTS OF HYDROSCAPE ALTERATION ON LARGE FISH BEHAVIOR, DENSITY, AND COMMUNITIES IN A DYNAMIC WETLAND 


\section{Abstract}

Alteration of hydroscape structure and connectivity, both natural and anthropogenic, can have important consequences for animal habitat use, density, and community structure. Consideration of the linkage of animal movement and hydroscape may facilitate restoration and conservation programs in impacted systems. Over a five-year period, we examined the effects of canal filling, levee degradation, and experimental flow pulses on fish behavior, CPUE, and community structure in a seasonally dynamic wetland. Radio transmitters were surgically-implanted in Largemouth Bass (Micropterus salmoides) and Bowfin (Amia calva) and their weekly movement rates $\left(\mathrm{m}^{- \text {day }}\right)$ and habitat preferences were monitored. Electroshocking transects were spatially structured to determine if fish CPUE and community composition changed as a result of hydroscape alteration, canal proximity, or both. Multi-model selection revealed that models with hydroscape alteration better explained individual movement patterns than models with environmental cues alone, particularly for Bowfin. Bowfin averaged $15 \%$ closer proximity to the canal treatment areas after filling and levee removal compared to before treatment, but were $150 \%$ farther away from the canal in the untreated (control) areas compared to before treatment. Movement rate, from the canal into the marsh or vice versa, were up to 4-times greater than movements within either marsh or canal habitats for both species. Fill treatments had little effect on overall fish CPUE, but increased the area of vegetated habitat supporting high fish density. Some species responded positively to canal filling, notably Largemouth Bass, which doubled CPUE in some treatments, while others responded negatively, notably Florida gar; CPUE of Lake Chubsuckers decreased in the partial fill area compared to controls or before canal filling, but not in the complete fill. 
Fish community composition differed between pre-existing and modified hydroscape structure, but was not affected by canal-fill treatments within the modified area. Our study indicates that hydroscape structure influences fish movement and local density in species-specific ways that effect community structure. Levee removal permitted both Largemouth Bass and Bowfin to move between previously isolated habitats and canal fill treatments created habitat that probably attracted fish to formerly deep areas that were seldom used.

\section{Introduction}

In seasonal hydroscapes, habitats suitable during one season may be hostile or unavailable during another season, and staying within an ephemeral habitat presents a tradeoff of risks (Dean et al. 2009). For example, Colossoma macropomum will move into Amazonian floodplains to feed and deposit eggs in the flooded forest, but must move back to nearby lakes and rivers before the forest completely dries (Loubens and Panfilli 1997, Winemiller and Jepsen 1998). When hydroscape dynamics cycle in a period shorter than the lifespan of an animal, coping behaviors, including responding to environmental cues, are adaptive. Cues to seasonal change include shifts in temperature (Wood et al. 2006) and photoperiod (Stefansson et al. 2008). Seasonally dynamic conditions influence the distribution of animals across the landscape, and may force them to seek refuge habitats. Refuge quality can have important effects on population persistence (Agostinho and Zalewski 1995, Magoulick and Kobza 2003), as can refuge spatial arrangement (Parkos et al. 2011). Furthermore, importance of refuge and ephemeral habitats can vary among species, creating a seasonal mosaic of habitat patches 
that contribute to metapopulation and metacommunity processes (Mouquet and Loreau 2003, Stoffels et al. 2015).

Understanding how environmental cues and landscape quality affect animal behavior is of fundamental importance to management strategies (Berger 2004, Both et al. 2006). Recent efforts in aquatic community restoration include the removal of barriers (e.g. dams, levees) that may restrict dispersal and migration or create unsuitable habitat (Hohausova et al. 2010, Cooper et al. 2016). Beyond removal of barriers to movement, spatial heterogeneity of habitat quality can be enhanced through strategic alteration of the hydroscape (Peterson et al. 2005) and manipulation of hydrological stage and water velocity (Poff et al. 1997). Understanding how wetland fluctuation influences animal movement is necessary to predict effects of hydroscape manipulation on fish density and community structure, and ultimately management success. Experimental study of landscape ecology is challenging (Nabe-Nielson et al. 2010) because of difficulties replicating treatments (Hargrove and Pickering 1992). However, before-aftercontrol-impact (BACI) study designs permit evaluation of responses to planned manipulation that provide insight into links of landscape structure and ecological processes (Downes et al. 2002, Jenerette and Shen 2012). Hydroscape manipulations such as dam removals and wetland modifications have the potential to permit an experimental framework for analysis of behavioral linkages to landscape structure.

The freshwater Everglades of Florida, USA, are an ideal place to examine the influence of changing hydroscapes on fishes. The Everglades experiences annual wet (May through October) and dry (November through April) seasonal cycles (Gunderson 
and Loftus 1993). Previous work on long-lived, large fishes (life span greater than one year, standard length greater than $8 \mathrm{~cm}$ ) in the Everglades has shown a strong effect of water depth on both community composition (Trexler et al. 2002, Chick et al. 2004, Parkos et al. 2011) and behavioral ecology (Parkos and Trexler 2014, Parkos et al. 2015, Boucek and Rehage 2015). The Everglades is now a highly managed network of water retention areas, bounded by canals and levees (Light and Dineen 1994). In the historic Everglades, deep sloughs and alligator ponds provided dry-season refuge necessary for fishes to persist through drought years, whereas in the current Everglades, deep refuges are often in the form of drainage canals that act as seasonal points of dispersal for fishes (Loftus and Kushlan 1987). Large-fish density, but not community composition, has been shown to be influenced by the proximity to deep-water canals, with highest density of large fishes within 5 meters of a canal (Rehage and Trexler 2006). Annually, fishes must make choices of whether to leave stable dry-season refuge habitats, where competition for food may be high, or enter the flooded marsh, where threat of desiccation is elevated.

Plans for restoration of the Everglades include removal of barriers to water flow (levees) and the filling of canals (USACE and SFWMD 1999; Sklar et al. 2005).

Response of large fishes to hydroscape alteration, including modifying canals that were in place for 50 or more years, is a source of uncertainty for restoration planning. We evaluated the impact of the regional hydroscape with a landscape-scale physical model (DPMST 2010) that included filling a section of a canal and degrading a levee that had separated two water management units hydrologically disconnected since the $1960 \mathrm{~s}$ (Light and Dineen 1994), altering hydroscape structure and habitat connectivity (Figure. 
1). We examined the role of hydroscape alteration (filling of a canal, implementation of an experimental flow pulse) and environmental cues affecting large-fish movement and habitat use in Largemouth Bass (Micropterus salmoides, hereafter LMB) and Bowfin (Amia calva), as well as CPUE of all large fishs and the large-fish community structure. We evaluated a BACI hypothesis for these variables. Because of the limited spatial scale of the hydroscape alteration, we hypothesized that the experimental flow pulse and canalfill treatments would not affect movement rates and that movement patterns would be best explained by environmental cues. The effects of environmental cues on individual behavior across the greater hydroscape, beyond the physical model, were also evaluated. BACI hypotheses were also used to determine if hydroscape alteration affected large fish density and community structure. We hypothesized that large fish density and community structure would become similar between marsh sites and canal sites that were filled in with sediment and became more similar structurally to the marsh. We further hypothesized that canal fill treatments would increase large fish density because of increased structure provided by the canal-fill treatments as well as providing more open water than is provided in the marsh.

\section{Methods}

This study was conducted in the Everglades, Florida, USA ( $25^{\circ} 50^{\prime} 15^{\prime}$ N $\left.80^{\circ} 37^{\prime} 07^{\prime \prime} \mathrm{S}\right)$, where the primary study area was approximately 37 kilometers long and 1.8 kilometers wide (Figure 1A, B) and initially constrained on all sides by earthen levees (the L-67C and L-67A levees). Along the eastern edge of the study area is the only deep-water habitat (L-67C canal), which is approximately 4 meters deep and 8 meters wide (Figure 
1C) and has vertical sides. The canal and the western marsh were connected at moderateto-high water (most of the study period). The marsh, comprising the area west of the L67 canal to the L-67A levee, was roughly uniform in depth and composed of sloughs and slightly elevated ridges (McVoy et al. 2011). Slough vegetation was dominated by white waterlily (Nymphaea odorata), Gulf Coast spikerush (Elocharis cellulosa), and bladderworts (Utricularia spp.) (Gunderson and Loftus 1993). Floating mats of periphyton were also abundant in the sloughs (Table 1). Ridges were vegetated by sawgrass (Cladium jamaicense) and tended to have higher stem density than the relatively more open sloughs.

The study was conducted between December, 2010, and March, 2015, with December, 2010, to December, 2012, providing 'Before' manipulation data and January, 2013, to March, 2015, ‘After' data. The physical model was constructed during late 2012 and early 2013. The alterations included three approximately 300-m long canal-fill treatments: a Complete-Fill treatment, where the L67-C canal was filled to approximately marsh level with sediment; a Partial-Fill treatment, where the canal was filled approximately halfway; and a No-Fill control treatment, where the canal was not modified in any way (Figure 1C). Immediately to the east of all three treatments, the L67C levee was degraded to marsh level, allowing water to flow from the west to the east across two previously separated hydrological units. The physical model also introduced sheet flow (wide expanses of slow moving surface water) from 10 culverts delivering 750 cfs between early November, 2013, to late December, 2013, and early November, 2014, late January, 2015. Though elevated water flow velocities were noted immediately downstream from the culverts when they were open, flow velocities at our study sites 
were not elevated (Culverts open: $1.47 \mathrm{~cm} / \mathrm{sec}, \mathrm{SE}=0.26$; culverts closed: $1.53 \mathrm{~cm} / \mathrm{sec}$, $\mathrm{SE}=0.21$; velocities estimated with a SonTek FlowTracker Acoustic Doppler Velocimeter). However, $\mathrm{SF}_{6}$ tracers (Ho et al. 2009) indicated that that water introduced from the culverts moved through our study area (David Ho, University of Hawaii, personal communication).

To determine effects of hydroscape alteration on individual behavior, radiotelemetry was used to track movements for Bowfin and LMB, two abundant large piscivores of the study system. Specimens used for tracking were collected with an airboat-mounted electroshocker. We determined effects of hydroscape structure and alteration on large-fish communities and CPUE, by using an airboat-mounted electroshocker and a sampling regime with two distances from the canal, as well as within the canal.

Individual fish could be tracked for three to twelve months based on battery life of the transmitters. Therefore, specimens were collected in seven batches from May, 2011, to October, 2014 (Appendix 1). Mean sizes for tagged LMB was $32.0 \mathrm{~cm}$ (SL) and 43.1 $\mathrm{cm}$ (SL) for Bowfin. Minimum sizes used ensured tag weight was less than $2 \%$ of the body weight of the fish (Winter 1983, Appendix 1). Masses were determined using a length-mass table for Bowfin (www.FishBase.org) and a length-mass calculator for LMB (Florida Fish and Wildlife Conservation Commission). The first two batches of fishes were implanted with $3.1 \mathrm{~g}$ and $3.8 \mathrm{~g}$ transmitters (Model PD-2, Holohil Systems Ltd.). Subsequent batches were implanted with the $3.8 \mathrm{~g}$ tags until October 2014, when $8.5 \mathrm{~g}$ RI-2B tags were used. Transmitter model was changed because of longer battery life of 
the RI-2B transmitters, allowing us to track fishes over an entire year. Fishes were anesthetized with MS-222 in a holding tank (100 mg MS-222/liter). Stainless steel forceps and scissors were sterilized in $95 \%$ ethanol and rinsed with deionized water prior to surgery. All personnel involved in the surgery process wore latex gloves. After anesthetization, a 2-4 cm incision was made ventrally just off the midventral line and the transmitter, also sterilized in ethanol and rinsed with DI water, was inserted in the body cavity. During this process, the gills of the fish were kept wet using a maintenance dose of MS-222 (40 mg MS-222/liter). The incision was closed with two to four sutures using non-absorbable polypropylene, 3/0, braided surgical silk. After surgery, fish recovered in a separate holding tank. When fish could maintain balance and vigorous fin movement, they were released back to the collection site. Average times recorded were: 5.5 minutes for anesthesia, 6.0 minutes for surgery, and 5.8 minutes for recovery (Appendix 1). Fishes were released no more than 40 meters from the point of capture.

Following 7-14 days to allow for agitation dispersal (Turchin 1998), fishes were located on an approximately weekly basis via jonboat, airboat, or fixed-wing aircraft, and position as determined with a handheld GPS unit. Relocation error from fishes found via watercraft was minimal, estimated to be five meters, equal to the error associated with civilian GPS units. Location error associated with fixed-wing aircraft was 53-165 meters, with an average of 109 meters (Parkos and Trexler 2014). Occasionally, fishes were in regions that were not accessible by foot or watercraft. In these cases, locations and bearings were taken so that triangulations could be calculated (LOAS, Ecological Software Solutions, LLC). Fishes were repeatedly located until the transmitter battery 
died, typically 4-6 months for the PD-2 transmitters and 9-12 months for the RI-2B transmitters.

Large-fish CPUE and community composition was sampled on an approximately quarter-annual basis, determined by stages of marsh water depth. Electroshocking was conducted during daylight hours with an airboat-mounted electroshocker over 5-minute transects following Chick et al. (1999). Fishes greater than and equal to $8.0 \mathrm{~cm}$ (standard length) were collected and lengths recorded. Three different plot types were established: Canal sites, where sampling took place along the littoral edge of the canal (DIDSON sonar surveys indicated very few fish in the open-water portion of the canal during daylight, see below and Hijuelos 2012); Near-Canal (hereafter NC) sites, which took place in the marsh 1-70 meters from the canal edge; and Far-from-Canal (hereafter FC) sites, which took place in the marsh 150-550 meters from the canal edge (Figure 1C). There were three plots of each Site type, roughly parallel to the canal-fill treatments. Canal sampling incorporated two parallel transects, along the eastern and western edges of the L-67C canal. Each pair of transects was considered one replicate. These were linear transects. There were one pair of transects for both the Complete-Fill and PartialFill treatments, and three pairs of transects for the No-Fill treatment. Marsh plots incorporated 1-3 transects, depending on availability of suitable habitat to sample. The NC plots were open-water sloughs directly connected to the canal, an uncommon configuration in our study area. Control sites were incorporated during August, 2011, and transects were added over the course of the following year as plots were further evaluated. Established transects of sites, particularly those within the canal fill treatments, were occasionally not sampled during the period of December, 2012, to 
August, 2013, because of construction involved in the physical model. In total, 19 sampling events occurred between December, 2010, and March, 2015.

We used a dual-frequency identification sonar (DIDSON) as a non-invasive survey tool used to estimate density of fishes in the canal-fill treatments and complement the electrofishing data. The DIDSON is a multi-beam, imaging sonar that can record acoustic data at short ranges $(<30 \mathrm{~m})$ and has been used extensively for fisheries applications (Tiffan et al. 2004, Boswell et al. 2008, Burwen et al. 2010). The DIDSON surveys began in March, 2012, in the Complete-Fill treatment and May, 2012, in the Partial and No-Fill treatments, and continued through November, 2014 at an approximately monthly basis. A $10 \mathrm{~m}$ window length was used and 6 frames/sec framerate. Two 5-minute recordings were taken along the midpoint of the canal facing horizontally; one facing north and one facing south into open water. Another set of approximately three recordings were taken facing east (towards the littoral zone of the canal margin). Fish density was counted from a 30-second continuous segment (approximately 180 frames) randomly taken from each of these recordings and these counts were averaged to provide density estimates for each fill treatment. Density was determined by the mean number of fishes observed divided by the un-vegetated area of the recording. North-South and East samples were analyzed separately. Fishes of all size classes were included in DIDSON analyses, including those less than $8 \mathrm{~cm}$ SL.

Water depth was estimated with the Everglades Depth Estimation Network (EDEN; Telis 2006; Liu et al. 2009), and was adjusted to local depth by in situ measured depth. Maximum daily temperature $\left(\mathrm{C}^{\circ}\right)$ was used as a proxy for water temperature. 
Data were gathered from the National Oceanic and Atmospheric Administration National Climate Data Center weather stations (http://www.ncdc.noaa.gov/cdo-web/).

Photoperiod data were taken from the Astronomical Applications Department, U.S. Naval Observatory (Station GHCND:USW00012888).

\section{Statistical Methods and Data Analyses}

We used our BACI hypothesis to test for effects of hydroscape alteration on large-fish behavior, CPUE, and community composition. Data were divided by Site (Control and Impact) and Time (Before and After or During alteration). Analyses examining individual behaviors in the physical model separated Control and Impact regions on the basis of observed $\mathrm{SF}_{6}$ tracer pathways through the marsh during the experimental flow periods. Areas within the flow path were considered "Impact", regardless of whether an experimental flow period was occurring. The only exception was for analyses examining step-length distances in canal-fill treatments, where "Impact" were segments of the canal subject to a fill treatment, and "Control" were all other areas of the canal. For large-fish CPUE and community composition, site was composed of three habitat types: Canal, NC, and FC habitats. In the Canal sites, fill treatments (Complete-Fill, Partial-Fill, No-Fill, Control) were used in place of Site. We examined whether large-fish CPUE in the NoFill treatment plots was different from Control canal plots to the north and south. If there were no differences in CPUE, these plot types were combined so canal treatment was divided between No-Fill, Partial-Fill, and Complete-Fill. All behavioral analyses were species-specific. All analyses involving parametric methods were conducted in $\mathrm{R}$ ver. 3.2.2 (R Core Team 2015) and packages "car" (Fox and Weisberg 2011), "ggthemes" 
(Arnold 2015), “adehabitat" (Calenge 2006), and "nlme" (Pinheiro et al. 2015).

Dependent variables for all behavioral and density analyses were natural-log (ln) or square-root transformed to meet model assumptions, with 1 added to all values when necessary to avoid undefined operations.

To assess whether fish length and transmitter size were correlated with movement rate and distance from the canal, a linear model was used examining the interaction of standard fish length $\times$ transmitter size on movement behaviors.

We used multi-model selection (Burnham and Anderson 2010) to evaluate alternative hypotheses about the effects of hydroscape structure on fish movement behavior. Environmental predictor variables for step length and distance-from-canal analyses included average daily marsh depth $(\mathrm{cm})$, average daily change of marsh depth ( $\mathrm{cm} /$ day), average daily photoperiod (minutes/day) and average daily maximum temperature $\left(\mathrm{C}^{\circ}\right)$, all over the preceding 30-day period. To determine if small-scale changes in abiotic factors determined step length, the average daily marsh depth $(\mathrm{cm})$, average daily marsh depth change $(\mathrm{cm} /$ day), average daily maximum air temperature $\left(\mathrm{C}^{\circ}\right)$, and average photoperiod (minutes/day) between relocations of individuals were also included as predictors variables. Predictor variables of different time scales were not included in the same model (e.g., Daily depth change over the preceding 30 days + Daily depth change between relocations). These predictor variables will be referred to as the environmental-cue variables. Distance-from-canal analyses used weekly mean distances from the canal as replicates, not individual relocations, so only environmental predictor variables over the preceding 30-day period were used. Spatial autocorrelation for 
distance-from-canal models was included in generalized least-squares models (corAR1, maximum likelihood). For these analyses, explanatory power of models was calculated using pseudo- $\mathrm{R}^{2}$ values (Anderson 2008). For all BACI-based behavioral analyses, the full model was: Time (Before/After) + Site $($ Control/Impact $)+$ Site $\times$ Time + environmental cues. Models were run iteratively, with a single predictor variable removed with each model until only the environmental cues remained. For all analyses using multi-model selection, the best model was chosen based on the lowest AIC value for all analyses. If models had a model fit of $\Delta \mathrm{AIC}<2.0$ when compared to the best model, the most parsimonious model was chosen.

Movement rates were calculated by taking distances between relocation points and dividing the distance by the number of days between relocations (meters/24 hours). Multi-model selection was used to determine which predictor variables were most influential to step length. Movement rates were examined in three different contexts to address the BACI hypotheses: across the study region (B/A: before and after physical model construction; C/I: within (Impact) or outside (Control plots) of the experimental flow area, regardless of whether experimental flows were taking place); during experimental flow periods (B/A: not during or during experimental flow periods; $\mathrm{C} / \mathrm{I}$ : within or outside of the experimental flow area); and in the canal fill treatments (B/A: before or after completion of canal fill treatment construction, C/I: filled versus unfilled canal segments). Distance-from-canal models examined mean weekly distance from the canal within species based on B/A (before or after physical model construction) and $\mathrm{C} / \mathrm{I}$ (within or outside of the experimental flow area, regardless of whether flow was occurring). 
We used ANCOVA models to determine if movement rates were influenced by being in the experimental flowpath or canal fill treatments. Experimental flowpath models just included Site (Control/Impact) and Water Depth. Time was included in canal-fill models (Before/After canal fill construction) and marsh depth over the preceding 30 days before sample collection was used as a covariate (Full model: Time $\times$ Site $\times$ Water Depth). If fishes moved into or out of the impact regions, those relocation samples were removed. If fished moved completely through the impact regions but sequential relocation events were both in the control areas, those movements were considered "Control". Distances from the canal were calculated as the Euclidean distance between a relocation point and the middle axis of the canal using Google Earth (ver. 7.5.1). Data were divided between those in the control and the impact areas of the experimental flow pulse. Distances from the canal were averaged together for their respective Control/Impact groups for each weekly relocation (Total weekly relocations for Bowfin $n=140 ;$ LMB $n=140$ ).

Behavioral analyses that summarized movement at a larger spatial scale than our physical model were included as complementary analyses to our BACI design. We examined movement rates across the entire study area, divided between intra- and interhabitat movements, to determine if the effect of habitat and ecotone influenced step lengths. Movement rate analyses were conducted using general linear models and were divided a priori into four categories: Within Marsh, Within Canal, Into Marsh From Canal, and Into Canal From Marsh. All possible combinations of environmental cues influencing daily movement rates within habitats were examined using a multi-model approach. Because no individual fish was found in every sampling event, data were not 
averaged across sampling events. Every relocation of an individual was included as a replicate (total $n=1,442$ for Bowfin, total $n=1,593$ for LMB). Complimentary to movement rate prediction models, a single-factor Analysis of Variance (ANOVA) was used to analyze if differences in movement rates across habitat categories existed. If differences were evident, a Tukey's post-hoc test was used to determine which categories were driving differences in step length. To assess the effects of the regional hydroscape on movement away from the canal, weekly distances from the canal were also analyzed with environmental predictor variables and no BACI design. All possible combinations of environmental cues over the preceding 30 days were examined with a multi-model selection approach. Distance-from-canal data were averaged for each weekly relocation. Only fish that exhibited movement in the marsh at least once were used for these analyses.

Habitat selection choices influenced by water depth were examined using logistic generalized linear models which estimated the probability of all individuals occupying the marsh based on the previous 30-day average daily marsh depth. Each set of weekly relocations were treated as replicates. To prevent bias from single individuals on the model output, only relocation events where at least two fishes were found were included in these calculations. Data were divided between "Increasing" and "Decreasing" depths, designated based on when the sample was collected between periods of seasonal marsh maxima or minima during a hydrologic cycle. Average water depth over the preceding 30 days was nested in these depth-change categories. Slopes were then plotted with $95 \%$ confidence intervals to determine what marsh depths probability of marsh occupancy was different between periods of depth increase and decrease. 
Large-fish CPUE was calculated using an ANCOVA model that incorporated our BACI design, as well as the mean daily marsh depth $($ Site $\times$ Time $\times$ Water Depth over the preceding 30-day period). Depths were averaged at the site level (FC, NC, and their respective controls). For canal sites, depths from the NC (middle plot) or NC Control sites (averaged across north and south control sites) were used. Within canal habitats, the CPUE of total fishes, LMB, and all sunfishes (a combined group representing Lepomis gulosus, L. macrochirus, L. microlophus, and L. punctatus) were examined. Low catch rates of individual species and species groups in the NC and FC habitats limited analysis to total-fish CPUE. Effects of temporal autocorrelation on CPUE between samples was examined (corAR1, maximum likelihood). The best model was chosen by lowest AIC value. If model fit was equal (AIC < 2.0), the model without autocorrelation correction was chosen.

DIDSON density data were analyzed using an ANCOVA model examining the interaction of Time $\times$ Site $\times$ Water Depth over the preceding 30-day period. When construction of the Complete-Fill treatment began in January, 2013, the survey site for that treatment was moved slightly south to open water, just south of where the canal plug divided the open canal and the Complete-Fill treatment. This was done to accommodate shallow-depth restrictions for the DIDSON. This model was run separately for the north/south-facing samples and for east-facing samples.

Differences in community similarity were tested using permutational analysis of variance $($ PERMANOVA, number of permutations $=9999)$. We used the Morisita-Horn index because of its property of density invariance (Jost et al. 2011). PERMANOVA 
analyses were calculated using data standardized to the total catch for each species, followed by square-root transformation to preserve density differences for common species while still providing some weight to uncommon species (Clarke and Warwick 2001). Our BACI design was tested using Time, Site, and Sampling Period as factors, as well as their interactions. Sampling period was used in place of water depth change and corresponded to specific stages in the hydrologic cycle. Sampling periods were organized into the following categories: August/September as "Wet", November/December as “Transition”, January/February as "Early Dry”, and March as "Late Dry". If CPUE of the No-Fill treatments between the Control and Impact sites were similar, these were grouped together for community analyses. If results were significant, data were compared using pairwise comparisons between periods of the hydrologic year that correspond to specific times of marsh water depth and whether water was rising or falling. Similarity percentage (SIMPER) descriptions were run on significant PERMANOVA results to determine which species were contributing to differences among communities. PERMDISP, a test examining the dispersion of groups of points and complementary to the PERMANOVA, was used (number of permutations = 999) to test whether the dispersion of one community was greater than another. Community analyses were conducted in Primer ver. 6.0.

\section{Results}

\section{Individual movement behavior}

We observed an effect of tag size (Small: 3.2 - $3.8 \mathrm{~g}$; Large: $8.5 \mathrm{~g}$ ) on movement rates that depended on fish size used for this project, but only in Bowfin (tag size $\times$ standard 
length: $\mathrm{t}=-2.32, \mathrm{df}=91, P=0.022$ ). In that species, movement rate and fish size was positively correlated with large tags, but negatively correlated with small tags. However, explanatory power of this interaction was low $\left(\mathrm{R}^{2}=0.04\right)$ and so was not expected to greatly influence results. Movement rates in LMB were not influenced by tag size $\times$ standard length $(\mathrm{t}=0.56, \mathrm{df}=94, P=0.45)$. Mean distance from canal was not affected by the interaction of tag size $\times$ standard length for either species (Bowfin: $t=1.02, d f=$ 91, $P=0.30 ;$ LMB: $\mathrm{t}=-0.71, \mathrm{df}=94, P=0.47)$.

Including the BACI design (Time + Site, but not including interaction of Time $\times$ Site) in models of movement rates equaled or improved model fit compared to models with just environmental cues (Appendix 2 for all best-fit models), especially for LMB. There was little explanatory power for any of the best-supported models (highest $\mathrm{R}^{2}$ for Bowfin $=0.07 ; \mathrm{LMB}<0.01)$. Movement rate models using the BACI design yielded similar results when examining predictor variables affecting step lengths during experimental flow periods (Appendix 3 for all models of best fit) or within/outside of the canal fill treatments (Appendix 4 for all models of best fit). Movement rates diminished during experimental flow periods (Control: 87.87 m/day, 95\% C.I. \pm 44.93 ; Impact: 37.56 m/day, 95\% C.I. \pm 9.52 ) for Bowfin (Site $\times$ Depth Change: $\mathrm{F}=7.76$, df $=1,287, P<$ 0.01 ) but not LMB (Site $\times$ Depth Change: $\mathrm{F}=1.86$, df $=1,257, P=0.17)$. Differences in movement rates between canal-fill treatments versus unfilled stretches were not different for either species $($ Time $\times$ Site $\times$ Depth Change: Bowfin: $\mathrm{F}=0.53, \mathrm{df}=1,399, P=0.46$; LMB: $\mathrm{F}=1.29, \mathrm{df}=1,693, P=0.25)$. 
In contrast to step length, the BACI design improved fit of mean distance from the canal to our data. Mean distance from the canal for Bowfin was best explained by Site + Time + Site $\times$ Time + the environmental predictor variables $\left(\right.$ Pseudo- $\mathrm{R}^{2}=0.24$; Table 2). Average distance from the canal decreased in the Impact sites by $15 \%$, from $490.40 \mathrm{~m}$ (95\% C.I.: \pm 107.43$)$ to $304.27 \mathrm{~m}$ (95\% C.I.: \pm 28.95$)$, but increased in the Control sites by almost $150 \%$, from 580.09 m (95\% C.I.: \pm 70.42$)$ to 845.19 m (95\% C.I.: \pm 72.87 ). Best model support for LMB was similar, though the most parsimonious model (Site + Time but no Site $\times$ Time interaction) was equally supported with the full BACI model (Pseudo- $\mathrm{R}^{2}=0.09$; Table 2). As with Bowfin, LMB distance from the canal decreased after alteration, though this pattern was also observed in the Control sites (Impact Before: 438.42 m, 95\% C.I.: \pm 149.56; Impact After: 350.76 m, 95\% C.I.: \pm 56.36; Control Before: 706.80 m, 95\% C.I.: \pm 81.66; Control After: 454.50 m, 95\% C.I.: $\pm 68.71)$.

Beyond the proximity of the physical model, abiotic variables affecting movement rates varied by species and habitat type, but were most often attributed to single environmental cues, particularly depth change variables (Table 3, Appendix 4 for all models of best fit). Movement rates across ecotones were best-explained by these single-predictor models. In contrast, movement rates within the marsh for both species were best explained by the average daily depth between the previous relocations of individuals (Table 3). However, $\triangle \mathrm{AIC}$ was never greater than 3.0 for either species across any ecotone compared to the null model and $\mathrm{R}^{2}$ values were never greater than 0.09 . 
Movement rates were greatest when moving across ecotones. Movement rates across ecotones (both directions) were $400 \%$ faster in Bowfin when moving into the marsh from the canal compared to within the marsh $(\mathrm{F}=3.40, \mathrm{df}=3,208, P<0.01)$ (Fig 2a, Appendix 5). For LMB, movement rates were $\sim 25 \%$ faster than movement within the $\operatorname{marsh}(\mathrm{F}=2.66, \mathrm{df}=3,223, P<0.05)($ Fig $2 \mathrm{~b}$, Appendix 5).

When including the entire study area (not limited to the physical model), factors influencing average distance from the canal were depth-based for both species, with both species being closest to the canal as marsh water depths are at their seasonal low-points (Fig. 3). For Bowfin, two models fit equally well: average daily depth over the preceding 30 days + average daily depth change over that same time, and average daily depth change over the preceding 30 days + average daily maximum temperature (Fig. 3a for distance from canal versus daily depth change, Table 4), both with moderate support (Pseudo- $\mathrm{R}^{2}=0.25$ ). For LMB, average daily depth over the preceding 30 days provided the best support (Fig. 3b distance from canal versus daily depth change, Table 4), though explanatory power was low (Pseudo- $\left.\mathrm{R}^{2}=0.04\right)$.

Probability of marsh occupancy by individual fishes increased as water depth increased (Figs. 4a, b). Bowfin displayed a higher willingness to move into the marsh when water levels were increasing (z value: 11.32 , residual df: $156, P<0.01$ ) than during similar water levels that were decreasing (z value: 4.82 , residual df: $156, P<0.01$ ). For example, when marsh water depth was $40 \mathrm{~cm}$, probability of marsh occupancy was $72 \%$ when marsh depth was increasing, but only $60 \%$ when decreasing. A similar pattern was seen with LMB, where there was a higher probability of marsh occupancy during periods 
of depth increase (z value: 5.35, residual df: 157, $P<0.01$ ) than during similar depths as depth decreased ( $\mathrm{z}$ value: 4.15 , residual df: $157, P<0.01$ ). There was a substantial difference in marsh occupancy during greatest marsh water depth, with $\sim 15 \%$ less probability of marsh occupancy at $60 \mathrm{~cm}$ depth when water levels are decreasing compared to increasing. Comparing interspecific probabilities in marsh occupancy, Bowfin were much more likely to occupy the marsh than were LMB during both rising and falling water levels. For example, during peak water depths during periods of increasing water levels, Bowfin exhibited a $95 \%$ probability of marsh occupancy, but probability of marsh occupancy was only $75 \%$ for LMB.

We found no difference in total fish, LMB, or sunfish CPUE in the No-Fill canal treatments versus Canal-Control sites (littoral zone only), so these sites were grouped together for CPUE analyses. A temporal autocorrelation correction factor failed to produce a better fitting model, and so were not included in analyses. The interactions of Site $\times$ Time $\times$ Water Depth or Site $\times$ Time failed to explain total large fish $($ Site $\times$ Time $\times$ Depth: $\mathrm{F}=0.07, \mathrm{df}=2,106, P=0.92), \mathrm{LMB}($ Site $\times$ Time $\times$ Depth: $\mathrm{F}=0.26, \mathrm{df}=2,106$, $P=0.76)$, or grouped sunfish $($ Site $\times$ Time $\times$ Depth: $\mathrm{F}=0.32, \mathrm{df}=2,106, P=0.72)$ CPUE. Though not statistically significant, there was a noticeable trend of higher of LMB in the fill treatments than the No-Fill treatment after hydroscape alteration. LMB CPUE increased by 2.2 times in the Complete-Fill treatment after hydroscape alteration, compared to a 1.85 times increase in the No-Fill treatment over the same time. Sunfish CPUE was highly variable, but the Complete-Fill treatment increased by almost 2.7 fishes per transect. In both FC and NC sites, total fish CPUE estimated from DIDSON data did not change between the interactions of Site $\times$ Time $\times$ Water Depth or Site $\times$ 
Time $($ Site $\times$ Time $\times$ Depth: FC: $\mathrm{F}=0.19, \mathrm{df}=1,76, P=0.66 ; \mathrm{NC}: \mathrm{F}=0.16, \mathrm{df}=1,69, P$ $=0.68$ ). Surveys using DIDSON corroborated the electroshocking data, with no effect of Site $\times$ Time $\times$ Depth (North-South surveys: $\mathrm{F}=1.56, \mathrm{df}=2,56, P=0.21$; East surveys: $\mathrm{F}$ $=0.86, \mathrm{df}=2,66, P=0.42)$ on fish density in the canal treatments. Comparing the openwater (North-South) and littoral (East) facing DIDSON data, recordings at the littoral zone yielded 2.5 times more fishes than recordings down the middle of the canal (Direction of recording: $\mathrm{F}=33.80, \mathrm{df}=1,135, P<0.05$ ).

Canal CPUE was up to five times greater than marsh CPUE (Figs. 5a \& b), with canal CPUE decreasing as marsh water depths increased (Canal Proximity $\times$ Time $\times$ Depth: $\mathrm{F}=4.03$, df $=2,178, P<0.05)$. Prior to hydroscape alteration, $\mathrm{CPUE}$ at the FC and NC sites increased as marsh depths increased (Canal Proximity $\times$ Depth: $F=5.21$, df $=2,80, P<0.05$; Fig. 5a). However, after alteration, CPUE at both sites decreased as marsh water depths increased. While CPUE did not change across water depths during this period (Canal Proximity $\times$ Depth: $\mathrm{F}=0.12, \mathrm{df}=2,98, P=0.88$ ), CPUE was still much higher in Canal sites (Fig. 5b). At the Control sites, only the interaction of Distance From Canal $\times$ Depth Change altered CPUE $(\mathrm{F}=6.12, \mathrm{df}=1,77, P<0.05)$, with Canal site CPUE approximately $30 \%$ higher than those in the NC sites and approximately three times higher than the FC sites during all water depths after alteration. After alteration, all sites experienced decreasing CPUE as water depths increased (Figs. 5c \& d).

Community composition of No-Fill canal transects in Impact versus Control sites revealed no differences with either Site $\times$ Time $\times$ Sampling Period $($ Pseudo-F $=1.41, \mathrm{df}=$ 
$3,80, P=0.15)$ or Site $\times$ Time (Pseudo-F $=1.26, \mathrm{df}=1,80, P=0.29$ ), so all No-Fill canal transects were grouped together for future analyses. Community composition analyses revealed no differences in composition between the interaction of any predictor variables including Site $\times$ Time at both the Canal (Pseudo-F $=0.90, \mathrm{df}=2,90, P=0.52)$ and $\mathrm{FC}$ sites (Pseudo-F $=0.51, \mathrm{df}=1,63, P=0.73)$. Community composition at $\mathrm{NC}$ sites changed with Site $\times$ Time $($ Pseudo-F $=2.15, \mathrm{df}=1,51, P=0.05)$, though pairwise comparisons revealed that these differences were driven by changes at the NC Control sites. An examination of communities across all site types reveal differences across Site $\times$ Time $\times$ Sampling Period (Pseudo-F $=1.41, \mathrm{df}=15,212, P=0.01$ ), where Canal sites differed from the FC and NC sites (Figs 6a \& b, Table 4).

Dispersion of communities (variance among samples within treatments) was generally the same across Impact and Control sites, with less dispersion in the Canal sites than in the $\mathrm{NC}$ and $\mathrm{FC}$ sites $(\mathrm{F}=13.48, \mathrm{df}=11,248, P<0.01)$ (Figs. $6 \mathrm{a} \& 6 \mathrm{~b})$. No differences in dispersion between the NC and FC sites were detected. SIMPER analyses revealed that a similar suite of species was responsible for community differences across the Canal versus FC and NC sites. For the NC sites, lower CPUE of LMB, Lake Chubsucker (Erimyzon sucetta), and Florida Gar were responsible for differences from Canal sites (Appendix 6). Higher CPUE of LMB, Lake Chubsucker, Bluegill, in Canal sites and higher CPUE of Warmouth in the FC sites drove community differences between FC and Canal sites. These results largely reflect what was seen at the Control sites. 


\section{Discussion}

Previous work in the Everglades has shown that hydroscape structure can be critical in shaping seasonal migration of fishes (Goss and Trexler 2014, Parkos and Trexler 2014, Hoch et al. 2015) and seasonal fluctuations in density (Ruetz et al. 2005, Trexler et al. 2005, Rehage and Trexler 2006). Hydroscape alterations in other freshwater systems have caused a range of responses in fishes, from very large (Stoffels et al. 2014, Hogg et al. 2015) to very small (Maloney et al. 2008). These are critical study topics, as dispersal among local habitat patches can facilitate regional persistence of a metacommunity (Mouquet and Loreau 2003) with fundamental significance for management and conservation strategies. Our manipulation of hydroscape structure in the DPM demonstrated how habitat connectivity and spatial arrangement can drive community structure in a wetland through changes in fish habitat use. As predators move around the landscape, their impacts on prey behavior and production have the potential to fundamentally alter ecosystem function (Schmitz 2010, Atwood et al. 2015, Hays et al. 2016).

Large-fish behavior, CPUE, and community composition were altered by modification of hydroscape structure, but varied by species and site. Bowfin movement was affected by hydroscape manipulation, but not movements of LMB. Species-specific effects on movement may explain the effects of hydoscape alteration we observed on fish local CPUE and community composition. Models that included the interaction of time (Before/After) and treatment (Control/Impact) were almost always better supported than those with just environmental cues. These results provide support that the physical model 
was influencing individual movement and possibly local large fish CPUE and community structure as a result. Contrary to our hypotheses, movement rates were over $50 \%$ slower in the experimental flow area as those in the control region for Bowfin. Bowfin and LMB responses were linked to several environmental cues, in support of our hypotheses. Increased CPUE was noted in the Complete-Fill and, to a lesser extent, the Partial-Fill canal treatments, though increases were not significantly different compared to before alteration. As seen in past work (Rehage and Trexler 2006), CPUE (and DIDSONestimated density) was highest at the vegetated margins of Canal sites compared to FC and NC sites. Filling the canal to half marsh-level or marsh level created vegetated areas like the canal margin and expanded the extent of habitat with high large-fish density (both from CPUE and DIDSON-estimated density). Increased densities of fishes observed from DIDSON recordings oriented towards the littoral edge of the canal compared to those directed into the open-water canal middle indicate that the littoral edge is preferred habitat for fishes. Differences in community composition were correlated with canal proximity, both before and after hydroscape alteration, and dependent on the stage of the hydrologic cycle. Lack of convergence in either density or community composition east and west of the canal failed to support our hypothesis of increased similarity after hydroscape alterations related to levee removal, possibly because not enough time passed for such fundamental changes.

Environmental cues can inform movement-based decisions in animals and affect behavior (Delgado et al. 2010). In our study, large fish behavior was correlated with changes in several cues, but was dependent on both context and species. Compared to LMB, Bowfin moved much further into the marsh and away from canals, were influenced 
by multiple environmental cues, and showed higher tolerance to decreasing water levels before moving back to the canal. These results are similar to those of another study, where movement patterns of LMB and Mayan Cichlids (Cichlasoma urophthalmus) were examined (Parkos and Trexler 2014). In that study, Mayan Cichlids were more apt to move into the marsh from the canal, and undertake larger movement rates in shallow marshes than were LMB. When marsh water-levels drop, prey fish reach high densities along the canal margins (Rehage and Trexler 2006; Chapter 2) and may also affect predator movement. We were unable to assess this effect in this study because the large areas covered by the tagged fish precluded estimation of prey density outside the immediate study area.

Despite drastic changes to the canal structure from the physical model, effects on large-fish CPUE in the Impact area were subtle. Contrary to our hypotheses, there was no convergence in large fish CPUE between NC and Canal sites. This was despite the Canal sites becoming more similar in depth to the NC sites, as well as colonization of vegetation in the Canal sites (personal observation). However, a general increase in sunfishes and LMB was observed in the canal-fill treatments after hydroscape alteration. These may be the results of increased spawning habitats, higher prey density, or increased cover from predators. Canal proximity did affect the large fish CPUE at the NC and FC sites. Prior to alteration, there was a positive relationship between CPUE and water depth change, but this pattern reversed after alteration, with decreasing CPUE as water depths increased. The canal fill reaches were tens of meters from the NC sites. The effects of major structural changes in other ecosystems, such as dam removal, have 
been documented to affect fish community composition and density in sites far from the actual changes (Hogg et al. 2015).

The role that flow regimes and "environmental flows" can have in structuring aquatic communities is of increasing interest (Olden and Naiman 2010, Poff and Zimmerman 2010, Jordan and Arrington 2014). Restoration of flow regimes involve not only reintroduction of flow that should mimic natural patterns, but also reconnection of hydrological habitats and restoration of environmental cues that may inform an animal when the optimal time for dispersal approaches. Results from dam removal studies vary considerably, even within the same study and stretch of river (Catalano et al. 2007), but highlight the importance of aquatic habitat connectivity. Previous studies of levee removal impacts on the surrounding landscape are limited and are primarily focused on river floodplains (Bayley 1991, Gergel et al. 2002). By expanding research to seasonal marshes, particularly those with a restored flow regime, a broader view of the biological effects of dynamic hydroscapes can be taken.

Our results reveal the role that hydroscape alteration can have on behavior, CPUE, and community structure of large fishes in a dynamic wetland. The experimental approach used provided a powerful method to examine the role that the filling of canals and degradation of levees can have on aquatic animals and, ultimately, ecosystem function. Continued monitoring of the study areas is important as the canal fill treatments and degraded section of levee continue to consolidate sediment and vegetation continues to recolonize the area. There is evidence that large fishes are moving across the degraded section of levee in increasing numbers as we move further away from the 
initial degradation. In 2013-2014, three fishes (two LMB and one Bowfin) crossed from the study area into the hydrologic unit east of the study area (Figure 1C). In 2014-2015, this number increased to two Bowfin and three LMB. In the most recent tracking season, six fishes have crossed the degraded levee, including several Florida Gar implanted with transmitters in October, 2015 (Trexler, unpublished data). Movement patterns of individuals have direct impacts on local abundance and community structure, highlighting the importance of tracking these inter-compartment dispersal events. We have demonstrated that relatively minor changes in hydroscape structure, such as increases in marsh water depth or filling canal sections, can alter fish behavior, creating changes to the aquatic community that extend beyond the immediate area of impact. Large-scale field studies such as reported here can be used to answer fundamental questions in fisheries ecology and guide successful management efforts.

\section{Acknowledgements}

We wish to think the hardworking technicians, graduate students, and post-docs of the Trexler lab for their assistance with this project. J Parkos III taught MB how to conduct fish surgery and J Dummitt spent countless hours assisting with fish surgeries. Funding for this project came from the Cristina Menendez Fellowship (MRB) and Cooperative Agreement W32CS501185613 between FIU and the US Geological Survey. Collections were made under Florida state permit S-11-04. This material was developed in collaboration with the Florida Coastal Everglades Long-Term Ecological Research program under National Science Foundation Grant No. DEB-1237517.All animals were 
handled according to Institutional Animal Care and Use Committee protocols 13-044-

CR02 and 13-041-CR02. This is publication xxx from the Southeast Environmental

Center (SERC) at FIU.

Citations

Agostinho, A.A., and M. Zalewski. 1995. The dependence of fish community structure and dynamics on floodplain and riparian ecotone zone in Parana River, Brazil.

Pages 141-148 in The Importance of Aquatic-Terrestrial Ecotones for Freshwater Fish. Springer Netherlands, Dordrecht.

Anderson, D.R. 2008. Model Based Inference in the Life Sciences. A Primer on Evidence. Springer, New York City, New York.

Arnold, J.B. 2015. ggthemes: Extra themes, scales and geoms for 'ggplot2', R package version 2.2.1, http://CRAN.R-project.org/package=ggthemes.

Atwood, T. B., R. M. Connolly, E. G. Ritchie, C. E. Lovelock, M. R. Heithaus, G. C. Hays, J. W. Fourqurean, and P. I. Macreadie. 2015. Predators help protect carbon stocks in blue carbon ecosystems. Nature Climate Change 12:1038-1045.

Bayley, P.B. 1991. The flood pulse advantage and the restoration of river-floodplain systems. River Res Appl 6:75-86.

Berger, J. 2004. The last mile: how to sustain long-distance migration in mammals. Conserv Biol 18:320-331.

Boswell, K.M., M.P. Wilson, and J.H. Cowan. 2008. A semiautomated approach to estimating fish size, density, and behavior from dual-frequency identification sonar (DIDSON) data. N Am J Fish Manage 28:799-807.

Both, C., S. Bouwhuis, C.M. Lessells, and M.E. Visser. 2006. Climate change and population declines in a long-distance migratory bird. Nature 441:81-83.

Boucek, R.E., and J.S. Rehage. 2015. A tale of two fishes: using recreational angler records to examine the link between fish catches and floodplain connections in a subtropical coastal river. Estuaries Coasts 38:124-135. 
Burnham, K.P., and D.R. Anderson. 2002. Model Selection and Multimodel Inference: A Practical Information-Theoretic Approach. Springer-Verlag New York, New York City.

Burwen, D., S. Fleischman, and J. Miller. 2010. Accuracy and precision of salmon length estimates taken from DIDSON sonar images. T Am Fish Soc 139:1306-1314.

Bush, M.B., and J.C. Trexler. In review. Experimental test of effect of hydroscape structure on wetland fish behavior, population, and community structure.

Calenge, C. 2006. The package adehabitat for the R software: a tool for the analysis of space and habitat use by animals. Ecol Model 197: 516-519.

Catalano, M.J., M.A. Bozek, and T.D. Pellett. 2007. Effects of dam removal on fish assemblage structure and spatial distributions in the Baraboo River, Wisconsin. $\mathrm{N}$ Am J Fish Manage 27:519-530.

Chick, J.H., S. Coyne, and J.C. Trexler. 1999. Effectiveness of airboat electroshocking for sampling fishes in shallow, vegetated habitats. N Am J Fish Manage 19:957967.

Chick, J.H., C.R. Ruetz III, and J.C. Trexler. 2004. Spatial scale and density patterns of large fish communities in freshwater marshes of the Florida Everglades. Wetlands 24:652-664.

Clarke, K.R., and R.M. Warwick. 2001. Change in marine communities: an approach to statistical analysis and interpretation. $2^{\text {nd }}$ ed. Primer-E Ltd. Plymouth, UK.

Cooper, A.R., D.M. Infante, K.E. Wehrly, L. Wang, and T.O. Brenden. 2016. Identifying indicators and quantifying large-scale effects of dams on fishes. Ecol Indic 61:646-657.

Dean, W.R.J., P. Barnard, M.D. Anderson. 2009. When to stay, when to go: trade-offs for southern African arid-zone birds in times of drought. S Afr J Sci 105:24-28.

Decomp Physical Model Science Team (DPMST). 2010. The Decomp Physical Model Science Plan. Located in Documentum at: Cabinets/Project Teams/Decomp/Decomp Physical Model (DPM)/Environmental Assessment/Final - Dec 2009/Print/Science Plan

Delgado, M..D.M., Penteriani, V., Revilla, E., and Nams, V.O. 2010. The effect of phenotypic traits and external cues on natal dispersal movements. J Anim Ecol 79:620-632. 
Downes, B. J., L. A. Barmuta, P. G. Fairweather, D. P. Faith, M. J. Keough, P. S. Lake, B. D. Mapstone, and G. P. Quinn. 2002. Monitoring Ecological Impacts. Concepts and Practice in Flowing Waters. Cambridge University Press. Cambridge, UK.

Fox, J., and S. Weisberg. 2011. An $\{\mathrm{R}\}$ Companion to Applied Regression. $2^{\text {nd }}$ Ed. SAGE Publications, Thousand Oaks, California.

Gergel, S.E., M.D. Dixon, and M.G. Turner. 2002. Consequences of human-altered floods: levees, floods, and floodplain forests along the Wisconsin River. Ecol Appl 12:1755-1770.

Gunderson, L. H., and W. F. Loftus. 1993. The Everglades. Pages 199-255 in W.H. Martin, S.G. Boyce, and A.C. Echternacht, editors. Biodiversity of the Southeastern United States. John Wiley \& Sons, New York City, New York.

Hargrove, W. W., and J. Pickering. 1992. Pseudoreplication: a sinequa-non for regional ecology. Landscape Ecology 6:251-258.

Hays, G. C., et al. 2016. Key questions in marine megafauna movement ecology. Trends Ecology Evolution 31:463-475.

Hijuelos, A. C. 2012. Spatial and temporal patterns in the distribution, behavior, and activity of fishes in canals of the Everglades. Master of Science Thesis, Florida International University.

Ho DT, Engel VC, Variano EA, Schmieder PJ, and Condon ME (2009) Tracer studies of sheet flow in the Florida Everglades. Geophy. Res. Lett. 36, L09401, doi:10.1029/2009GL037355

Hoch, J.M., E.R. Sokol, A.D. Parker, and J.C. Trexler. 2015. Migration strategies vary in space, time, and among species in the small-fish metacommunity of the Everglades. Copeia 2015:157-169.

Hogg, R.S., S.M. Coghlan Jr., J. Zydlewski, and C. Gardner. 2015. Fish community response to a small-stream dam removal in a Maine coastal river tributary. T Am Fish Soc 144:467-479.

Hohausova, E., R.J. Lavoy, and M.S. Allen. 2010. Fish dispersal in a seasonal wetland: influence of anthropogenic structures. Mar Freshwater Res 61:682-694.

Jenerette, G. D. and W. Shen. 2012. Experimental landscape ecology. Landscape Ecology 27:1237-1248. 
Jones, M.J., and I.G. Stuart. 2009. Lateral movement of Common Carp (Cyprinus carpio L.) in a large lowland river and floodplain. Ecol Freshw Fish 18:72-82.

Jordan, F., and D.A. Arrington. 2014. Piscivore responses to enhancement of the channelized Kissimmee River, Florida, U.S.A. Rest Ecol 22:418-425.

Jost, L., A. Chao, and R.L. Chazdon. 2011. Compositional similarity and B(beta) diversity. Pages 66-84 in A.E. Magurran and B.J. McGill, editors. Biological Diversity. Oxford University Press, Oxford, UK.

Light, S.S., and J.W. Dineen. 1994. Water control in the Everglades: A historical perspective. Pages 47-84 in M. Davis and J.C. Ogden, editors. Everglades: The Ecosystem and Its Restoration. St. Lucie Press, Boca Raton, Florida.

Loftus, W.F. 2000. Accumulation and fate of mercury in an Everglades aquatic food web. Doctoral Dissertation, Florida International University, Miami, Florida.

Loftus, W. F. and J.A. Kushlan. 1987. Freshwater fishes of southern Florida. Bull FL State Museum, Biological Sciences 31: 147-344.

Loubens, G., and P. Jacques. 1997. Biologie de Colossoma macropomum (Teleostei: Serrasalmidae) dans le basin Mamore (Amazon bolivienne). Ich Exp Freshw 8:122.

Liu, Z., J.C. Volin, V.D. Owen, L.G. Pearlstine, J.R. Allen, F.J. Mazzotti, and A.L. Higer. 2009. Validation and ecosystem applications of the EDEN water-surface model for the Florida Everglades. Ecohydrology 2:182-194.

Magoulick, D.D., and R.M. Kobza. 2003. The role of refugia for fishes during drought: a review and synthesis. Freshw Biol 48:1186-1198.

McVoy, C.W., W. Parksaid, J. Obeysekera, J. Vanarman, T.W. Dreschel. 2011. Landscapes and Hydrology of the Predrainage Everglades. University Press of Florida, Gainesville, Florida.

Mouquet, N., and M. Loreau. 2003. Community patterns in source-sink metacommunities. Am Nat 162:544-557.

Nabe-Nielsen, J., R. M. Sibly, M. C. Forchhammer, V. E. Forbes, and C. J. Topping. 2010. The effects of landscape modifications on the long-term persistence of animal populations. PLoS One. doi:10.1371/journal.pone.0008932

Olden, J.D., and R.J. Naiman. Incorporating thermal regimes into environmental flow assessments: modifying dam operations to restore freshwater ecosystem integrity. Freshw Biol 55:86-107. 
Parkos, J.J. III, C.R. Ruetz III, and J.C. Trexler. 2011. Disturbance regime and limits on benefits of refuge use for fishes in a fluctuating hydroscape. Oikos 120:15191530 .

Parkos, J.J. III, and J.C. Trexler. 2014. Origins and functional connectivity in a humanmodified wetland landscape. Can J Fish Aquat Sci 71:1418-1429.

Parkos, J.J. III, L.F. Wolski, W.F. Loftus, and J.C. Trexler. 2015. Dynamic movement patterns of Florida Gar within a fluctuating hydroscape. Copeia 103:132-140.

Peterson, S.B., J.M. Teal, W.J. Mitsch, Editors. 2005. Delaware Bay salt marsh restoration. Special issue of Ecol Eng 25:199-314.

Pinheiro, J., D. Bates, S. DebRoy, and D. Sarkar. 2015. nlme: Linear and Nonlinear Mixed Effects Models, R package version 3.1-127, http://CRAN.Rproject.org/package=nlme.

Poff, N.L., J.D. Allan, M.B. Bain, J.R. Karr, K.L. Prestegaard, B.D. Richter, R.E. Sparks, J.C. Stromberg. 1997. The natural flow regime. BioScience 47:769-784.

Poff, N.L., and J.K.H. Zimmerman. 2010. Ecological responses to altered flow regimes: a literature review to inform the science and management of environmental flows. Freshw Biol 55:194-205.

R Core Team. 2015. R: A Language and Environment for Statistical Computing, https://www.R-project.org/.

Schmitz, O. J. 2010. Resolving Ecosystem Complexity. Princeton University Press, Princeton, NJ.

Sklar, F.H., M.J. Chimney, S. Newman, P. McCormick, D. Gawlik, S.L. Miao, C. McVoy, W. Said, J. Newman, C. Coronado, G. Crozier, M. Korvela, and K. Rutchey. 2005. The ecological-societal underpinnings of Everglades restoration. Front Ecol Environ 3:161-169.

Stefansson, S.O., B.T. Bjornsson, S.D. McCormick. 2008. Smoltification. Pages 639-681 in R.N. Finn and B.K. Kapoor. Fish Larval Physiology. CRC Press, Enfield, New Hampshire.

Stoffels, R. J., K. R. Clarke, and D. S. Linklater. 2015. Temporal dynamics of a local fish community are strongly affected by immigration from the surrounding metacommunity. Ecology and Evolution 5:200-212. 
Stoffels, R. J., K. R. Clarke, R. A. Rehwinkel, and B. J. McCarthy. 2014. Response of a floodplain fish community to river-floodplain connectivity: natural versus managed reconnection. Canadian Journal of Fisheries and Aquatic Science 71:236-245.

Telis, P.A. 2006. The Everglades Depth Estimation Network (EDEN) for support of ecological and biological assessments. U.S. Geological Survey Fact Sheet 20063087.

Tiffan, K.F., D.W. Rondorf, and J.J. Skalicky. 2004. Imaging fall Chinook Salmon redds in the Columbia River with a dual-frequency sonar. N Am J Fish Manage 24:1421-1426.

Trexler, J.C., W.F. Loftus, C.F. Jordan, J. Chick, K.L. Kandl, T.C. Ruetz, and O.L. Bass. 2002. Ecological scale and its implications for freshwater fishes in the Florida Everglades. Pages 153-181 in J.W. Porter and K.G. Porter, editors. The Everglades, Florida Bay, and Coral Reefs of the Florida Keys: An Ecosystem Sourcebook. CRC, Boca Raton, Florida.

Trexler, J.C., W.F. Loftus, and S. Perry. 2005. Disturbance frequency and community structure in a twenty-five year intervention study. Oecologia 145:140-152.

USACE and SFWMD. 1999. Central and Southern Florida Comprehensive Review Study final Integrated Feasibility Report and Programmatic Implementation Statement. http://141.232.10.32/pub/restudy_eis.aspx.

Winemiller, K.O., and D.B. Jepsen. 1998. Effects of seasonality and fish movement on tropical river food webs. J Fish Biol 53 (Suppl. A): 267-296.

Winter, J.D. 1983. Underwater biotelemtry. Pages 371-395 in L.A. Nielsen and J.D. Johnsen, editors. Fisheries Techniques. American Fisheries Society. Bethesda, Maryland.

Wood, C.R., J.W. Chapman, D.R. Reynolds, J.F. Barlow, A.D. Smith, and I.P. Woiwod. 2006. The influence of the atmospheric boundary layer on nocturnal layers of noctuids and other moths migrating over southern Britain. Int J Biometeorol 50:193-204. 


\section{Tables}

Table 1 - Abiotic and biotic conditions of our study area. Periphyton volume, emergent plant stem density, and fish density were estimated by use of a 1- $\mathrm{m}^{2}$ throw trap (Bush and Trexler in review). Fish density includes all species captured in the throw trap, which are generally less than 5-cm standard length and are indicative of prey density for LMB and Bowfish at these sites. Error is 1 standard deviation. These metrics were not taken for sites within the L-67C canal.

\begin{tabular}{|c|c|c|c|c|c|}
\hline SITE & ALTERATION & DEPTH (cm) & $\begin{array}{c}\text { PERIPHYTON } \\
\left(\mathrm{mL} \mathrm{m}^{-2}\right)\end{array}$ & 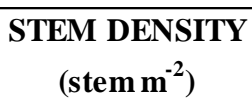 & $\begin{array}{l}\text { FISH DENSITY } \\
\text { (ind } \mathbf{~}^{-2} \text { ) }\end{array}$ \\
\hline \multirow{2}{*}{ FC } & Pre & $53.2 \pm 12.6$ & $3314.0 \pm 2285.2$ & $185.5 \pm 112.9$ & $8.4 \pm 5.5$ \\
\hline & Post & $61.8 \pm 8.4$ & $3251.1 \pm 1906.2$ & $491.8 \pm 314.6$ & $19.8 \pm 9.9$ \\
\hline \multirow{2}{*}{ FC Control } & Pre & $46.4 \pm 11.2$ & $4032.6 \pm 3105.17$ & $340.8 \pm 354.6$ & $12.0 \pm 4.3$ \\
\hline & Post & $57.2 \pm 9.7$ & $5170.3 \pm 1638.6$ & $460.4 \pm 721.8$ & $14.2 \pm 6.7$ \\
\hline \multirow{2}{*}{$\mathrm{NC}$} & Pre & $40.9 \pm 11.8$ & $773.9 \pm 780.0$ & $563.6 \pm 1176.0$ & $14.6 \pm 10.7$ \\
\hline & Post & $51.2 \pm 10.6$ & $1631.7 \pm 1276.23$ & $739.4 \pm 1459.2$ & $47.1 \pm 25.7$ \\
\hline \multirow{2}{*}{ NC Control } & Pre & $45.1 \pm 9.8$ & $1242.2 \pm 1744.6$ & $437.7 \pm 759.7$ & $20.9 \pm 13.6$ \\
\hline & Post & $55.0 \pm 9.8$ & $2021.6 \pm 982.1$ & $514.8 \pm 492.9$ & $28.3 \pm 10.9$ \\
\hline
\end{tabular}


Table 2 - BACI distance from canal models. Only the most parsimonious models of best fit $(\Delta \mathrm{AIC}<2.0$ from the lowest scoring model) are shown, along with the null model.

\begin{tabular}{|c|c|c|c|c|c|}
\hline $\begin{array}{l}\text { Fish and Distance From } \\
\text { Canal }\end{array}$ & Model & AIC & $\triangle \mathrm{AIC}$ & $\omega_{\mathrm{i}}$ & Pseudo - $\mathbf{R}^{2}$ \\
\hline \multirow[t]{2}{*}{ Bowfin Distance From Canal } & $\begin{array}{l}\text { Before/After + Contro//Impact + Before/After*Contro//Impact + Average Daily Depth } \\
\text { Over Preceding } 30 \text { Days + Average Daily Depth Change Over Preceding } 30 \text { Days + } \\
\text { Average Daily Photoperiod Over Preceding } 30 \text { Days + Average Daily Maximum } \\
\text { Temperature Over Preceding } 30 \text { Days }\end{array}$ & 1402.40 & 0.00 & 0.99 & 0.25 \\
\hline & Null Model & 1462.50 & 56.43 & $<0.001$ & - \\
\hline \multirow{3}{*}{ LMB Distance From Canal } & $\begin{array}{l}\text { Before/After }+ \text { Control/Impact }+ \text { Average Daily Depth Over Preceding } 30 \text { Days }+ \text { Average } \\
\text { Daily Depth Change Over Preceding } 30 \text { Days + Average Daily Photoperiod Over } \\
\text { Preceding } 30 \text { Days + Average Daily Maximum Temperature Over Preceding } 30 \text { Days }\end{array}$ & 1403.10 & 0.00 & 0.61 & 0.10 \\
\hline & $\begin{array}{l}\text { Before/After + Control/Impact + Before/After*Contro//Impact + Average Daily Depth } \\
\text { Over Preceding } 30 \text { Days + Average Daily Depth Change Over Preceding } 30 \text { Days + } \\
\text { Average Daily Photoperiod Over Preceding } 30 \text { Days + Average Daily Maximum } \\
\text { Temperature Over Preceding } 30 \text { Days }\end{array}$ & 1405.10 & 1.97 & 0.22 & 0.10 \\
\hline & Null Model & 1414.77 & 11.01 & 0.00 & - \\
\hline
\end{tabular}


Table 3 - Step length models for the all locations including fish moving outside the BACI area. Only the most parsimonious models of best fit $(\triangle \mathrm{AIC}<2.0$ from the lowest scoring model) are shown, along with the null model.

\begin{tabular}{|c|c|c|c|c|c|}
\hline Step Length & Model & AIC & $\Delta \mathrm{AIC}$ & $\omega_{\mathrm{i}}$ & $\mathbf{R}^{2}$ \\
\hline \multirow{2}{*}{ Bowfin Within Marsh } & Average Daily Depth Between Previous Relocation & 3165.90 & 0.00 & 0.25 & 0.06 \\
\hline & Null Model & 3225.60 & 59.71 & $<0.001$ & - \\
\hline \multirow{2}{*}{ Bowfin Into Marsh } & Average Daily Depth Over Preceding 30 Days & 293.50 & 0.22 & 0.14 & 0.04 \\
\hline & Null Model & 296.14 & 2.86 & 0.03 & - \\
\hline \multirow[t]{2}{*}{ Bowfin Within Canal } & $\begin{array}{l}\text { Average Daily Depth Over Preceding } 30 \text { Days + Average Daily Depth Change Over } \\
\text { Preceding } 30 \text { Days + Average Daily Photoperiod Over Preceding } 30 \text { Days }\end{array}$ & 1407.40 & 0.00 & 0.54 & 0.09 \\
\hline & Null Model & 1439.30 & 31.93 & $<0.001$ & - \\
\hline \multirow{3}{*}{ Bowfin Into Canal } & Average Daily Depth Change Over Preceding 30 Days & 309.77 & 0.71 & 0.08 & 0.03 \\
\hline & Average Daily Maximum Temperature Over Preceding 30 Days & 310.46 & 1.40 & 0.06 & 0.02 \\
\hline & Null Model & 311.21 & 2.15 & 0.04 & - \\
\hline \multirow{2}{*}{ LMB Within Marsh } & Average Daily Depth Between Previous Relocation & 2424.40 & 1.15 & 0.12 & 0.03 \\
\hline & Null Model & 2450.10 & 26.83 & $<0.001$ & - \\
\hline \multirow{2}{*}{ LMB Into Marsh } & Average Daily Photoperiod Between Previous relocation & 377.34 & 0.89 & 0.09 & 0.02 \\
\hline & Null Model & 378.77 & 2.32 & 0.05 & \\
\hline \multirow[t]{2}{*}{ LMB Within Canal } & $\begin{array}{l}\text { Average Daily Depth Over Preceding } 30 \text { Days + Average Daily Depth Change Over } \\
\text { Preceding } 30 \text { Days + Average Daily Maximum Temperature Over Preceding } 30 \text { Days + } \\
\text { Average Daily Photoperiod Over Preceding } 30 \text { Days }\end{array}$ & 2606.00 & 0.00 & 0.76 & 0.02 \\
\hline & Null Model & 2618.40 & 12.33 & $<0.01$ & \\
\hline \multirow{6}{*}{ LMB Into Canal } & Average Daily Photoperiod Between Previous relocation & 338.69 & 0.00 & 0.08 & 0.03 \\
\hline & Average Daily Maximum Temperature Between Previous relocation & 338.73 & 0.03 & 0.08 & 0.05 \\
\hline & Average Daily Photoperiod Over Preceding 30 Days & 338.91 & 0.22 & 0.07 & 0.05 \\
\hline & Average Daily Depth Change Between Previous Relocation & 339.35 & 0.65 & 0.06 & 0.02 \\
\hline & Average Daily Depth Change Over Preceding 30 Days & 339.78 & 1.08 & 0.05 & 0.02 \\
\hline & Null Model & 340.77 & 2.07 & 0.03 & - \\
\hline
\end{tabular}


Table 4 - Distance-from-Canal models. Only the most parsimonious models of best fit $(\triangle \mathrm{AIC}<2.0$ from the lowest scoring model) are shown, along with the null model.

\begin{tabular}{|c|c|c|c|c|c|}
\hline Distance from Canal & Model & AIC & $\Delta \mathrm{AIC}$ & $\omega_{\mathrm{i}}$ & Pseudo - $\mathbf{R}^{2}$ \\
\hline \multirow{4}{*}{ Bowfin Distance From Canal } & $\begin{array}{l}\text { Average Daily Depth Over Preceding } 30 \text { days + Average Daily Depth Change Over } \\
\text { Preceding } 30 \text { Days }\end{array}$ & 896.70 & 0.00 & 0.47 & 0.25 \\
\hline & $\begin{array}{l}\text { Average Daily Depth Change Over Preceding } 30 \text { Days +Average Daily Maximum } \\
\text { Temperature Over Preceding } 30 \text { Days }\end{array}$ & 898.23 & 1.52 & 0.22 & 0.25 \\
\hline & $\begin{array}{l}\text { Average Daily Depth Over Preceding } 30 \text { days + Average Daily Depth Change Over } \\
\text { Preceding } 30 \text { Days + Average Daily Photoperiod Over Preceding } 30 \text { Days }\end{array}$ & 898.34 & 1.64 & 0.21 & 0.25 \\
\hline & Null Model & 938.51 & 41.81 & $<0.001$ & - \\
\hline \multirow{2}{*}{ LMB Distance From Canal } & Average Daily Depth Over Preceding 30 Days & 925.28 & 0.00 & 0.29 & 0.04 \\
\hline & Null Model & 930.30 & 5.02 & 0.02 & - \\
\hline
\end{tabular}


Table 5 - PERMANOVA analyses from Time $\times$ Site $\times$ Hydroperiod. Number of permutations $=9999$.

\begin{tabular}{lccc}
\hline Main Test & Pseudo-F & df & $P$ \\
\hline DepthChange $\times$ Time $\times$ Site & 1.41 & 15,212 & 0.01 \\
Time $\times$ Site & 1.87 & 5,212 & $<0.01$ \\
DepthChange $\times$ Site & 1.51 & 15,212 & $<0.01$ \\
DepthChange $\times$ Time & 2.40 & 3,212 & $<0.01$ \\
\hline Pairwise Tests & & & \\
\hline Wet Sampling Period & t-statistic & df & $P$ \\
Before Alteration & 2.03 & 12 & $<0.01$ \\
Canal Sites vs FC Sites & 2.24 & 12 & $<0.01$ \\
Canal Sites vs NC Sites & 0.99 & 6 & 0.37 \\
FC Sites vs NC Sites & 0.63 & 4 & 0.72 \\
Canal Control Sites vs FC Control Sites & 1.27 & 5 & 0.16 \\
Canal Control Sites vs NC Control Sites & 1.02 & 3 & 0.49 \\
FC Control Sites vs NC Control Sites & & & \\
\hline After Alteration & 2.81 & 13 & $<0.01$ \\
\hline Canal Sites vs FC Sites & 1.36 & 12 & 0.13 \\
Canal Sites vs NC Sites & 1.55 & 7 & 0.09 \\
FC Sites vs NC Sites & 1.02 & 6 & 0.39 \\
Canal Control Sites vs FC Control Sites & 1.09 & 4 & 0.40 \\
Canal Control Sites vs NC Control Sites & 0.49 & 4 & 1.00 \\
FC Control Sites vs NC Control Sites & & & \\
\hline
\end{tabular}

\section{Transition Sampling Period}

Before Alteration

\begin{tabular}{llll}
\hline Canal Sites vs FC Sites & 1.15 & 6 & 0.31 \\
Canal Sites vs NC Sites & 0.81 & 4 & 0.64 \\
FC Sites vs NC Sites & 0.65 & 4 & 0.74 \\
Canal Control Sites vs FC Control Sites & 0.93 & 6 & 0.57 \\
Canal Control Sites vs NC Control Sites & 0.33 & 4 & 1.00 \\
FC Control Sites vs NC Control Sites & 1.07 & 4 & 0.46 \\
\hline After Alteration & & & \\
\hline Canal Sites vs FC Sites & 2.11 & 13 & $<0.01$ \\
Canal Sites vs NC Sites & 1.23 & 12 & 0.15 \\
FC Sites vs NC Sites & 0.57 & 7 & 0.87 \\
Canal Control Sites vs FC Control Sites & 1.56 & 6 & 0.08 \\
Canal Control Sites vs NC Control Sites & 1.82 & 6 & 0.02 \\
FC Control Sites vs NC Control Sites & 0.97 & 6 & 0.42 \\
\hline
\end{tabular}


Table 5 continued

\begin{tabular}{lccc}
\hline Early Dry Sampling Period & & & \\
Before Alteration & & & \\
\hline Canal Sites vs FC Sites & 2.31 & 11 & $<0.01$ \\
Canal Sites vs NC Sites & 2.00 & 11 & $<0.01$ \\
FC Sites vs NC Sites & 0.30 & 8 & 0.92 \\
Canal Control Sites vs FC Control Sites & 3.43 & 2 & 0.33 \\
Canal Control Sites vs NC Control Sites & 2.64 & 1 & 0.33 \\
FC Control Sites vs NC Control Sites & 4.38 & 1 & 0.33 \\
\hline After Alteration & & & \\
\hline Canal Sites vs FC Sites & 1.89 & 21 & 0.01 \\
Canal Sites vs NC Sites & 2.24 & 20 & $<0.01$ \\
FC Sites vs NC Sites & 0.92 & 15 & 0.54 \\
Canal Control Sites vs FC Control Sites & 1.78 & 10 & 0.02 \\
Canal Control Sites vs NC Control Sites & 2.73 & 10 & $<0.01$ \\
FC Control Sites vs NC Control Sites & 0.72 & 10 & 0.77 \\
\hline
\end{tabular}

Late Dry Sampling Period

Before Alteration

\begin{tabular}{lccc}
\hline Canal Sites vs FC Sites & 2.23 & 11 & $<0.01$ \\
Canal Sites vs NC Sites & 2.35 & 10 & 0.01 \\
FC Sites vs NC Sites & 1.38 & 3 & 0.30 \\
Canal Control Sites vs FC Control Sites & 1.19 & 2 & 0.33 \\
Canal Control Sites vs NC Control Sites & 1.90 & 1 & 0.33 \\
FC Control Sites vs NC Control Sites & 0.74 & 1 & 1.00 \\
\hline After Alteration & & & \\
\hline Canal Sites vs FC Sites & 2.06 & 20 & $<0.01$ \\
Canal Sites vs NC Sites & 2.47 & 19 & $<0.01$ \\
FC Sites vs NC Sites & 0.82 & 15 & 0.60 \\
Canal Control Sites vs FC Control Sites & 1.80 & 10 & $<0.01$ \\
Canal Control Sites vs NC Control Sites & 1.56 & 10 & 0.11 \\
FC Control Sites vs NC Control Sites & 1.27 & 10 & 0.18 \\
\hline
\end{tabular}




\section{Figure Captions}

Figure 1 - Map of Study Area. A. Regional location of the study in southern Florida, USA. B. The primary study area bounded by levees L67 A and C, the location of added water inflow (arrow) and the control and impact study areas (star). Polygons with diagonal lines are terrestrial tree islands. C. The primary experimental area with marsh and canal sampling sites. Sawgrass ridges are represented by dark gray. Open water sloughs are light gray.

Figures 2 - Bowfin (a) and LMB (b) step lengths (daily distance moved in meters) within and across marsh and canal habitats. Error bars represent $95 \%$ confidence intervals. Data are back-transformed from $\ln (\mathrm{x}+1)$.

Figures 3 - Bowfin (a) and LMB (b) average distance from the canal. Error bars represent $95 \%$ confidence intervals. Solid background line is the average marsh water depth. Data were not back-transformed because the model of best fit for Bowfin was Average Daily Depth + Average Daily Depth Change.

Figure 4 - Bowfin (a) and LMB (b) predicted occupancy of the marsh. The solid line is when marsh water depth is increasing. The dotted line is when marsh water depth is decreasing. The shaded area around the lines represent $95 \%$ confidence intervals. 
Figures 5 - CPUE of total large fishes across all three site types with the Impact area before hydroscape alteration (a) and after hydroscape alteration (b), and in the Control areas before hydroscape alteration (c) and after hydroscape alteration (d). Solid lines represent Canal sites, dotted lines represent NC sites, and dot-dash lines represent FC sites. Shaded areas represent $95 \%$ confidence intervals. Data are back-transformed from $\ln (\mathrm{x}+1)($ graphs a and $\mathrm{b})$ and $\operatorname{sqrt}(\mathrm{x}+1)($ graphs $\mathrm{c}$ and $\mathrm{d})$.

Figures 6 - nMDS of community position and dispersion for Canal, NC, and FC sites for Impact (A) and Control (B) sites. nMDS was generated for all sites but graphically divided between Impact and Control for clarity. Dark shapes represent Before alteration and light gray shapes represent After alteration. Solid lines represent Canal or Canal Control. Long-dashed lines represent NC or NC Control. Dotted lines represent FC or FC Control. Stress $=0.21$. 
Figures

Figure 1

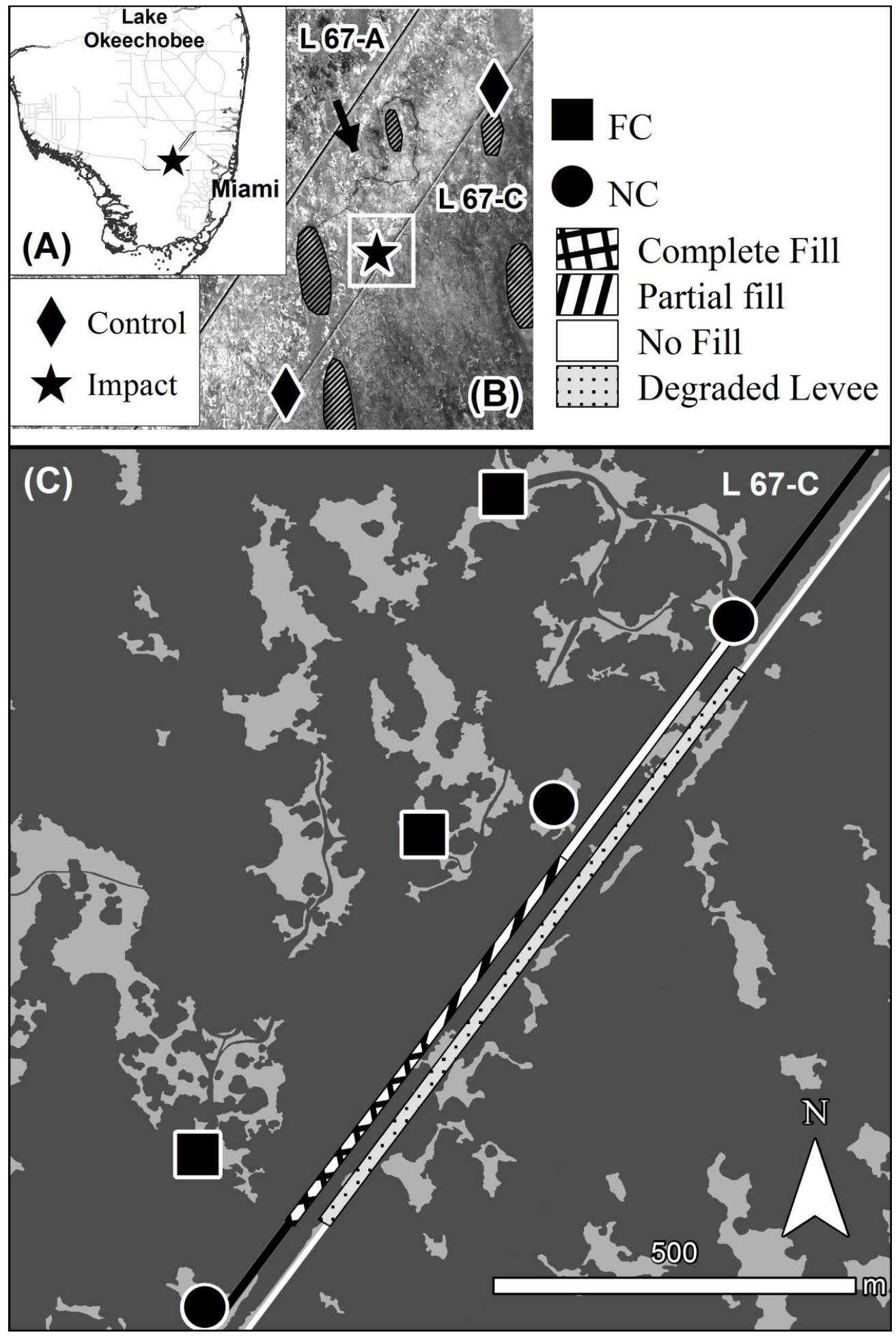


Figure 2

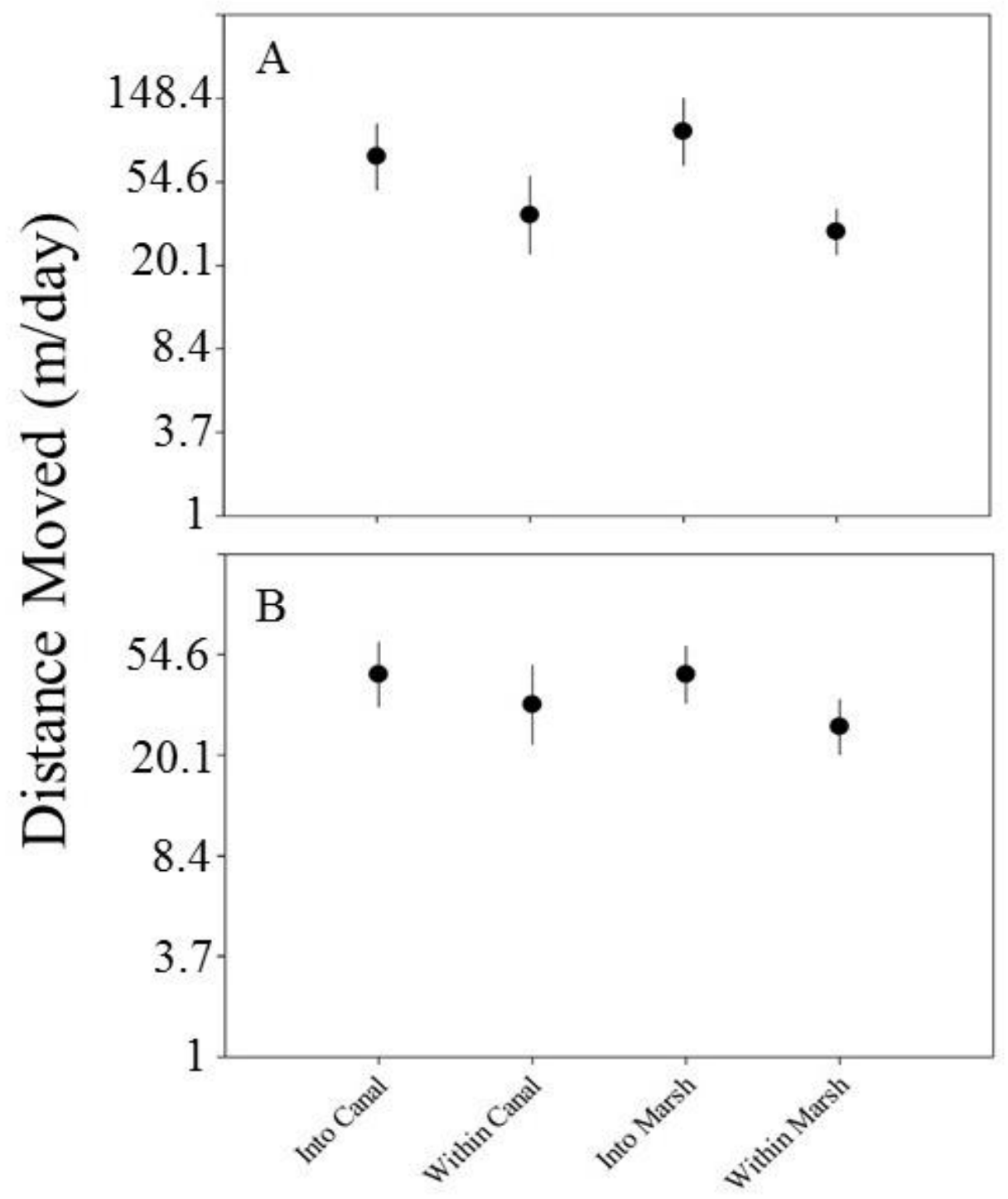


Figure 3
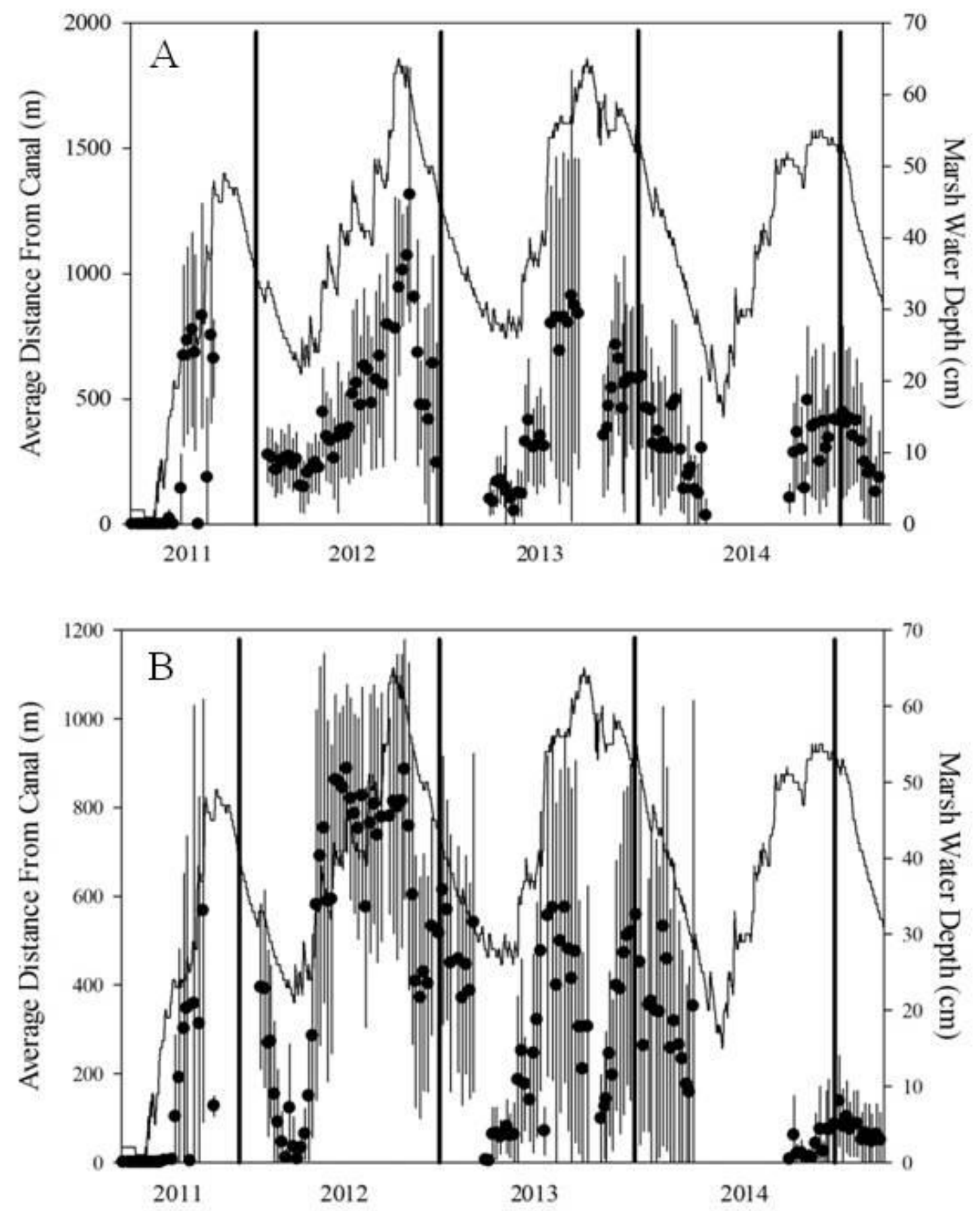
Figure 4

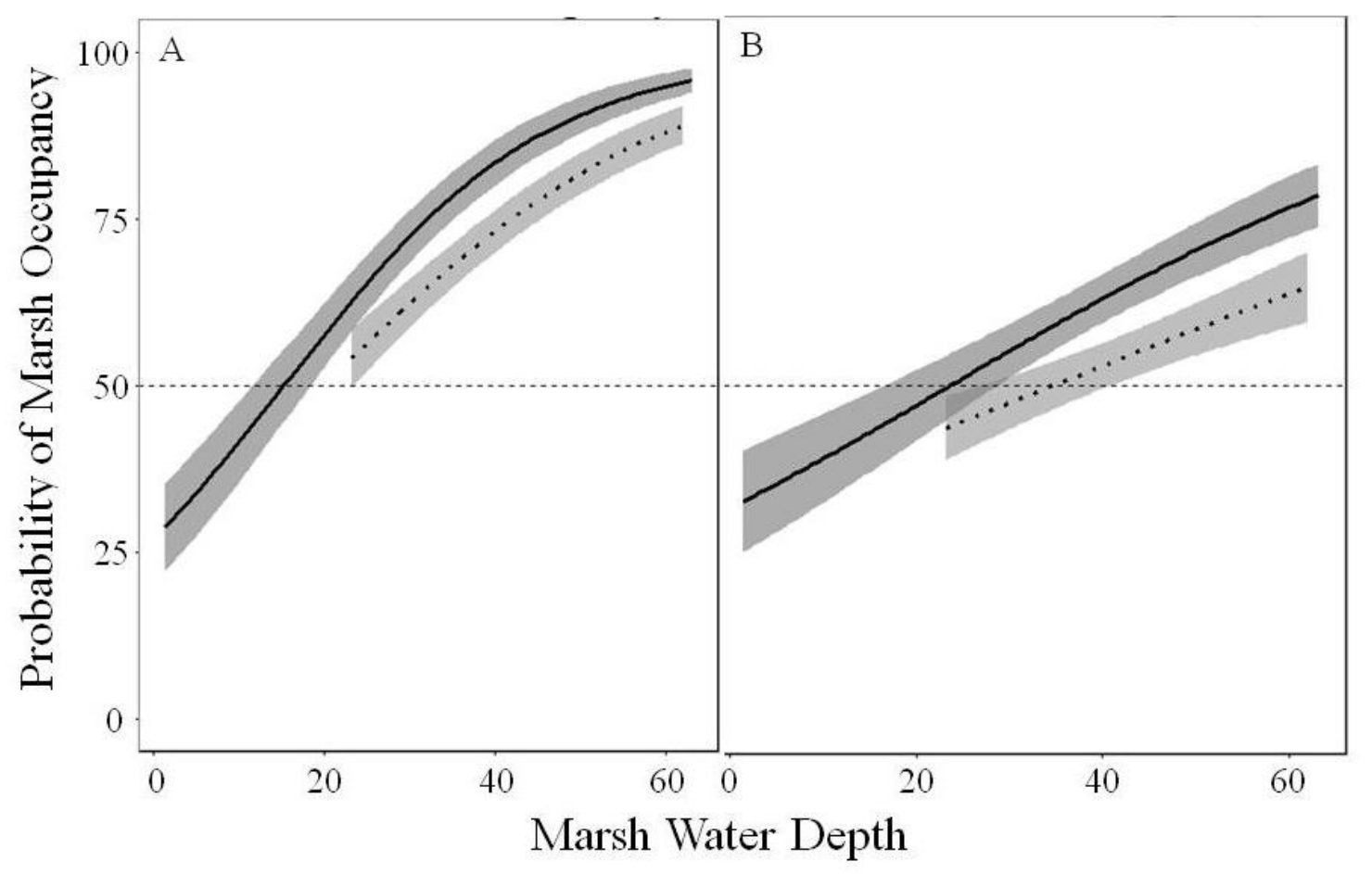


Figure 5
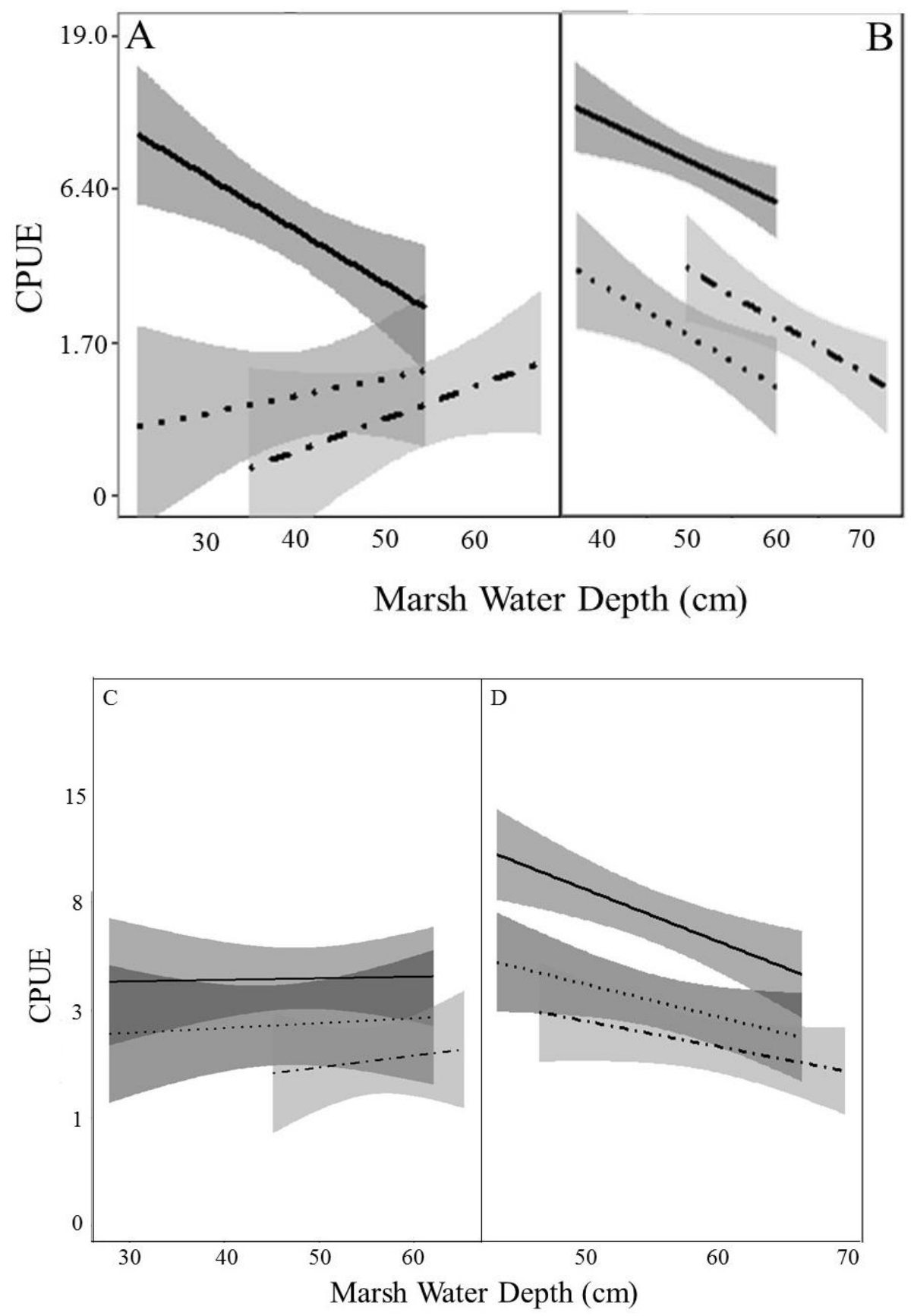
Figure 6
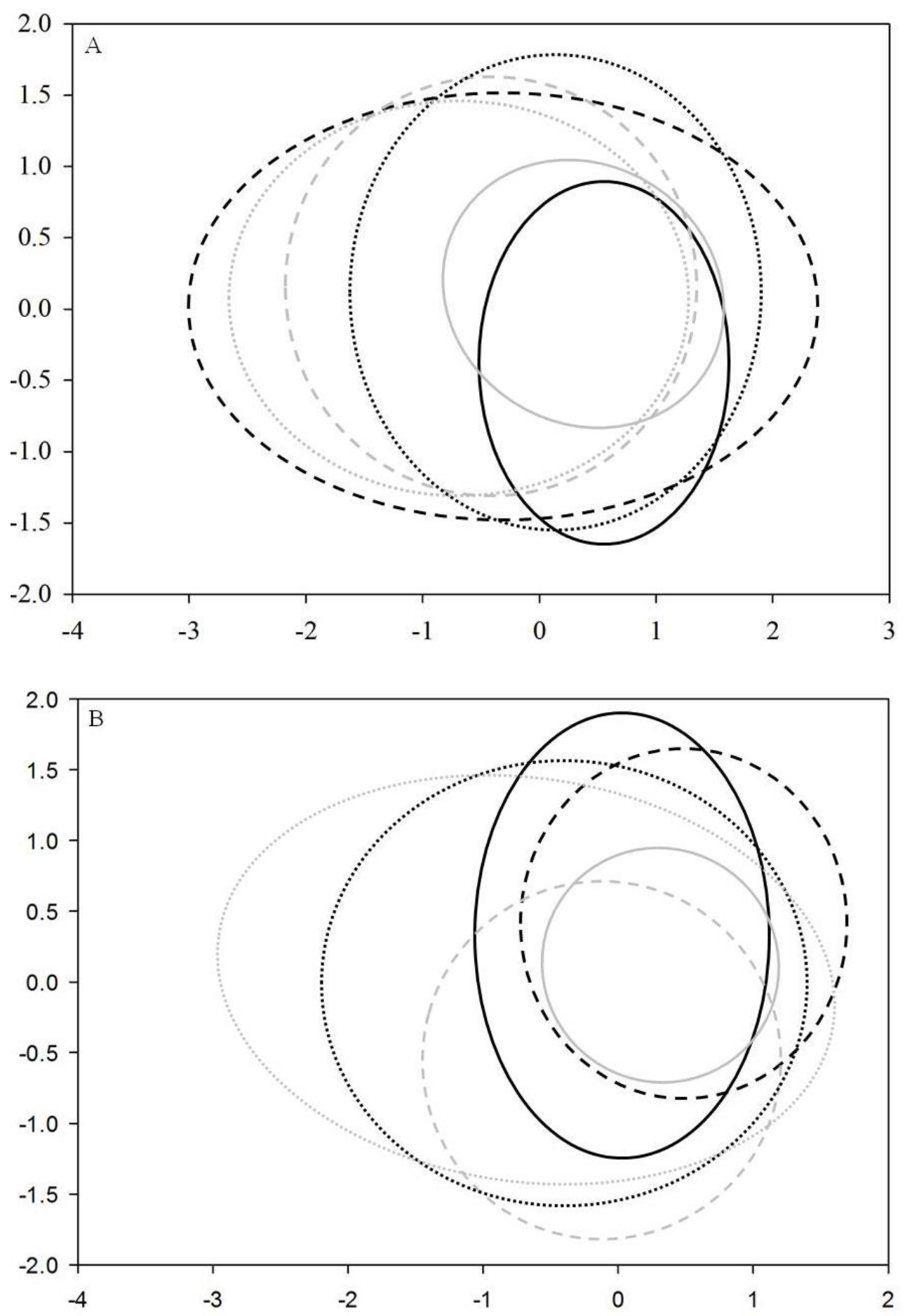


\section{Appendices Captions}

Appendix 1 - Fishes implanted with radio transmitters, including dates, biological data, and surgery times.

Appendix 2 - All Step Length models with equal $(\Delta \mathrm{AIC}<2.0)$ fit, restricted to the overall BACI design

Appendix 3 - All Step Length models with equal $(\Delta \mathrm{AIC}<2.0)$ fit, restricted to periods of the experimental flow pulse

Appendix 4 - All Step Length models with equal $(\triangle \mathrm{AIC}<2.0)$ fit, restricted to filled and unfilled segments of the canal

Appendix 5 - All Step Length models with equal $(\triangle \mathrm{AIC}<2.0)$ fit, over the entire hydroscape

Appendix 6 - Results of SIMPER analyses between Canal and Marsh sites. Only most abundant species contributing up to $75 \%$ of dissimilarity listed. 


\section{Appendices}

\section{Appendix 1}

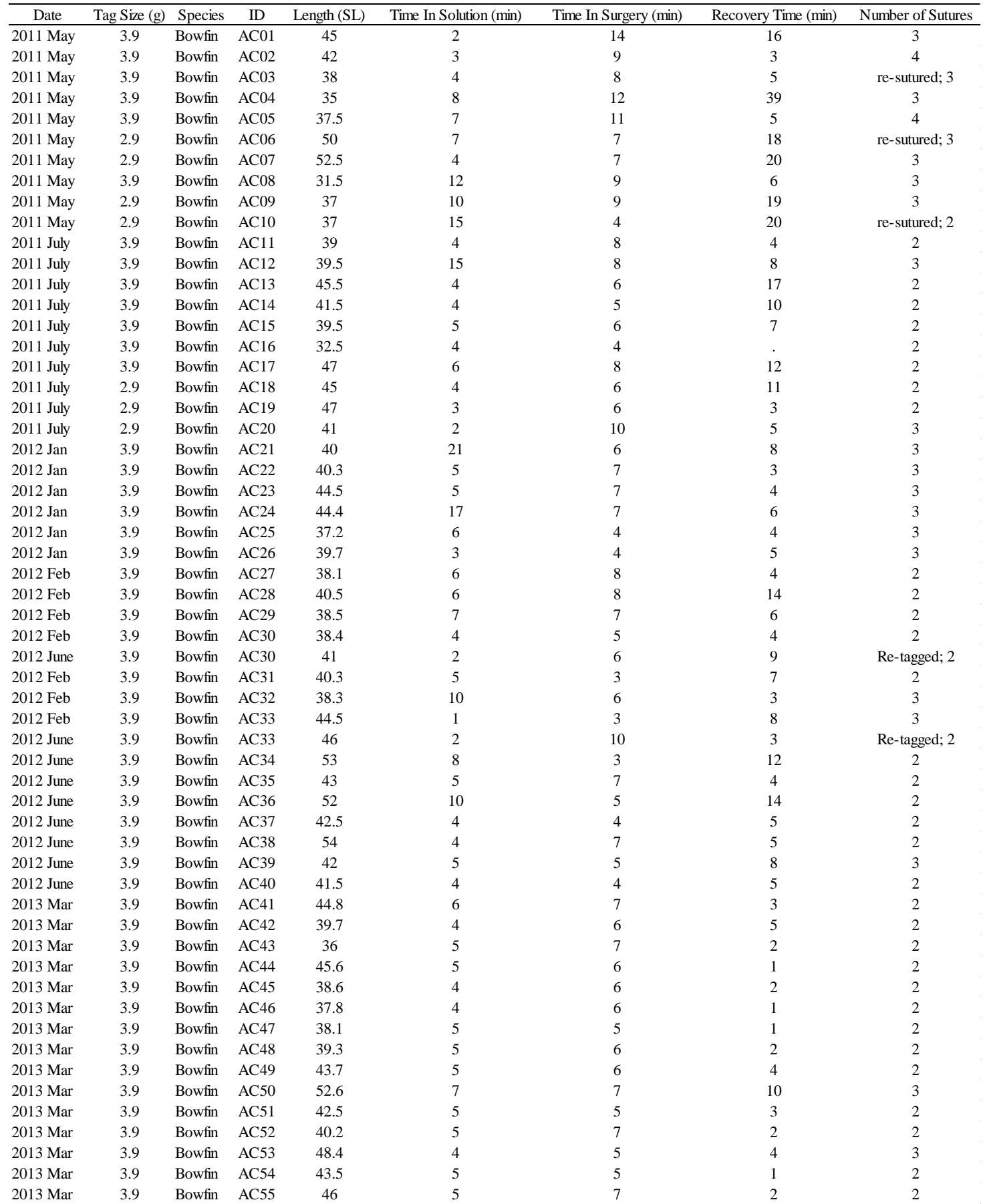


Appendix 1 continued

\begin{tabular}{|c|c|c|c|c|c|c|c|c|}
\hline 2013 Mar & 3.9 & Bowfin & AC56 & 42 & 3 & 4 & 2 & 2 \\
\hline $2013 \mathrm{Mar}$ & 3.9 & Bowfin & AC57 & 39.2 & 3 & 6 & 2 & 2 \\
\hline $2013 \mathrm{Mar}$ & 3.9 & Bowfin & AC58 & 50.3 & 4 & 7 & 1 & 3 \\
\hline 2013 Oct & 3.9 & Bowfin & AC59 & 38.8 & 3 & 5 & . & 3 \\
\hline 2013 Oct & 3.9 & Bowfin & AC60 & 36.4 & 5 & 5 & . & 2 \\
\hline 2013 Oct & 3.9 & Bowfin & AC61 & 52.5 & 4 & 8 & . & 3 \\
\hline 2013 Oct & 3.9 & Bowfin & AC62 & 43.1 & 3 & 4 & . & 2 \\
\hline 2013 Oct & 3.9 & Bowfin & AC63 & 43.3 & 6 & 7 & . & 2 \\
\hline 2013 Oct & 3.9 & Bowfin & AC64 & 40.6 & 3 & 5 & 5 & 2 \\
\hline 2013 Oct & 3.9 & Bowfin & AC65 & 46.1 & 3 & 5 & 4 & 2 \\
\hline 2013 Oct & 3.9 & Bowfin & AC66 & 42.3 & 4 & 6 & . & 2 \\
\hline 2013 Oct & 3.9 & Bowfin & AC67 & 43.2 & 3 & 6 & 1 & 3 \\
\hline 2013 Oct & 3.9 & Bowfin & AC68 & 37.9 & 4 & 8 & . & 2 \\
\hline 2013 Oct & 3.9 & Bowfin & AC69 & 35.4 & 5 & 5 & 13 & 2 \\
\hline 2013 Oct & 3.9 & Bowfin & $\mathrm{AC} 70$ & 41.9 & 2 & 7 & 1 & 3 \\
\hline 2013 Oct & 3.9 & Bowfin & $\mathrm{AC} 71$ & 36.5 & 3 & 5 & 5 & 2 \\
\hline 2013 Oct & 3.9 & Bowfin & AC72 & 38.3 & 4 & 5 & 1 & 2 \\
\hline 2013 Oct & 3.9 & Bowfin & AC73 & 39.9 & 2 & 6 & . & 3 \\
\hline 2013 Oct & 3.9 & Bowfin & AC74 & 46.5 & 3 & 6 & . & 2 \\
\hline 2013 Oct & 3.9 & Bowfin & AC75 & 41.4 & 8 & 6 & 7 & 3 \\
\hline 2013 Oct & 3.9 & Bowfin & AC76 & 45.3 & 4 & 6 & 1 & 3 \\
\hline 2013 Oct & 3.9 & Bowfin & AC77 & 44.3 & 6 & 6 & . & 2 \\
\hline 2013 Oct & 3.9 & Bowfin & AC78 & 58.1 & 3 & 6 & 2 & 3 \\
\hline 2014 Sept & 8.5 & Bowfin & AC79 & 40.1 & 6 & 8 & 2 & 2 \\
\hline 2014 Sept & 8.5 & Bowfin & $\mathrm{AC} 80$ & 37.8 & 4 & 5 & 1 & 3 \\
\hline 2014 Sept & 8.5 & Bowfin & $\mathrm{AC} 81$ & 49.3 & 5 & 6 & 2 & 3 \\
\hline 2014 Sept & 8.5 & Bowfin & AC82 & 44.5 & 5 & 7 & 1 & 3 \\
\hline 2014 Sept & 8.5 & Bowfin & AC83 & 56 & 6 & 7 & 1 & 3 \\
\hline 2014 Sept & 8.5 & Bowfin & AC84 & 53 & 6 & 7 & 2 & 3 \\
\hline 2014 Sept & 8.5 & Bowfin & AC85 & 39.3 & 3 & 7 & 2 & 3 \\
\hline 2014 Sept & 8.5 & Bowfin & AC86 & 44.6 & 5 & 7 & 1 & 3 \\
\hline 2014 Sept & 8.5 & Bowfin & AC87 & 60.5 & 6 & 6 & 1 & 3 \\
\hline 2014 Sept & 8.5 & Bowfin & AC88 & 41.8 & 7 & 5 & 2 & 2 \\
\hline 2014 Sept & 8.5 & Bowfin & AC89 & 45.4 & 3 & 6 & 1 & 3 \\
\hline 2014 Sept & 8.5 & Bowfin & AC90 & 38.7 & 4 & 8 & 1 & 3 \\
\hline 2014 Sept & 8.5 & Bowfin & AC91 & 40 & 6 & 7 & . & 2 \\
\hline 2014 Sept & 8.5 & Bowfin & AC92 & 47.5 & 5 & 7 & 2 & 3 \\
\hline 2014 Sept & 8.5 & Bowfin & AC93 & 48.3 & 4 & 5 & 5 & 3 \\
\hline 2014 Sept & 8.5 & Bowfin & AC94 & 41 & 7 & 6 & 2 & 3 \\
\hline 2014 Sept & 8.5 & Bowfin & AC95 & 52.6 & 6 & 7 & 3 & 3 \\
\hline 2014 Sept & 8.5 & Bowfin & AC96 & 41 & 4 & 6 & 3 & 2 \\
\hline 2014 Sept & 8.5 & Bowfin & АC97 & 55 & 4 & 5 & 1 & 3 \\
\hline 2014 Oct & 8.5 & Bowfin & AC98 & 52.3 & 5 & 5 & 5 & 2 \\
\hline 2011 May & 3.9 & FLMB & MS01 & 29 & 15 & 7 & 5 & 3 \\
\hline 2011 May & 3.9 & FLMB & MS02 & 26 & 3 & 6 & 5 & 3 \\
\hline 2011 May & 3.9 & FLMB & MS03 & 28 & 4 & 8 & 4 & 5 \\
\hline 2011 May & 2.9 & FLMB & MS05 & 30 & 5 & 19 & 26 & 3 \\
\hline 2011 May & 3.9 & FLMB & MS06 & 26 & 8 & 6 & 6 & 3 \\
\hline 2011 May & 2.9 & FLMB & MS07 & 27 & 4 & 6 & 6 & 2 \\
\hline 2011 May & 2.9 & FLMB & MS08 & 24.5 & 11 & 6 & 4 & 3 \\
\hline 2011 May & 2.9 & FLMB & MS09 & 27 & 8 & 6 & 10 & 3 \\
\hline 2011 May & 2.9 & FLMB & MS10 & 23 & 8 & 6 & 9 & 3 \\
\hline 2014 Oct & 8.5 & FLMB & MS100 & 30 & 4 & 6 & 1 & 3 \\
\hline 2014 Oct & 8.5 & FLMB & MS101 & 29.9 & 6 & 5 & 1 & \\
\hline 2011 May & 2.9 & FLMB & MS11 & 26 & 18 & 5 & 11 & 3 \\
\hline 2011 July & 3.9 & FLMB & MS12 & 26 & 7 & 6 & 11 & 3 \\
\hline 2011 July & 3.9 & FLMB & MS13 & 29.5 & 4 & 4 & . & 2 \\
\hline 2011 July & 3.9 & FLMB & MS14 & 27.5 & 6 & 4 & 4 & 2 \\
\hline
\end{tabular}


Appendix 1 continued

\begin{tabular}{|c|c|c|c|c|c|c|c|c|}
\hline 2011 July & 2.9 & FLMB & MS15 & 32 & 12 & 4 & 6 & 2 \\
\hline 2011 July & 2.9 & FLMB & MS16 & 30 & 8 & 7 & 5 & 3 \\
\hline 2011 July & 2.9 & FLMB & MS17 & 39 & 6 & 6 & 11 & 2 \\
\hline 2011 July & 2.9 & FLMB & MS18 & 26.5 & 11 & 5 & 4 & 2 \\
\hline 2011 July & 2.9 & FLMB & MS19 & 25.5 & 3 & 8 & 5 & 3 \\
\hline 2011 July & 2.9 & FLMB & MS20 & 30 & 4 & 4 & 4 & 2 \\
\hline 2011 July & 2.9 & FLMB & MS21 & 28 & 4 & 5 & 2 & 2 \\
\hline $2012 \mathrm{Jan}$ & 3.9 & FLMB & MS22 & 26.5 & 5 & 6 & 10 & 3 \\
\hline $2012 \mathrm{Jan}$ & 3.9 & FLMB & MS23 & 29.8 & 12 & 6 & 4 & 3 \\
\hline $2012 \mathrm{Jan}$ & 3.9 & FLMB & MS24 & 35.3 & 2 & 6 & 3 & 3 \\
\hline 2012 Feb & 3.9 & FLMB & MS25 & 35.2 & 6 & 4 & . & 2 \\
\hline 2012 Feb & 3.9 & FLMB & MS26 & 28.6 & 7 & 4 & 5 & 2 \\
\hline 2012 Feb & 3.9 & FLMB & MS27 & 30 & 10 & 4 & 4 & 3 \\
\hline $2012 \mathrm{Feb}$ & 3.9 & FLMB & MS28 & 28.7 & 5 & 7 & 3 & 3 \\
\hline 2012 June & 3.9 & FLMB & MS29 & 29.5 & 22 & 8 & 23 & 2 \\
\hline 2012 June & 3.9 & FLMB & MS30 & 34.5 & 4 & 4 & 4 & 2 \\
\hline 2012 June & 3.9 & FLMB & MS31 & 28 & 5 & 4 & 12 & 3 \\
\hline 2012 June & 3.9 & FLMB & MS32 & 32.5 & 3 & 5 & 14 & 2 \\
\hline 2012 June & 3.9 & FLMB & MS33 & 27 & 5 & 4 & 3 & 2 \\
\hline 2012 June & 3.9 & FLMB & MS34 & 28 & 2 & 4 & 10 & 2 \\
\hline 2012 June & 3.9 & FLMB & MS35 & 36.5 & 3 & 3 & 9 & 2 \\
\hline 2012 June & 3.9 & FLMB & MS36 & 27 & 8 & 3 & 10 & 2 \\
\hline 2012 June & 3.9 & FLMB & MS37 & 29 & 2 & 6 & 7 & 3 \\
\hline 2012 June & 3.9 & FLMB & MS38 & 35 & 10 & 9 & 5 & 3 \\
\hline 2012 June & 3.9 & FLMB & MS39 & 30.5 & 3 & 5 & 4 & 2 \\
\hline 2012 June & 3.9 & FLMB & MS40 & 28.5 & 4 & 3 & 7 & 2 \\
\hline 2012 June & 3.9 & FLMB & MS41 & 32 & 4 & 6 & 4 & 3 \\
\hline 2013 Mar & 3.9 & FLMB & MS42 & 31.2 & 7 & 5 & 7 & 2 \\
\hline 2013 Mar & 3.9 & FLMB & MS43 & 29.7 & 7 & 7 & 3 & 2 \\
\hline 2013 Mar & 3.9 & FLMB & MS44 & 33.8 & 14 & 5 & 4 & 2 \\
\hline 2013 Mar & 3.9 & FLMB & MS45 & 32.2 & 5 & 5 & 3 & 2 \\
\hline 2013 Mar & 3.9 & FLMB & MS46 & 42.3 & 9 & 6 & 15 & 3 \\
\hline $2013 \mathrm{Mar}$ & 3.9 & FLMB & MS47 & 41 & 6 & 5 & 25 & 2 \\
\hline $2013 \mathrm{Mar}$ & 3.9 & FLMB & MS48 & 42.1 & 4 & 5 & 3 & 2 \\
\hline $2013 \mathrm{Mar}$ & 3.9 & FLMB & MS49 & 29 & 6 & 5 & 12 & 2 \\
\hline 2013 Mar & 3.9 & FLMB & MS50 & 32.8 & 4 & 5 & 3 & 2 \\
\hline 2013 Mar & 3.9 & FLMB & MS51 & 29.7 & 4 & 5 & 4 & 3 \\
\hline 2013 Mar & 3.9 & FLMB & MS52 & 31.5 & 5 & 5 & 5 & 2 \\
\hline 2013 Mar & 3.9 & FLMB & MS53 & 27.4 & 5 & 6 & 4 & 2 \\
\hline 2013 Mar & 3.9 & FLMB & MS54 & 31.9 & 4 & 5 & 10 & 3 \\
\hline 2013 Mar & 3.9 & FLMB & MS55 & 37.9 & 4 & 5 & 2 & 2 \\
\hline 2013 Mar & 3.9 & FLMB & MS56 & 37.8 & 4 & 5 & 7 & 2 \\
\hline 2013 Mar & 3.9 & FLMB & MS57 & 35.3 & 11 & 5 & 3 & 3 \\
\hline 2013 Mar & 3.9 & FLMB & MS58 & 38.1 & 4 & 5 & 10 & 3 \\
\hline 2013 Mar & 3.9 & FLMB & MS59 & 29.2 & 5 & 5 & 2 & 3 \\
\hline 2013 Mar & 3.9 & FLMB & MS60 & 28.6 & 3 & 5 & 2 & 3 \\
\hline 2013 Mar & 3.9 & FLMB & MS61 & 30.8 & 6 & 5 & 3 & 3 \\
\hline 2013 Oct & 3.9 & FLMB & MS62 & 41 & 3 & 5 & 6 & 2 \\
\hline 2013 Oct & 3.9 & FLMB & MS63 & 27.9 & 4 & 5 & 10 & 2 \\
\hline 2013 Oct & 3.9 & FLMB & MS64 & 27 & 4 & 5 & 1 & 2 \\
\hline 2013 Oct & 3.9 & FLMB & MS65 & 28.8 & 4 & 6 & 1 & 3 \\
\hline 2013 Oct & 3.9 & FLMB & MS66 & 25.4 & 15 & 5 & 1 & 2 \\
\hline 2013 Oct & 3.9 & FLMB & MS67 & 42.8 & 9 & 4 & 3 & 2 \\
\hline 2013 Oct & 3.9 & FLMB & MS68 & 25.5 & 11 & 7 & 2 & 3 \\
\hline 2013 Oct & 3.9 & FLMB & MS69 & 30.5 & 3 & 5 & 1 & 2 \\
\hline 2013 Oct & 3.9 & FLMB & MS70 & 43.4 & 4 & 6 & 8 & 3 \\
\hline 2013 Oct & 3.9 & FLMB & MS71 & 28.2 & 6 & 8 & 1 & 3 \\
\hline 2013 Oct & 3.9 & FLMB & MS72 & 27.2 & 4 & 7 & 3 & 3 \\
\hline
\end{tabular}




\section{Appendix 1 continued}

\begin{tabular}{|c|c|c|c|c|c|c|c|c|}
\hline 2013 Oct & 3.9 & FLMB & MS73 & 42.4 & 2 & 6 & 5 & 3 \\
\hline 2013 Oct & 3.9 & FLMB & MS74 & 39.5 & 8 & 6 & 3 & 3 \\
\hline 2013 Oct & 3.9 & FLMB & MS75 & 38 & 3 & 5 & 6 & 3 \\
\hline 2013 Oct & 3.9 & FLMB & MS76 & 31.2 & 3 & 6 & 2 & 3 \\
\hline $2013 \mathrm{Oct}$ & 3.9 & FLMB & MS77 & 36.6 & 2 & 6 & 4 & 3 \\
\hline 2013 Oct & 3.9 & FLMB & MS78 & 30.9 & 2 & 6 & 4 & 3 \\
\hline 2013 Oct & 3.9 & FLMB & MS79 & 26.2 & 2 & 7 & 5 & 3 \\
\hline 2013 Oct & 3.9 & FLMB & MS80 & 27.8 & 4 & 6 & 4 & 3 \\
\hline 2013 Oct & 3.9 & FLMB & MS81 & 28.1 & 5 & 6 & 1 & 3 \\
\hline 2014 Sept & 8.5 & FLMB & MS82 & 43.2 & 6 & 7 & 1 & 4 \\
\hline 2014 Sept & 8.5 & FLMB & MS83 & 45 & 5 & 6 & 6 & 3 \\
\hline 2014 Sept & 8.5 & FLMB & MS84 & 35.2 & 6 & 6 & 2 & 3 \\
\hline 2014 Sept & 8.5 & FLMB & MS85 & 30.4 & 6 & 7 & 2 & 4 \\
\hline 2014 Sept & 8.5 & FLMB & MS86 & 37.3 & 5 & 6 & 2 & 4 \\
\hline 2014 Sept & 8.5 & FLMB & MS87 & 35.1 & 5 & 6 & 1 & 4 \\
\hline 2014 Sept & 8.5 & FLMB & MS88 & 29.7 & 3 & 6 & 2 & 3 \\
\hline 2014 Sept & 8.5 & FLMB & MS89 & 32.8 & 3 & 7 & 8 & 4 \\
\hline 2014 Sept & 8.5 & FLMB & MS90 & 32.7 & 6 & 6 & 10 & 4 \\
\hline 2014 Sept & 8.5 & FLMB & MS91 & 42.7 & 6 & 6 & 8 & 4 \\
\hline 2014 Sept & 8.5 & FLMB & MS92 & 42.5 & 5 & 5 & 2 & 4 \\
\hline 2014 Sept & 8.5 & FLMB & MS93 & 33 & 2 & 6 & 15 & 3 \\
\hline 2014 Sept & 8.5 & FLMB & MS94 & 34.9 & 6 & 6 & 7 & 3 \\
\hline 2014 Sept & 8.5 & FLMB & MS95 & 39 & 5 & 5 & 17 & 3 \\
\hline 2014 Sept & 8.5 & FLMB & MS96 & 45 & 3 & 6 & 6 & 3 \\
\hline 2014 Oct & 8.5 & FLMB & MS97 & 29.6 & 4 & 6 & 3 & 3 \\
\hline 2014 Oct & 8.5 & FLMB & MS98 & 34 & 4 & 5 & 5 & 3 \\
\hline 2014 Oct & 8.5 & FLMB & MS99 & 28.8 & 6 & 5 & 6 & 3 \\
\hline
\end{tabular}




\section{Appendix 2}

\begin{tabular}{|c|c|c|c|c|c|}
\hline $\begin{array}{l}\text { Step Length } \\
\text { Overall }\end{array}$ & Model & AIC & $\Delta \mathrm{AIC}$ & $\omega_{\mathrm{i}}$ & $\mathbf{R}^{2}$ \\
\hline \multirow[b]{2}{*}{ Bowfin } & $\begin{array}{l}\text { Before/After + Contro//Impact + Before/After*Control/Impact + Average Daily Depth Over Preceding } 30 \text { Days + Average Daily } \\
\text { Depth Change Over Preceding } 30 \text { Days + Average Daily Photoperiod Over Preceding } 30 \text { Days + Average Daily Maximum } \\
\text { Temperature Over Preceding } 30 \text { Days }\end{array}$ & 4469.80 & 0.00 & 0.38 & 0.07 \\
\hline & $\begin{array}{l}\text { Before/After + Contro//Impact + Average Daily Depth Over Preceding } 30 \text { Days + Average Daily Depth Change Over Preceding } \\
30 \text { Days + Average Daily Photoperiod Over Preceding } 30 \text { Days + Average Daily Maximum Temperature Over Preceding } 30 \text { Days }\end{array}$ & 4470.40 & 0.59 & 0.28 & 0.07 \\
\hline \multirow{3}{*}{ LMB } & $\begin{array}{l}\text { Average Daily Depth Over Preceding } 30 \text { Days + Average Daily Depth Change Over Preceding } 30 \text { Days + Average Daily } \\
\text { Photoperiod Over Preceding } 30 \text { Days + Average Daily Maximum Temperature Over Preceding } 30 \text { Days }\end{array}$ & 4971.10 & 0.00 & 0.47 & $<0.01$ \\
\hline & $\begin{array}{l}\text { Before/After + Average Daily Depth Over Preceding } 30 \text { Days + Average Daily Depth Change Over Preceding } 30 \text { Days + Average } \\
\text { Daily Photoperiod Over Preceding } 30 \text { Days + Average Daily Maximum Temperature Over Preceding } 30 \text { Days }\end{array}$ & 4972.90 & 1.85 & 0.18 & $<0.01$ \\
\hline & $\begin{array}{l}\text { Contro//Impact + Average Daily Depth Over Preceding } 30 \text { Days + Average Daily Depth Change Over Preceding } 30 \text { Days + } \\
\text { Average Daily Photoperiod Over Preceding } 30 \text { Days + Average Daily Maximum Temperature Over Preceding } 30 \text { Days } \\
\text { Null Model }\end{array}$ & 4973.10 & 2255.20 & 0.17 & $<0.01$ \\
\hline
\end{tabular}




\section{Appendix 3}

\begin{tabular}{|c|c|c|c|c|c|}
\hline $\begin{array}{l}\text { Step Length } \\
\text { During Flow } \\
\text { Pulses } \\
\end{array}$ & Model & AIC & $\Delta \mathbf{A I C}$ & $\omega_{i}$ & $\mathbf{R}^{2}$ \\
\hline \multirow{3}{*}{ Bowfin } & $\begin{array}{l}\text { Contro//Impact + Average Daily Depth Over Preceding } 30 \text { Days + Average Daily Depth Change Over Preceding } 30 \text { Days + } \\
\text { Average Daily Photoperiod Over Preceding } 30 \text { Days + Average Daily Maximum Temperature Over Preceding } 30 \text { Days }\end{array}$ & 4470.40 & 0.00 & 0.72 & 0.07 \\
\hline & $\begin{array}{l}\text { Flow + Contro/Impact + Average Daily Depth Over Preceding } 30 \text { Days + Average Daily Depth Change Over Preceding } 30 \text { Days } \\
+ \text { Average Daily Photoperiod Over Preceding } 30 \text { Days + Average Daily Maximum Temperature Over Preceding } 30 \text { Days }\end{array}$ & 4472.40 & 1.93 & 0.27 & 0.07 \\
\hline & Null Model & 6544.00 & 81.80 & $<0.001$ & - \\
\hline \multirow{3}{*}{ LMB } & $\begin{array}{l}\text { Flow + Average Daily Depth Over Preceding } 30 \text { Days + Average Daily Depth Change Over Preceding } 30 \text { Days + Average Daily } \\
\text { Photoperiod Over Preceding } 30 \text { Days + Average Daily Maximum Temperature Over Preceding } 30 \text { Days }\end{array}$ & 4958.70 & 0.00 & 0.50 & 0.01 \\
\hline & $\begin{array}{l}\text { Flow + Contro/Impact + Average Daily Depth Over Preceding } 30 \text { Days + Average Daily Depth Change Over Preceding } 30 \text { Days } \\
+ \text { Average Daily Photoperiod Over Preceding } 30 \text { Days + Average Daily Maximum Temperature Over Preceding } 30 \text { Days }\end{array}$ & 4959.40 & 0.70 & 0.35 & 0.01 \\
\hline & Null Model & 7226.30 & 2267.60 & 0.00 & - \\
\hline
\end{tabular}




\section{Appendix 4}

\begin{tabular}{|c|c|c|c|c|c|}
\hline $\begin{array}{l}\text { Step Length In } \\
\text { Canal Fill }\end{array}$ & Model & AIC & $\Delta \mathbf{A I C}$ & $\omega_{\mathrm{i}}$ & $\mathbf{R}^{2}$ \\
\hline \multirow{3}{*}{ Bowfin } & $\begin{array}{l}\text { Canal Fill + Average Daily Depth Over Preceding } 30 \text { Days + Average Daily Depth Change Over Preceding } 30 \text { Days + Average } \\
\text { Daily Photoperiod Over Preceding } 30 \text { Days + Average Daily Maximum Temperature Over Preceding } 30 \text { Days }\end{array}$ & 1596.40 & 0.00 & 0.59 & 0.15 \\
\hline & $\begin{array}{l}\text { Canal Fill + Before/After + Average Daily Depth Over Preceding } 30 \text { Days + Average Daily Depth Change Over Preceding } 30 \\
\text { Days + Average Daily Photoperiod Over Preceding } 30 \text { Days + Average Daily Maximum Temperature Over Preceding } 30 \text { Days }\end{array}$ & 1597.90 & 1.46 & 0.28 & 0.15 \\
\hline & Null Model & 2148.80 & 552.39 & $<0.001$ & - \\
\hline \multirow{3}{*}{ LMB } & $\begin{array}{l}\text { Canal Fill + Average Daily Depth Over Preceding } 30 \text { Days + Average Daily Depth Change Over Preceding } 30 \text { Days + Average } \\
\text { Daily Photoperiod Over Preceding } 30 \text { Days + Average Daily Maximum Temperature Over Preceding } 30 \text { Days }\end{array}$ & 2706.00 & 0.00 & 0.57 & 0.03 \\
\hline & $\begin{array}{l}\text { Canal Fill + Before/After + Average Daily Depth Over Preceding } 30 \text { Days + Average Daily Depth Change Over Preceding } 30 \\
\text { Days + Average Daily Photoperiod Over Preceding } 30 \text { Days + Average Daily Maximum Temperature Over Preceding } 30 \text { Days }\end{array}$ & 2707.80 & 1.73 & 0.24 & 0.03 \\
\hline & Null Model & 3623.10 & 917.06 & $<0.001$ & - \\
\hline
\end{tabular}




\section{Appendix 5}

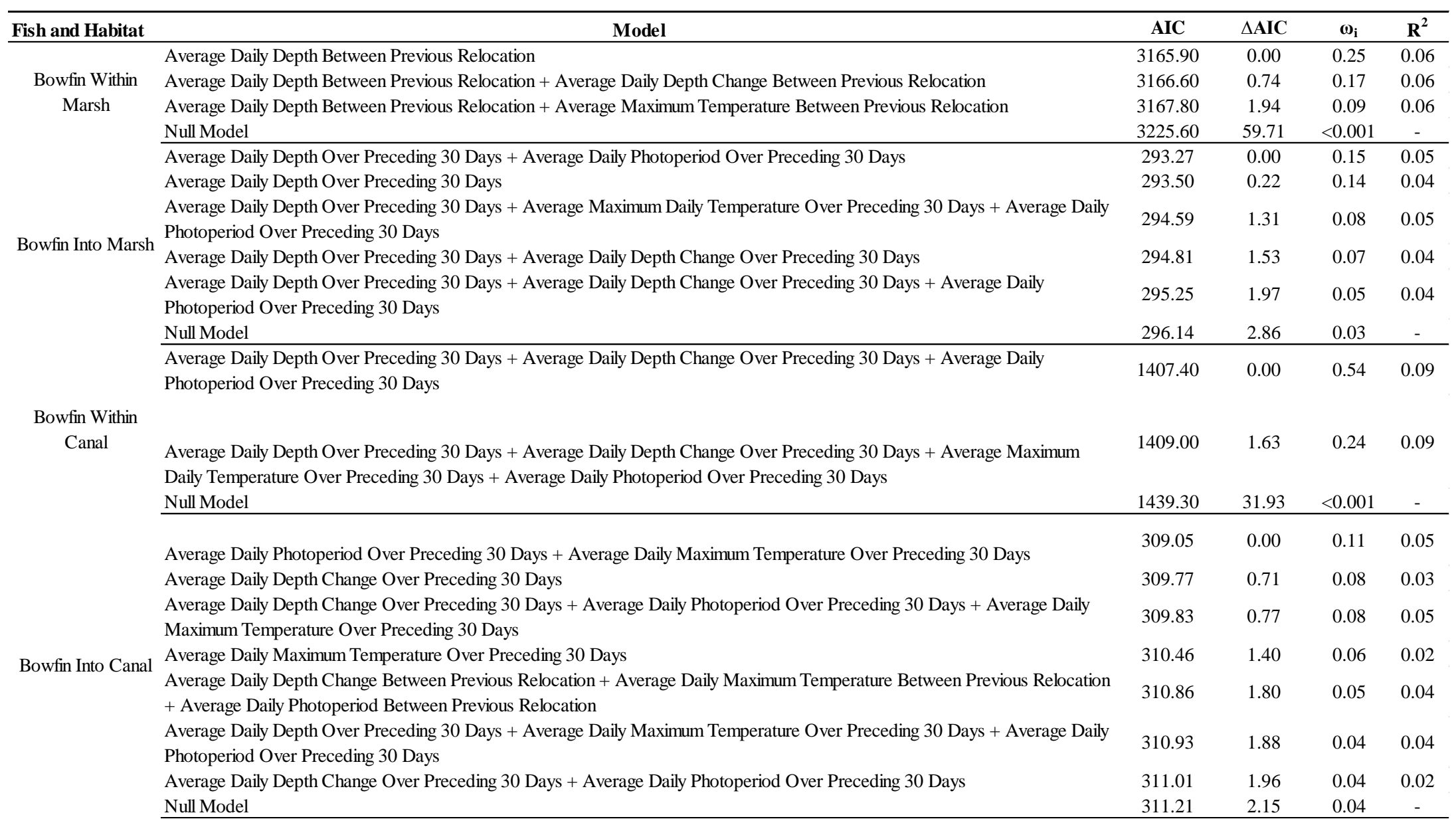




\section{Appendix 5 continued}

Average Daily Depth Between Previous Relocation + Average Daily Depth Change Between Previous Relocation

Average Daily Depth Between Previous Relocation + Average Daily Depth Change Between Previous Relocation + Average Photoperiod Between Previous Relocation

Average Daily Depth Between Previous Relocation

LMB Within Marsh Average Daily Depth Over Preceding 30 Days + Average Daily Depth Change Over Preceding 30 Days + Average Daily Maximum Temperature Over Preceding 30 Days

Average Daily Depth Over Preceding 30 Days + Average Daily Depth Change Over Preceding 30 Days + Average Daily Maximum Temperature Over Preceding 30 Days + Average Daily Photoperiod Over Preceding 30 Days

Null Model

Average Daily Photoperiod Over Preceding 30 Days + Average Daily Maximum Temperature Over Preceding 30 Days Average Daily Photoperiod Between Previous relocation

Average Daily Depth Over Preceding 30 Days + Average Daily Maximum Temperature Over Preceding 30 Days + Average Daily

LMB Into Marsh

Average Daily Depth Change Over Preceding 30 Days + Average Daily Maximum Temperature Over Preceding 30 Days +

Average Daily Photoperiod Over Preceding 30 Days

Average Daily Depth Change Between Previous Relocation + Average Daily Photoperiod Between Previous Relocation Null Model

LMB Within Canal Average Daily Depth Over Preceding 30 Days + Average Daily Depth Change Over Preceding 30 Days + Average Daily Maximum Temperature Over Preceding 30 Days + Average Daily Photoperiod Over Preceding 30 Days

Null Model

\begin{tabular}{llll}
2423.20 & 0.00 & 0.22 & 0.04 \\
2424.20 & 0.98 & 0.13 & 0.04 \\
2424.40 & 1.15 & 0.12 & 0.03 \\
2425.20 & 1.97 & 0.08 & 0.04 \\
2425.20 & 1.98 & 0.08 & 0.04 \\
2450.10 & 26.83 & $<0.001$ & - \\
\hline 376.44 & 0.00 & 0.14 & 0.04 \\
377.34 & 0.89 & 0.09 & 0.02 \\
378.07 & 1.62 & 0.07 & 0.09 \\
378.26 & 1.81 & 0.06 & 0.03 \\
378.37 & 1.92 & 0.06 & 0.02 \\
378.77 & 2.32 & 0.05 & - \\
\hline 2606.00 & 0.00 & 0.76 & 0.02 \\
2618.40 & 12.33 & $<0.01$ & - \\
\hline & & &
\end{tabular}




\section{Appendix 5 continued}

\begin{tabular}{|c|c|c|c|c|c|}
\hline \multirow{12}{*}{ LMB Into Canal } & Average Daily Photoperiod Between Previous relocation & 338.69 & 0.00 & 0.08 & 0.03 \\
\hline & Average Daily Maximum Temperature Between Previous relocation & 338.73 & 0.03 & 0.08 & 0.05 \\
\hline & Average Daily Depth Change Between Previous relocation + Average Daily Maximum Temperature Between Previous relocation & 338.87 & 0.18 & 0.07 & 0.06 \\
\hline & Average Daily Photoperiod Over Preceding 30 Days & 338.91 & 0.22 & 0.07 & 0.05 \\
\hline & Average Daily Depth Change Between Previous Relocation & 339.35 & 0.65 & 0.06 & 0.02 \\
\hline & Average Daily Depth Change Between Previous Relocation + Average Daily Photoperiod Between Previous Relocation & 339.58 & 0.88 & 0.05 & 0.03 \\
\hline & Average Daily Depth Change Over Preceding 30 Days & 339.78 & 1.08 & 0.05 & 0.02 \\
\hline & Average Daily Maximum Temperature Between Previous Relocation + Average Daily Photoperiod Between Previous Relocation & 340.10 & 1.41 & 0.04 & 0.02 \\
\hline & Average Daily Depth Change Over Preceding 30 Days + Average Daily Photoperiod Over Preceding 30 Days & 340.20 & 1.51 & 0.04 & 0.02 \\
\hline & Average Daily Photoperiod Over Preceding 30 Days + Average Daily Maximum Temperature Over Preceding 30 Days & 340.25 & 1.55 & 0.04 & 0.02 \\
\hline & Average Daily Depth Over Preceding 30 Days + Average Daily Photoperiod Over Preceding 30 Days & 340.67 & 1.97 & 0.03 & 0.02 \\
\hline & Null Model & 340.67 & 2.07 & 0.03 & - \\
\hline
\end{tabular}




\section{Appendix 6}

\begin{tabular}{lccc}
\hline NC versus Canal Sites & & & \\
Species & NC Av Abund & Canal Av Abund & Cum \% Dissimilarity \\
\hline FLMB & 3.20 & 8.35 & 16.60 \\
Lake Chubsucker & 3.98 & 4.71 & 28.90 \\
Warmouth & 4.18 & 3.25 & 40.55 \\
Florida Gar & 2.35 & 4.30 & 51.94 \\
Bluegill & 2.17 & 3.94 & 62.31 \\
Bowfin & 3.12 & 3.23 & 72.00 \\
Redear Sunfish & 2.10 & 3.13 & 81.06 \\
\hline FC versus Canal Sites & FC Av Abund & Canal Av Abund & Cum \% Dissimilarity \\
\hline FLMB & 2.74 & 8.35 & 16.89 \\
Warmouth & 5.87 & 3.25 & 30.37 \\
Lake Chubsucker & 3.09 & 4.71 & 41.74 \\
Bowfin & 4.14 & 3.23 & 52.72 \\
Bluegill & 2.13 & 3.94 & 63.57 \\
Florida Gar & 0.95 & 4.30 & 74.37 \\
Redear Sunfish & 1.84 & 3.13 & 82.64 \\
\hline NC Control versus Canal Control Sites & NC Control Av Abund & Canal Control Av Abund & Cum \% Dissimilarity \\
\hline FLMB & 3.03 & 8.37 & 19.24 \\
Warmouth & 4.85 & 3.83 & 31.63 \\
Lake Chubsucker & 4.14 & 3.87 & 43.55 \\
Bluegill & 2.21 & 3.20 & 53.79 \\
Bowfin & 2.92 & 2.64 & 63.88 \\
Florida Gar & 1.68 & 2.99 & 72.81 \\
Redear Sunfish & 1.94 & 2.38 & 81.50 \\
\hline FC Control versus Canal Control Sites & FC Control Av Abund & Canal Control Av Abund & Cum \% Dissimilarity \\
\hline FLMB & 3.44 & 8.37 & 17.21 \\
Bowfin & 4.55 & 2.64 & 29.63 \\
Lake Chubsucker & 2.78 & 3.87 & 42.04 \\
Warmouth & 3.60 & 3.83 & 53.89 \\
Bluegill & 2.23 & 3.20 & 64.02 \\
Florida Gar & 0.33 & 2.99 & 72.68 \\
Redear Sunfish & 1.98 & 2.38 & 81.03 \\
\hline
\end{tabular}




\section{CHAPTER IV}

ECOTONE PROXIMITY AND CONSUMER BEHAVIOR IN A DYNAMIC FRESHWATER HABITAT 


\section{Abstract}

Hydroscape configuration can influence trophic interactions shaping community and metacommunity dynamics. The Everglades, Florida, USA, is a seasonally dynamic, freshwater marsh with a network of deep-water drainage canals. Previous studies have shown density of macroinvertebrates and fishes are highest near canals, possibly resulting from associated nutrient enrichment or dry-season refuge. To assess the role canal proximity had on perceived predation risk for small consumers, $1-\mathrm{m}^{2}$ cages that excluded larger predators $(2.5-\mathrm{cm}$ mesh) and others that did not were placed adjacent to a canal and in a marsh interior several hundred meters away for 13 days, then cleared of consumers. The experiment was repeated during periods of high, mid, and low water depth. Multimodel selection was used to determine what factors influenced consumer and algal densities. Abiotic and forage-nutrition metrics including stem density and periphtyon quality were measured. The interaction of sampling period, exclosure treatment, and habitat best predicted small consumer density. Effect sizes revealed greater predator avoidance behaviors in Canal sites than Marsh sites. Amount of palatable algae was best explained by the interaction of treatment and habitat. Other variables were similar between sites, though periphyton volume was five times greater in Marsh sites and stem density was more than twice as high in Canal sites. CPUE of large piscivores was over twice as high in Canal sites compared to Marsh sites. Elemental phosphorus (\%) was elevated in canal sites. These differences in hydroscape variables may affect perceived predation risk. Our results suggest that hydroscape structure and configuration influence predator-avoidance behaviors, though effects vary with consumer identity. 


\section{Introduction}

Landscape configuration can influence success of anti-predatory behaviors affecting the community structure and distribution of prey species (Davey and Kelly 2007, Hall et al. 2015, Painter et al. 2015). Areas that allow for better detection of predators and decreased predation risk are preferentially sought by prey species (Turesson and Bronmark. 2007, Martin et al. 2010). In response, predators seek habitats that allow for better foraging opportunities, including better opportunities for ambush hunting (Eskew et al. 2009) or decreased competition for prey (Nilsson 2006). For animals of all trophic levels, position in the landscape may force tradeoffs among threats, including competition and predation, and resource availability. In dynamic hydroscapes, such as ephemeral wetlands, habitat quality and risks may change with seasons, complicating habitat selection decisions. If a population is to persist, adaptive behaviors must be adopted that minimize the selection of poor habitats (Blondel et al. 1992). Behavioral plasticity should be favored in ecosystems where the context for predator-prey interactions varies across time or space (Sih et al 2004).

Ecotones, the boundary zones between two habitats, often coincide with discontinuities in the distribution of nutrients, habitat complexity, and organismal abundance, affecting local and regional ecosystem processes (Murcia 1995). Ecotones can be natural attractors to prey species because of better foraging opportunities that offer quick escape from predators (Wahungu et al. 2001, Renhus et al. 2016), but can also attract predators (Sass et al. 2006). While largely limited to habitat preferences by game species, ecotone research in freshwater hydroscapes has shown the same suite of impacts as those found in terrestrial systems, including their impacts on abundance and 
community dynamics (Agostinho and Zalewski 1995, Rehage and Trexler 2006, Ruehl and Trexler 2015).

In modified dynamic systems, flood control efforts can impact natural hydrologic regimes (Page et al. 2005), including modifications that can introduce additional ecotones into an ecosystem. These modifications not only alter historic hydrological patterns, but also create habitat types that may have been uncommon or even absent prior to anthropogenic modification (Poff et al. 1997). For example, wetlands are often modified to incorporate deep-water drainage canals and earthen levees, affecting marsh inundation, duration, and depth (Toth et al. 1993). Canals can produce lacustrine habitats in shallow marshes, providing organisms with stable, permanent habitats that were previously temporary. Furthermore, they create an ecotone with a distinct edge, not a subtle gradient often seen as natural water bodies gradually deepen.

If the interface between the canal and marsh is extensive, with numerous access points, small fishes can easily enter or leave the marsh to access the benefits of shallow, thickly-vegetated conditions while still being near permanent bodies of water (Cucherousset et al. 2007). However, drainage canals often harbor large predators that are attracted to the lacustrine conditions that canals provide (Parkos and Trexler 2014). As proximity to a deep-water refuge increases, threat sources may switch from biotic to abiotic in the form of rapid temperature and oxygen fluctuations, as well as seasonal drying events (Amburgey et al. 2014). Hydroscapes provide some of the foundational works on trophic interactions (Werner et al. 1974, Werner et al. 1983, Carpenter et al. 1985), yet field studies examining the role of hydroscape configuration on community 
dynamics and small fish behavior are relatively limited, especially among non-harvested species.

Our study took place in the freshwater Everglades of Florida, USA, an ideal location to study the effects of a dynamic hydroscape configuration on community processes and behavior due extensive flood-control structures. The historic Everglades featured a slow-moving conveyance of water from its headwaters in Lake Okeechobee south until reaching either the Atlantic Ocean or Florida Bay (Davis et al. 1994). Deepwater habitats were relatively rare and restricted to occasional deep-water sloughs and solution and alligator holes (Loftus and Kushlan 1987). The modern Everglades is a network of water compartments, divided by drainage canals, earthen levees, and water pumps (Light and Dineen 1994). Furthermore, forage quality in marshes bordering canals may be more palatable because of phosphorus enrichment (Noe et al. 2001; Ruehl and Trexler 2015), which can dramatically alter the edibility of a periphyton mat (Gaiser et al. 2004, Trexler et al. 2015). The other habitat choice is the shallow but highly structured marsh, where there may be less predation risk (Ruehl and Trexler 2015), but the chance of being stranded in a drying, isolated pool is present. Experiments using exclosures, where certain size classes of a community are excluded, have shown large predators can have effects on trophic classes through both direct and indirect interactions (Power et al. 1985, Chick et al. 2008, Sargeant et al. 2011). We asked how proximity to a canal affects predator-avoidance behavior of small consumers in the Everglades, including small fishes and grass shrimp (Palaemonetes paludosus), using exclosure cages set at two different proximities from a deep-water canal. Our hypothesis is that the perceived risk of predation is greater along the canal than further in the marsh, and will 
be greatest during the March sampling period when water levels are low and piscivores are concentrated in the canal. Furthermore, nutrient quality will be greatest along the canal margin, thus explaining why primary consumer density is greatest near the canal despite increased numbers of predators.

\section{Methods}

\section{Study Area and Sampling}

We conducted this study in the central Everglades, Florida, USA $\left(25^{\circ} 50^{\prime} 15^{\prime \prime} \mathrm{N} 80^{\circ} 37^{\prime}\right.$ 07 " $\mathrm{S}$ ) in an area with a canal bounded by marsh habitat. The canal is 3.3 to $4.2 \mathrm{~m}$ deep and $8 \mathrm{~m}$ wide. West of the canal is shallow, densely vegetated marsh, which extends for approximately two $\mathrm{km}$ west and $37 \mathrm{~km}$ north and south. The marsh is a patchwork of relatively deep-water sloughs dominated by American white water-lily (Nymphaea odorata), Gulf Coast spikerush (Eleocharis cellulosa), and bladderworts (Utricularia spp.), and of slightly elevated ridges covered in dense sawgrass (Cladium jamaicense), as is typical for the Everglades (Gunderson and Loftus 1993). The Everglades experiences seasonal rainfall, with daily rain events beginning in approximately May and lasting until around November. This causes marsh water levels to rapidly rise over the course of the summer and then gradually recede until daily rains begin again.

Twelve sampling sites were established based on proximity to the canal. Six sites were immediately adjacent to the canal (hereafter Canal sites), and another six were established 107-303 $\mathrm{m}$ from the canal (hereafter Marsh sites), located in open sloughs that were surrounded by dense sawgrass. Intra-site distances varied greatly, from 31 1,038 $\mathrm{m}$ for Canal sites and $58-911 \mathrm{~m}$ for Marsh sites. Variability of intra-site distances and distances of Marsh sites from the canal resulted from limited slough locations 
suitable for conducting our study. The study was repeated in three months representative of the annual water cycle: October, 2014, during the height of marsh water levels; December, 2014, when marsh water levels were beginning to rapidly decline; and March, 2015, when marsh water levels were near their nadir (Figure 1).

The experimental treatments were comprised of a pair of $1-\mathrm{m}^{2}$ exclosures placed adjacent at each study site. One treatment, exclosure cages, were completely surrounded by 2-mm mesh except for one side, which was covered with $2.54-\mathrm{cm}$ wire mesh. This size was chosen to exclude large predators, mostly fish, without restricting movement of smaller animals, including small fishes (standard length $<8 \mathrm{~cm}$ ) and macroinvertebrates (Dorn et al. 2006; Chick et al. 2008). Control cages were similarly wrapped by $2 \mathrm{~mm}$ mesh except for one side, which was left open to permit free access for organisms of all sizes, including sub-adult American alligators (Alligator mississippiensis) (Dorn et al. 2006; personal observation). A $1-\mathrm{m}^{2}$ square of wire mesh was placed at the bottom of each cage with 225 plastic strips attached to act as cover at similar density to surrounding emergent vegetation and provide a substrate for growth of biofilms (colonizing algae and bacteria; Dorn et al. 2006; Chick et al. 2008). Plastic strips were $3.2 \mathrm{~cm}$ wide and were cut to the approximate depth of the water. A sample of $2000 \mathrm{~mL}$ of periphyton taken from the surrounding marsh was added to each cage to mimic typical periphyton cover. Cages were left in the marsh for 13 days, enough time for cage conditions to equilibrate to surrounding marsh and biofilms to develop, but not so long to create algal growth so dense to block the exchange of water and conditions generally unrepresentative of the area (personal observation). Experimental sides ( $2.54 \mathrm{~cm}$ mesh or no mesh) of the cages always faced the canal. After the 13-day period, cages were blocked off and cleared of 
all fishes, amphibians, and macroinvertebrates, which were preserved in the field and transported to the laboratory for processing. Within four days of clearing each cage, the density and community composition of aquatic organisms of the area was determined with three $1-\mathrm{m}^{2}$ throw-trap samples (Jordan et al. 1997). We also recorded the density of vegetation $\left(\right.$ stems $\left.\mathrm{m}^{-2}\right)$ and periphyton volume $\left(\mathrm{mL} \mathrm{m}^{-2}\right)$ from these throw-trap samples. Large fish CPUE was gathered from a separate study occurring in the same area and time as this study, using 5-minute airboat-mounted electroshocker transects (Chick et al. 1999). Large fish samples took place in November, 2014, January, 2015, and March, 2015. There were two near-canal transects and three interior-marsh transects. The mean of these transects represented one replicate per sampling period.

We characterized the base of the food-web for each experimental replicate by analysis of periphyton and biofilms in each cage and the surrounding marsh. Samples of free-floating periphyton were collected from the marsh prior to cage-establishment for each study site and event and frozen at $-18^{\circ} \mathrm{C}$ for later analysis. After each sampling period was over, plastic strips and samples of periphyton from the cages were collected and frozen. These samples were analyzed for stoichiometric $(\mathrm{C}: \mathrm{N}: \mathrm{P})$ and pigment composition to determine forage quality for consumers. Samples were collected from every site during every sampling period, though some samples were later lost due to freezer malfunction (approximately $8 \%$ of samples across all sampling periods combined, mostly samples collected before the October replicate). We estimated edibility of periphyton for small consumers from a portion of the epiphytic growth on the plastic strips that was scraped off and vigorously mixed with $10 \mathrm{~mL}$ of water. A sample from this mixture was then placed onto a slide and examined at 40x magnification under a 
microscope. The number of green algae, diatom, and cyanobacteria cells were counted until the cumulative summation totaled 300. An edibility index from these counts were calculated using the total number of green algae and diatom cells, known to be the most palatable of forage items for small consumers in the Everglades, divided by 300 (Trexler et al. 2015). We also determined cell density $\left(\right.$ cells $\mathrm{mm}^{-2}$ ) based on the area of the fieldof-view. We also recorded the ash-free dry mass (AFDM), stoichiometric data, and Chlorophyll a content of periphyton from the surrounding marsh, and the plastic strips and free-floating periphyton collected from the cages following standard methods (Gaiser et al. (2004) for AFDM; Millie et al. (1993) for Chlorphyll a; Fourqurean et al. (1992) for stoichiometry). Stoichiometric data were obtained using a CHN Analyzer (Fisions NA1500).

\section{Statistical Methods}

To determine if differences existed in small-fish density, grass shrimp density, edibility indices, and algal cell density between experimental and control cages, multi-model selection was used (Burnham and Anderson 2002). The full model included the interaction of Sampling Period (October, December, March), Treatment (Control or Exclosure), and Habitat (Marsh or Canal), and all possible combination of two variables as well as single variables were examined. A null model with just a constant was also fitted to the data. The best model was chosen based on the lowest AIC value for all models. If models had a $\triangle \mathrm{AIC}<2.0$ when compared to the best model, the most parsimonious model was chosen. To assess strength of predictor variables on consumer and algal densities and edibility indices between the exclosure types, effect size was calculated using a dynamic index with the following equation: 


$$
\text { Effect Size }=\frac{\ln \left(\mathrm{N}_{\mathrm{tc}} / \mathrm{N}_{\mathrm{tE}}\right)}{\mathrm{t},}
$$

In this equation, $\mathrm{N}_{\mathrm{tC}}$ is the density or index of dependent variables in the Control cages at time $t$ and $\mathrm{N}_{\mathrm{tE}}$ is the density or index of dependent variables in the Exclosure cages at time $t$ (Osenberg et al. 1997, Chick et al. 2008). In the case of our study, $t$ always equaled 13. Analyses were conducted in R ver. 3.2.2 (R Core Team 2015) and the package "car" (Fox and Weisberg 2011). Dependent variables were natural log (ln) or square-root transformed to meet standard assumptions, with 1 added to all samples when necessary to prevent undefined operations.

Community composition analyses were conducted using Permutational Analysisof-Variance (PERMANOVA), using the Morisita-Horn index because of its property of density-invariance (Jost et al. 2011) (permutations $=9,999)$. The interaction of Treatment $\times$ Habitat $\times$ Sample Period was examined. Throw-trap data were included in this analysis, allowing us to examine if community composition changed between cage treatments and if the Control open cages differed from the surrounding marsh. Data were standardized to the maximum catch for each species and then square-root transformed (Clarke and Warwick 2001). The Bray-Curtis similarity index was used for pairwise comparisons, which is equivalent to the Morisita-Horn index when calculated on standardized data. If the interaction indicated significant differences between samples, pairwise comparisons were used to determine which treatments were driving differences. A Similarity Percentage (SIMPER) analysis was conducted to determine which species were contributing most to dissimilarity between the experimental cages and the throw traps. 
To further assess if sampling impacts existed with our use of exclosures, a threeway ANOVA examining the three-way interaction of Treatment $\times$ Habitat $\times$ Sample Period was used to assess differences existed between densities of small fishes and grass shrimp in cage treatments and densities gathered by throw trap data.

A three-way ANOVA examining the interaction of Treatment $\times$ Habitat $\times$ Sample Period with AFDM as the dependent variable was used to determine if amount of palatable forage was affected by any of our predictor variables. For plastic strip samples, Treatment included just exclosure and control cages. For free-floating periphyton, a "Pre" sample was also included, collected immediately before exclosure establishment. Concentrations of Chl- $\alpha$ as well as elemental ratios (C:P, C:N, N:P) and elemental abundances (Phosphorus and Nitrogen) were also examined using the three-way ANOVA model of Treatment $\times$ Habitat $\times$ Sample Period. Due to freezer malfunction where most "Pre" October samples were lost, the model was initially used without any "Pre" samples across all sampling periods. To assess whether the "Pre" sample values may have been different from the experimental and control cage samples, the model was used again, but without any October data.

To examine if vegetation $\left(\right.$ stems $\left.\mathrm{m}^{-2}\right)$ and periphyton volume $\left(\mathrm{mL} \mathrm{m}^{-2}\right)$ differed between site types, we examined these variables using a two-way ANOVA with the interaction of Habitat $\times$ Month. 


\section{Results}

We found evidence of predator avoidance behaviors in small fishes and grass shrimp through the interaction of sampling period, habitat type, and cage treatment. With density of small fishes, the full model involving the three-way interaction of sampling period $\times$ treatment $\times$ habitat provided best $\left(R^{2}=0.22\right)$ or equal support compared to other models (Table 2). Models with sampling period as a main effect and the interaction of sampling period $\times$ treatment received equal support (Table 2). Grass shrimp density was also best explained by the three-way interaction of sampling period $\times$ treatment $\times$ habitat $\left(\mathrm{R}^{2}=0.49\right)$, with no other models receiving equal support. An examination of effect sizes within these two groups across sampling periods and habitat reveal stronger predator avoidance behaviors in Canal sites, especially in October and December where effect sizes were significantly less than 0 (Figure 2, Table 3). For grass shrimp, effect sizes were approximately seven times stronger for Canal habitats than for Marsh habitats (Table 3).

Model support for the edibility index (green algae + diatoms) was best with the interaction of treatment $\times$ habitat (Table 2). Unlike with small fish and grass shrimp densities, however, model support for the full model was poor $\left(\mathrm{R}^{2}=0.08\right)$. Differences in effect size for edibility indices were largely driven by large differences in edibility indices in Marsh samples compared to Canal samples (Figure 2, Table 3). Edibility indices were varied within site type. For example, control exclosures in Canal sites has higher edibility indices than in experimental exclosures (Control edibility index: 0.95, 95\% C.I. $=0.01 ;$ Experimental exclosure edibility index: $0.90,95 \%$ C.I. $=0.03$ ). However, in the Marsh sites, this pattern was reversed (Edibility index: 0.89, 95\% C.I. = 
0.04; Edibility index: $0.92,95 \%$ C.I. $=0.01)$. Algal cell density was best explained by habitat and sampling period as single factors, though both models received poor support (Habitat: $\mathrm{R}^{2}=0.07$; Sampling period: $\mathrm{R}^{2}=0.06$ ) (Table 2). Cell density was higher in Canal sites $\left(202.43\right.$ cells $\mathrm{mm}^{2}, 95 \%$ C.I. $\left.=35.44\right)$ than in Marsh sites $\left(155.90\right.$ cells $\mathrm{mm}^{2}$, $95 \%$ C.I. $=37.25)$.

Community composition was different between throw trap data and cage treatments, but not between the cage treatments. Composition of the small fish communitydid not change with the interaction of Habitat $\times$ Treatment $\times$ Sample Period (Pseudo-F $=0.77, \mathrm{df}=4,90, \mathrm{p}=0.69$ ). However, all variables as single main effects were significant $($ Habitat: Pseudo-F $=12.33, \mathrm{df}=1,90, \mathrm{p}<0.01$; Treatment: Pseudo-F $=$ 20.97, $\mathrm{df}=2,90, \mathrm{p}<0.01 ;$ Sample Period: Pseudo-F $=3.82, \mathrm{df}=2,90, \mathrm{p}<0.01)$, so pairwise comparisons of Habitat $\times$ Treatment $\times$ Sample Period were run after restricting analyses to Marsh or Canal. Pairwise comparisons revealed that community composition was always different for throw trap data comparing either the experimental or control cages across months. Experimental and control cage communities were never different from each other (Appendix 1). Because no differences were seen between exclosure types, these data were combined under one group and compared to throw trap data across sampling months and habitat type. Examining data under a category that combined Habitat, Treatment, and Sample Period, only a few species contributed to community dissimilarity: Eastern Mosquitofish (Gambusia holbrooki), Least Killifish (Heterandria formosa), Sailfin Molly (Poecilia latipinna), Bluefin Killifish (Lucania goodei), Everglades Pygmy Sunfish (Elassoma evergladei), and Bluespotted Sunfish (Enneacanthus gloriosus) contributed to at least $50 \%$ of community dissimilarity between 
throw trap samples and exclosure cages (both types combined) (Appendix 2). There were no consistent patterns in species relative abundance by habitat, sampling treatment, and sampling month, though Sailfin Mollies tended to have greater relative abundance in exclosure treatments (exclosure: 5.50; throw trap: 1.90) and Bluefin Killifish had greater relative abundance in throw trap samples (exclosure: 3.0; throw trap: 5.40). Restricting SIMPER analyses to differences across habitat type but pooling sampling treatment and month, these two species along with Least Killifish and Eastern Mosquitofish contributed the most to habitat community dissimilarity. All species were more abundant in Marsh sites than Canal sites, with the exception of Least Killifish.

Evidence for sampling artefacts from our study design on consumer densities indicated by differences between the Control (open) cages and marsh throw-trap data were few but present. Including throw-trap data, there were no differences in small fish density from the interaction of Habitat $\times$ Treatment $\times$ Sample Period $(\mathrm{F}=0.29, \mathrm{df}=4,90$, $\mathrm{p}=0.88)$, nor for grass shrimp $(\mathrm{F}=1.04, \mathrm{df}=4,89, \mathrm{p}=0.39)$. Small fish density in throw traps were over $200 \%$ greater in Canal sites (38.0 individuals $\mathrm{m}^{-2}$ ) compared to Marsh sites (17.3 individuals $\mathrm{m}^{-2}$ ). Increases in small fish densities in exclosures across sites were smaller in magnitude (Canal control: 41.55 individuals $\mathrm{m}^{-2}$; Canal experimental exclosure: 55.0 individuals $\mathrm{m}^{-2}$; Marsh control: 34.5 individuals $\mathrm{m}^{-2}$; Marsh experimental exclosure: 45.0 individuals $\mathrm{m}^{-2}$ ). However, variability in grass shrimp density was great. Density of grass shrimp in the December experimental cage samples was nearly as large as the average throw trap density (Exclosure: 32.8 individuals $\mathrm{m}^{-2}$; Throw-trap: 35.9 individuals $\mathrm{m}^{-2}$ ), and both were several times greater than the mean density of the control cages (12.3 individuals $\mathrm{m}^{-2}$ ). 
Organic content of periphyton was not affected by site type or sampling period. No differences were observed in periphyton organic content (AFDM) with artificial strips samples when examining the three-way interaction of Treatment $\times$ Habitat $\times$ Sample Period $(\mathrm{F}=0.34, \mathrm{df}=2,56, \mathrm{p}=0.71)$ or any two-way interaction. Similarly, there were no differences in periphyton organic content from free-floating samples either in the three-way interaction of Treatment $\times$ Habitat $\times$ Sample Period $(F=0.23, \mathrm{df}=3,76, \mathrm{p}=$ $0.87)$ or any two-way interaction.

Analyses did reveal limited differences in elemental abundance between Marsh and Canal sites. With all "Pre" samples removed, neither carbon $(\mathrm{F}=0.14, \mathrm{df}=2,57, \mathrm{p}=$ 0.86) nor nitrogen $(\mathrm{F}=0.07, \mathrm{df}=2,57, \mathrm{p}=0.93)$ percentages changed across Treatment $\times$ Habitat $\times$ Sample Period. However, differences in phosphorous concentrations were nearly significantly different across Treatment $\times$ Habitat $\times$ Sample Period $(F=2.68, \mathrm{df}=$ 2,57, $\mathrm{p}=0.07$; Appendix 3). Phosphorus concentrations near the canal were marginally higher than in the marsh when all samples were combined (Canal: 0.029\%, S.E. \pm 0.001 ; Marsh: $0.020 \%$, S.E. \pm 0.004$)$. The molar ratios of N:P, C:P, or C:N were not different across the interaction of Treatment $\times$ Habitat $\times$ Sample Period with "Pre" samples removed $(\mathrm{N}: \mathrm{P}: \mathrm{F}=0.48, \mathrm{df}=2,57, \mathrm{p}=0.61 ; \mathrm{C}: \mathrm{P}: \mathrm{F}=0.006, \mathrm{df}=2,57, \mathrm{p}=0.99 ; \mathrm{C}: \mathrm{N}: \mathrm{F}=$ $0.26, \mathrm{df}=2,57, \mathrm{p}=0.76)$. When "Pre" samples were included in analyses but October samples removed, results were similar. There were no differences in carbon $(\mathrm{F}=0.16$, df $=2,55, \mathrm{p}=0.84)$, nitrogen $(\mathrm{F}=0.13, \mathrm{df}=2,55, \mathrm{p}=0.87)$, or phosphorus $(\mathrm{F}=2.26, \mathrm{df}=$ $2,55, \mathrm{p}=0.11)$ percentages. There were also no differences in the elemental ratios of $\mathrm{N}: \mathrm{P}$ $(\mathrm{F}=1.94, \mathrm{df}=2,55, \mathrm{p}=0.15), \mathrm{C}: \mathrm{P}(\mathrm{F}=1.66, \mathrm{df}=2,55, \mathrm{p}=0.19)$, and $\mathrm{C}: \mathrm{N}(\mathrm{F}=0.13, \mathrm{df}$ $=2,55, \mathrm{p}=0.87)$. When examining Chl- $\alpha$ concentrations $(\mu \mathrm{g} / \mathrm{g})$, there were no 
differences between the three-way interaction of Treatment $\times$ Habitat $\times$ Sample Period when all "Pre" samples were removed $(\mathrm{F}=0.33, \mathrm{df}=2,57, \mathrm{p}=0.71)$ or when just "Pre" samples were included and October samples were removed $(\mathrm{F}=0.50, \mathrm{df}=2,56, \mathrm{p}=$ 0.60). However, Chl- $\alpha$ concentrations were different in the interaction of Treatment $x$ Habitat when "Pre" samples were included $(\mathrm{F}=3.66, \mathrm{df}=2,56, \mathrm{p}<0.05)$. This result was largely due to decreased levels of Chl- $\alpha$ concentrations in the "Pre" samples compared to the experimental cage samples, especially in Marsh sites.

Changes in habitat structure dependent on habitat type. Emergent stem densities of vegetation were higher at the Canal sites compared to Marsh sites when Site was a single main effect $(\mathrm{F}=18.41, \mathrm{df}=1,30, \mathrm{p}<0.05$; Figure 3$)$, though not with the interaction of Habitat $\times$ Month $(F=0.31, \mathrm{df}=2,30, \mathrm{p}=0.74)$, suggesting stable stem densities within site types across time. Similarly, periphyton volume was up to three times greater at the Marsh sites compared to Canal sites (Figure 4). The interaction of Habitat $\times$ Month was not significant $(F=0.67, \mathrm{df}=2,30, \mathrm{p}=0.51)$, but was when Habitat was a single main effect $(\mathrm{F}=18.41, \mathrm{df}=1,30, \mathrm{p}<0.05)$. Large fish CPUE was over twice as large at sites adjacent to the canal (2.66 fish, S.E. \pm 0.72$)$ compared to sites in the marsh interior (1.11 fish, S.E. \pm 0.48$)$.

\section{Discussion}

In our study system, the canal served as a hydroscape feature providing better forage, a seasonal refuge, and increased predator abundance. These factors can all work together to create a suite of challenges that confront small fishes and macroinvertebrates in the Everglades. Despite or perhaps because of these factors, our hypothesis that perceived 
predator risk in small fishes would be highest along the canal margin was not rejected. Our temporal hypothesis that more fish would use the exclosure habitats during March, when water levels were low and predators were concentrated in the canal, was not clearly answered. Densities of small fishes was best explained by a model involving the interaction of Treatment (Exclosure or Control), Sampling Period (October, December, March), and Habitat (Marsh or Canal). For both Canal and Marsh sites, effect sizes were highly variable and occasionally positive, indicating higher densities in Control cages. Composition of small fish community structure was not affected by cage treatments. Model support explaining grass shrimp density was also strongest with the three-way interaction of Treatment $\times$ Sampling Period $\times$ Habitat. Agreeing with our hypothesis, grass shrimp behaved as though the threat of predation was greatest at Canal sites, but did not display a strong preference for exclosure cages at Marsh sites. However, grass shrimp responded more to perceived predation when water levels were high (October and December) than when they were low (March). Model support for edibility indices performed best with just the interaction of Treatment and Habitat, though this model was just marginally better than the null model $(\triangle \mathrm{AIC}=2.86)$. In the Canal sites, edibility index effect sizes were always slightly positive, meaning edibility indices of control cages were higher than those in the experimental cages, whereas edibility indices were weakly negative in the Marsh sites. Because effect sizes were small, support for preferential foraging on green algae and diatoms in the experimental cages and decreasing the amount of palatable cells was weak. Decreased palatable cells may be the result of decreased perceived predation risk. Edibility index effect sizes were always negative in Marsh sites, suggesting preferential foraging behaviors in the control cages, 
where perceived predation risk was not evident in small fishes and grass shrimp. Our final hypothesis, that nutrient quality would be highest along the canal edge, providing small consumers with high-quality forage, was also partially refuted, with few differences observed in elemental abundances between Canal and Marsh sites. However, percentage of elemental phosphorus was higher in the Canal sites than in the Marsh sites and Chl- $\alpha$ concentrations tended to be lower in samples outside of the experimental cages.

Effects of hydroscape structure on community dynamics can be complicated and can vary across different size and trophic classes. Previous studies of the role of hydroscape configuration on community dynamics have shown that influences on consumer abundances can be difficult to tease apart, even in systems with stable water levels (Jeppesen et al. 1997). In a study with a similar experimental design but within just marsh habitats, Chick et al. (2008) found a similar effect size based on perceived predation risk across two different sampling periods on a combined group of small fishes and macroinvertebrates (average effect size: -0.025 ). Searching for the presence of trophic cascades, they found a significant impact on periphyton from small consumers in both sampling periods when large predators were excluded, but rarely found impacts on periphyton when large predators were allowed in experimental cages. Similar to this study, Dorn et al. (2006) found decapods, particularly grass shrimp, exhibited the larger responses in density to predator-exclosure cages compared to small fishes. In a reciprocal-transplant study using snails and periphyton at two different proximities to a canal, Ruehl and Trexler (2015) found that snails near canals in the Everglades tended to have higher growth rates when fed periphyton that was phosphorus enriched, a product of being near the canal. However, the increased presence of molluscivores caused $33 \%$ 
greater snail mortality at sites near the canal than sites far from the canal. Proximity of resource patches to known high-predation areas can also affect other behaviors, such as dispersal and the willingness for animals to occupy patches adjacent to known highpredator areas (Resetarits Jr and Binckley 2009). These "remote effects", when high abundance of predators in one area influence prey density in a separate but nearby area (Orrock et al. 2010), can scale up to affect community dynamics and metacommunity function. Our study hydroscape suggests that the proximity to the canal can influence the perceived risk of predation, but these effects can be difficult to detect and are not strong. Furthermore, the magnitude of perceived predation risk can be dependent on the type of consumer.

Effects of the experimental design on small consumers were present but limited. Most noticeable of these are the differences in community composition between the cages and the throw trap data. SIMPER analyses revealed that the species contributing the most to community dissimilarity were known to exhibit directed movement, such as Bluefin Killifish, or are herbivorous species such as Sailfin Mollies (Hoch et al. 2015). These behavioral traits may allow for more rapid occupancy of the experimental cages, whether it resulted from increased movement rates or access new epiphytic growth on the artificial vegetation. Grass shrimp densities were often higher in the experimental cages than the throw traps, suggesting an attraction to new growth on artificial strips. The open exclosures may have also acted as attractors for predators because of the relative openness of those habitats, deterring grass shrimp from colonizing these exclosures. This effect was also seen in a similar study (Dorn et al. 2006). 
While the percentage of elemental phosphorus was greater along the canal than in the marsh and Chl- $\alpha$ concentrations were lower in "Pre" samples, we did not observe differences in other metrics of forage quality, such as the AFDM of periphyton, the molar ratios of $\mathrm{C}: \mathrm{P}$ or $\mathrm{N}: \mathrm{P}$, and edibility indices. Previous studies have found that grazer presence can have a positive effect on nutrient content of periphyton, though whether that was from nutrient stimulation or regeneration was not known (Hillebrand and Kahlert 2001, Geddes and Trexler 2003). Other studies in the Everglades found that predator avoidance can focus small consumers into refuge habits, in turn decreasing algae abundance (Chick et al. 2008). Chl- $\alpha$ concentration differences between "Pre" and exclosure samples may be because of periphyton samples being disrupted when placed into exclosures and more areas of the periphyton mats being exposed to sunlight.

Agreeing with previous studies (Rehage and Trexler 2006), large predator CPUE was more than two times higher in sites adjacent to the canal compared to marsh sites. Differences in within-habitat structure may have also contributed to the differences observed in perceived predation risk between Marsh and Canal sites. These were large differences, with much higher volumes of periphyton found in the Marsh compared to the Canal margin and much greater stem densities found in Canal sites compared to Marsh sites (Figure 3). Slim spikerush (Elocharis elongata) was particularly different between

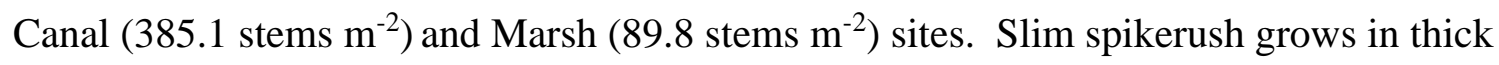
clumps and may acts as a barrier for larger fishes and a refuge for small consumer species. These differences may have decreased the magnitude in predation aversion behaviors in smaller fishes that we hypothesized would be present. While these behaviors were present, they were not much stronger in Canal sites than they were in 
Marsh sites. Grass shrimp did respond positively to the presence of a refuge habitat in Canal habitats, where their densities were also significantly larger than in Marsh habitats. Grass shrimp may be found in higher densities due to the greater stem densities found along the canal edge, offering some protection from predation for the tradeoff of marginally-better forage. The structured habitat of the marsh periphyton may provide better cover from predators and, along with lower densities of conspecifics, may decrease the need for refuge habitat as distance from the canal increases.

Though our hypotheses were largely supported by our results, this study brings to light the myriad factors that can influence aquatic community functioning based on proximity to major hydroscape features. Further research should investigate the role that different types of habitat structure can have as a refuge for prey species, such as expansive mats of periphyton compared to a dense stand of slim spikerush. Our study examining the role of proximity to hydroscape features on trophic interactions and aquatic community structure contributes to the expanding collective body of work in floodplain conservation and management. As restoration efforts continue, not only in the Everglades but in ephemeral freshwater habitats in other areas, mitigation of anthropogenic factors influencing trophic dynamics will be of increasing importance.

\section{Acknowledgements}

The researchers wish to thank the hard work of the field technicians and graduate students of the Trexler lab for field assistance, particularly J Sanchez, J Gatto, and LStokeltje. We also would like to thank J Sweatman for field assistance and F Tobias, P 
Lorenzo, and S Wilson for assistance with elemental analyses. Funding for this project came from Cooperative Agreement W32CS501185613 between FIU and the US Geological Survey. Collections were made under Florida state permit S-11-04 and in accordance with FIU IACUC (Protocol \#200404). This material was developed in collaboration with the Florida Coastal Everglades Long-Term Ecological Research program under National Science Foundation Grant No. DEB-1237517. This is publication xxx from the Southeast Environmental Center (SERC) at FIU.

Literature Cited

Agostinho, A,A, and M. Zalewski M. 1995. The dependence of fish community structure and dynamics on floodplain and riparian ecotone zone in Parana River, Brazil. Hydrobiologia 303:141-148.

Amburgey, S.M., L.L. Bailey, M. Murphy, E. Muths, and W.C. Funk. 2014. The effects of hydropattern and predator communities on amphibian occupancy. Can J Zool 92:927-937.

Blondel, J., P. Perret, M. Maistre, and P.C. Dias. 1992. Do harlequin Mediterranean environments function as source sink for Blue Tits (Parus caeruleus L.)? Landscape Ecol 6:213-219.

Burnham, K.P., and D.R. Anderson. 2002. Model Selection and Multimodel Inference: A Practical Information-Theoretic Approach. Springer-Verlag New York, New York City.

Carpenter, S.R., J.F. Kitchell, and J.R. Hodgson. 1985. Cascading trophic interactions and lake productivity. BioSci 35:634-639.

Chick, J.H., P. Geddes, and J.C. Trexler. 2008. Periphyton mat structure mediates trophic interactions in a subtropical marsh. Wetlands 28:378-389.

Clarke, K.R., and R.M. Warwick RM. 2001. Change in marine communities: an approach to statistical analysis and interpretation. $2^{\text {nd }}$ ed. Primer-E Ltd, Plymouth, UK.

Cucherousset, J., A. Carpentier, and J.M. Paillisson. 2007. How do fish exploit temporary water throughout a flooding episode? Fish Manage and Ecol 14:269-276. 
Davis, S.M., L.H. Gunderson, W.A. Park, J.R. Richardson, J.E. Mattson. 1994. Landscape dimension, composition, and function in a changing Everglades ecosystem. Pages 419-444 in M. Davis and J.C. Ogden (editors). Everglades: The Ecosystem and Its Restoration. St. Lucie Press, Boca Raton, Florida.

Davey, A.J., and D.J. Kelly. 2007. Fish community responses to drying disturbances in an intermittent stream: a landscape perspective. Freshw Biol 52:1719-1733.

Dorn, N. J., J. C. Trexler, and E. E. Gaiser. 2006. Exploring the role of large predators in marsh food webs: evidence for a behaviorally-mediated trophic cascade. Hydrobiologia 569:375-386

Eskew, E.A., J.D. Willson, and C.T. Winne. 2009. Ambush site selection and ontogenetic shifts in foraging strategy in a semi-aquatic pit viper, the eastern cottonmouth. $\mathrm{J}$ of Zool 277:179-186.

Fourqurean, J.W., J.C. Zieman, and G.V.N. Powell. 1992. Phosphorus limitation of primary production in Florida Bay: evidence from $\mathrm{C}: \mathrm{N}: \mathrm{P}$ ratios of the dominant seagrass Thalassia testudinum. Limn and Oceano 37:162-171.

Fox, J. and S. Weisberg. 2011. An R Companion to Applied Regression. $2^{\text {nd }}$ Ed, Sage, Thousand Oaks, CA.

Gaiser, E.E., L.J. Scinto, J.H. Richards, K. Jayachandran, D.L. Childers, J.C. Trexler, and R.D. Jones. 2004. Phosphorus in periphyton mats provides the best metric for detecting low-level P enrichment in an oligotrophic wetland. Water Res 38:507516.

Geddes, P. and J.C. Trexler. 2003. Uncoupling of omnivore-mediated positive and negative effects on periphyton mats. Oecologia 136:585-595.

Gunderson, L.H. and W.F. Loftus. 1993. The Everglades. Pages 199-255 in W.H. Martin, S.G .Boyce, and A.C. Echternacht (editors). Biodiversity of the Southeastern United States. John Wiley \& Sons, New York City, New York.

Hall, A.M., S.J. McCauley, and M.J. Fortin. 2015. Recreational boating, landscape configuration, and local habitat structure as drivers of odonate community composition in an island setting. Insect Cons and Div 8:31-42.

Hillebrand, H. and M. Kahlert. 2001. Effects of grazing and nutrient supply on periphyton biomass and nutrient stoichiometry in habitats of different productivity. Limnol Oceanogr 46:1881-1898. 
Hoch, J.M., E.R. Sokol, A.D. Parker, and J.C. Trexler. 2015. Migration strategies vary in space, time, and among species in the small-fish metacommunity of the Everglades. Copeia 103:157-169.

Jeppesen, E., J.P. Jensen, M. Sondergaard, T. Lauridsen, L.J. Pedersen, and L. Jensen. 1997. Top-down control in freshwater lakes: the role of nutrient state, submerged macrophytes and water depth. Pages 151-164 in A. Prejs and L. Kufel (editors). Shallow Lakes '95. Springer Netherlands, Dordrecht, Netherlands.

Jordan, F., S. Coyne, and J.C. Trexler. 1997. Sampling fishes in vegetated habitats: effects of habitat structure on sampling characteristics of the $1-\mathrm{m}^{2}$ throw trap. Trans Am Fish Soc 136:1012-1020.

Jost, L., A. Chao, and R.L. Chazdon. 2011. Compositional similarity and B(beta) diversity. Pages 66-84 in A.E. Magurran and B.J. McGill (editors). Biological Diversity. Oxford University Press, Oxford, UK.

Light, S.S., and J.W. Dineen. 1994. Water control in the Everglades: A historical perspective. Pages 47-84 in M. Davis and J.C. Ogden (editors). Everglades: The Ecosystem and Its Restoration. St. Lucie Press, Boca Raton, Florida.

Liu, Z., J. C. Volin, V. D. Owen, L. G. Pearlstine, J. R. Allen, F. J. Mazzotti, and A. L. Higer. 2009. Validation and ecosystem applications of the EDEN water-surface model for the Florida Everglades. Ecohydrology 2:182-194.

Martin, C.W., F.J. Fodrie, K.L. Heck Jr., and J. Mattila. 2010. Differential habitat use and antipredator response of juvenile roach (Rutilus rutilus) to olfactory and visual cues from multiple predators. Oecologia 162:893-902.

Millie, D.F., H.W. Paerl, and J.P. Hurley. 199.3 Microalgal pigment assessments using high-performance liquid chromatography: a synopsis of organismal and ecological applications. Can J Fish Aq Sci 50:2513-2527.

Murcia, C. 1995. Edge effects in fragmented forests: Implications for conservation. TREE 10:58-62.

Nilsson, P.A. 2006. Avoid your neighbours: size-determined spatial distribution patterns among northern pike individuals. Oikos 113:251-258.

Noe, G.B., D.L. Childers, and R.D. Jones. 2001. Phosphorus biogeochemistry and the impact of phosphorus enrichment: Why is the Everglades so unique? Ecosystems 4:603-624. 
Orrock, J.L., A. Sih, L.M. Dill, J.H. Grabowski, S.D. Peacor, B.L. Peckarsky, E.L. Preisser, J.R. Vonesh, and E.E. Werner. 2010. Predator effects in predator-free space: the remote effects of predators on prey. The Open Ecol J 3:22-30.

Osenberg, C.W., O. Sarnelle, and S.D. Cooper. 1997. Effect size in ecological experiments: the application of biological models in meta-analysis. Am Nat 150:798-812.

Page, K., A. Read, P. Frazier, and N. Mount. 2005. The effect of altered flow regime on the frequency and duration of bankfull discharge: Murrumbidgee River, Australia. Riv Res and App 21:567-578.

Painter, L.E., R.L. Beschta, E.J. Larsen, and W.J. Ripple. 2015. Recovering aspen follow changing elk dynamics in Yellowstone: evidence of a trophic cascade? Ecology 96:252 263 .

Parkos III, J.J., and J.C. Trexler. 2014. Origins of functional connectivity in a human modified wetland landscape. Can J Fish Aq Sci 71:1418-1429.

Poff, N.L., J.D. Allan, M.B. Bain, J.R. Karr, K.L. Prestegaard, B.D. Richter, R.E. Sparks, and J.C. Stromberg. The natural flow regime. Bioscience 47:769-784.

Power, M.E., W.J. Matthews, and A.J. Stewart. 1985. Grazing minnows, piscivorous bass, and stream algae: dynamics of a strong interaction. Ecology 66:1448-1456.

R Core Team. 2015. R: a language and environment for statistical computing, https://www.R project.org/.

Rehage, J.S., and J.C. Trexler. 2006. Assessing the net effect of anthropogenic disturbance on aquatic communities in wetlands: Community structure relative to distance from canals. Hydrobiologia 569:359-373.

Renhus, M., V. Braunisch, K. Hacklander, L. Jost, and K. Bollmann. 2016. The seasonal trade-off between food and cover in the Alpine mountain hare (Lepus timidus). Euro J Wild Res 62:11-21.

Resetarits, W.J., and C.A. Binckley. 2009. Spatial contagion of predation risk affects colonization dynamics in experimental aquatic landscapes. Ecol 90:869-876.

Ruehl, C.B., and J.C. Trexler. 2013. A suite of prey traits determine predator and nutrient enrichment effects in a tri-trophic food chain. Ecosphere 4:1-21.

Ruehl, C.B., and J.C. Trexler. 2015. Reciprocal transplant reveals trade-off of resource quality and predation risk in the field. Oecologia 179:117-127. 
Sargeant, B.L., E.E. Gaiser, and J.C. Trexler. 2011. Indirect and direct controls of macroinvertebrates and small fish by abiotic factors and trophic interactions in the Florida Everglades. Freshw Biol 56:2334-2346.

Sass, G.G., C.M. Gille, J.T. Hinke, and J.F. Kitchell. 2006. Whole-lake influences of littoral structural complexity and prey body morphology on fish predator-prey interactions. Ecol Freshw Fish 15:301-308.

Sih, A., A. Bell, and C. Johnson. Behavioral syndromes: an ecological and evolutionary overview. TREE 19:372-378.

Telis, P.A. 2006. The Everglades Depth Estimation Network (EDEN) for support of ecological and biological assessments. U.S. Geological Survey Fact Sheet 20063087.

Toth, L.A., J.T. Obeysekera, W.A. Perkins, and M.K. Loftin. 1993. Flow regulation and restoration of Florida’s Kissimmee River. Reg Riv: Res and Manag 8:155-166.

Trexler, J.C., E.E. Gaiser, J.S. Kominoski, and J.L. Sanchez. 2015. The role of periphyton mats in consumer community structure and function in calcareous wetlands: lessons from the Everglades. Pages 155-179 in J.S. Entry, A.D. Gottlieb, K. Jayachandran, and A. Ogram (editors). Taylor and Francis, Oxfordshire, UK.

Turesson, H., and C. Bronmark. 2007. Predator-prey encounter rates in freshwater piscivores: effects of prey density and water transparency. Oecologia 153:281 290.

Wahangu, G.M., C.P. Catterall, and M.F. Olsen. Predator avoidance, feeding and habitat use in the red-necked pademelon, Thylogale thetis, at rainforest edges. Aust J Zool 49:45-58.

Werner, E.E., J.F. Gilliam, D.J. Hall, and G.G. Mittelbach. 1983 An experimental test of the effects of predation risk on habitat use in fish. Ecology 64:1540-1548.

Werner, E.E., and D.J. Hall. 1974. Optimal foraging and the size selection of prey by the bluegill sunfish (Lepomis macrochirus). Ecology 55:1042-1052. 


\section{Tables}

Table 1 - Overview of abiotic and biotic parameters of our study area. Data were grouped between periods of high water (October and December) and low water (March) samples.

\begin{tabular}{|c|c|c|c|c|c|c|}
\hline SITE & Month & DEPTH (cm) & $\begin{array}{l}\text { PERIPHYTON } \\
\left(\mathrm{mL} \mathrm{m}^{-2}\right)\end{array}$ & $\begin{array}{c}\text { STEM DENSITY } \\
\left(\text { stem m}^{-2}\right)\end{array}$ & $\begin{array}{l}\text { FISH DENSITY } \\
\text { (ind } \mathbf{m}^{-2} \text { ) }\end{array}$ & $\begin{array}{l}\text { GRASS SHRIMP } \\
\text { DENSITY (ind } \mathrm{m}^{-2} \text { ) }\end{array}$ \\
\hline \multirow{2}{*}{ Canal } & Oct/Dec & $56.5 \pm 8.4$ & $1897.2 \pm 1007.8$ & $417.4 \pm 234.3$ & $43.2 \pm 16.7$ & $35.8 \pm 13.8$ \\
\hline & March & $37.9 \pm 5.7$ & $1419.4 \pm 438.0$ & $501.1 \pm 114.6$ & $27.7 \pm 28.7$ & $54.4 \pm 44.2$ \\
\hline \multirow{2}{*}{ Marsh } & Oct/Dec & $58.4 \pm 4.9$ & $4926.4 \pm 1246.2$ & $159.0 \pm 78.6$ & $21.2 \pm 9.8$ & $9.6 \pm 8.5$ \\
\hline & March & $38.4 \pm 4.3$ & $5177.8 \pm 1572.4$ & $177.5 \pm 80.5$ & $9.4 \pm 4.8$ & $14.9 \pm 9.6$ \\
\hline
\end{tabular}


Table 2 - Models for small fish, grass shrimp, and algal cell densities, and edibility indices. Only the most parsimonious models of best fit $(\triangle \mathrm{AIC}<2.0$ from the lowest scoring model) are shown, along with the null model and the full model if necessary.

\begin{tabular}{llcccc}
\hline Step Length & \multicolumn{1}{c}{ Model } & AIC & $\Delta$ AIC & $\boldsymbol{\omega}_{\mathbf{i}}$ & $\mathbf{R}^{\mathbf{2}}$ \\
\hline \multirow{4}{*}{ Small Fish Density } & Sample & 161.51 & 0.00 & 0.46 & 0.15 \\
& Sample ${ }^{*}$ Treatment & 162.38 & 0.86 & 0.30 & 0.18 \\
& Sample ${ }^{*}$ Treatment * Habitat & 163.21 & 1.69 & 0.20 & 0.22 \\
Grass Shrimp & Null Model & 171.53 & 10.02 & $<0.01$ & - \\
\cline { 2 - 6 } Density & Sample * Treatment * Habitat & 142.56 & 0.00 & 0.99 & 0.49 \\
& Null Model & 181.50 & 38.93 & $<0.01$ & - \\
\cline { 2 - 6 } Edibility Index & Treatment * Habitat & -288.50 & 0.00 & 0.48 & 0.08 \\
& Sample * Treatment * Habitat & -285.30 & 3.17 & 0.10 & 0.13 \\
& Null Model & -285.60 & 2.86 & 0.12 & - \\
\cline { 2 - 6 } Algal Cell Density & Habitat & 138.91 & 0.00 & 0.49 & 0.07 \\
& Sample & 140.33 & 1.42 & 0.24 & 0.06 \\
& Sample * Treatment * Habitat & 149.28 & 10.37 & $<0.01$ & 0.05 \\
& Null Model & 142.61 & 3.70 & 0.07 & - \\
\hline
\end{tabular}


Table 3 - Dynamic effect sizes for small fishes $\left(\# / \mathrm{m}^{2}\right)$, grass shrimp $\left(\# / \mathrm{m}^{2}\right)$, edibility index, and cell count $\left(\# / \mathrm{mm}^{2}\right), \pm 95 \%$ confidence interval.

\begin{tabular}{cccccc}
\hline Month & Site & Small Fish ES & Grass Shrimp ES & Edibility Index ES & Cell Density ES \\
& & & & & \\
\hline \multirow{2}{*}{ October } & Canal & $-0.027 \pm 0.021$ & $-0.057 \pm 0.035$ & $0.005 \pm 0.002$ & $0.009 \pm 0.027$ \\
& Marsh & $-0.024 \pm 0.041$ & $-0.018 \pm 0.040$ & $-0.0068 \pm 0.0067$ & $0.012 \pm 0.058$ \\
\cline { 2 - 6 } December & Canal & $-0.037 \pm 0.025$ & $-0.069 \pm 0.031$ & $0.0033 \pm 0.0037$ & $-0.023 \pm 0.052$ \\
& Marsh & $-0.035 \pm 0.053$ & $-0.005 \pm 0.017$ & $-0.0009 \pm 0.006$ & $0.034 \pm 0.078$ \\
\cline { 2 - 6 } March & Canal & $-0.032 \pm 0.048$ & $-0.017 \pm 0.018$ & $0.0035 \pm 0.005$ & $-0.016 \pm 0.040$ \\
& Marsh & $-0.038 \pm 0.061$ & $-0.004 \pm 0.032$ & $-0.0004 \pm 0.004$ & $0.026 \pm 0.044$ \\
\hline
\end{tabular}




\section{Figure Captions}

Figure 1 - Hydrograph of marsh water depth at sites near canal. Filled circles indicate approximate period of exclosure experiments. Water depths were calculated using the Everglades Depth Estimation Network (EDEN; Telis 2006, Liu et al. 2009) and adjusted using period in situ measurements.

Figure 2 - Effect sizes across sampling months and habitat types. See Methods for descriptions of dynamic effect size and edibility index calculations.

Figure 3 - Stem density $\left(\mathrm{m}^{-2}\right)$ collected from throw-trap data during period of experiment termination across sampling months. Closed circles represent Canal sites and open circles represent Marsh sites. Error bars represent 95\% confidence intervals. Data were back-transformed from sqrt( $\mathrm{x}+1)$.

Figure 4 - Periphyton volume $\left(\mathrm{mL} \mathrm{m}^{-2}\right)$ collected from throw-trap data during period of experiment termination across sampling months. Closed circles represent Canal sites and open circles represent Marsh sites. Error bars represent 95\% confidence intervals. Data were back-transformed from $\operatorname{sqrt}(\mathrm{x}+1)$. 
Figures

Figure 1

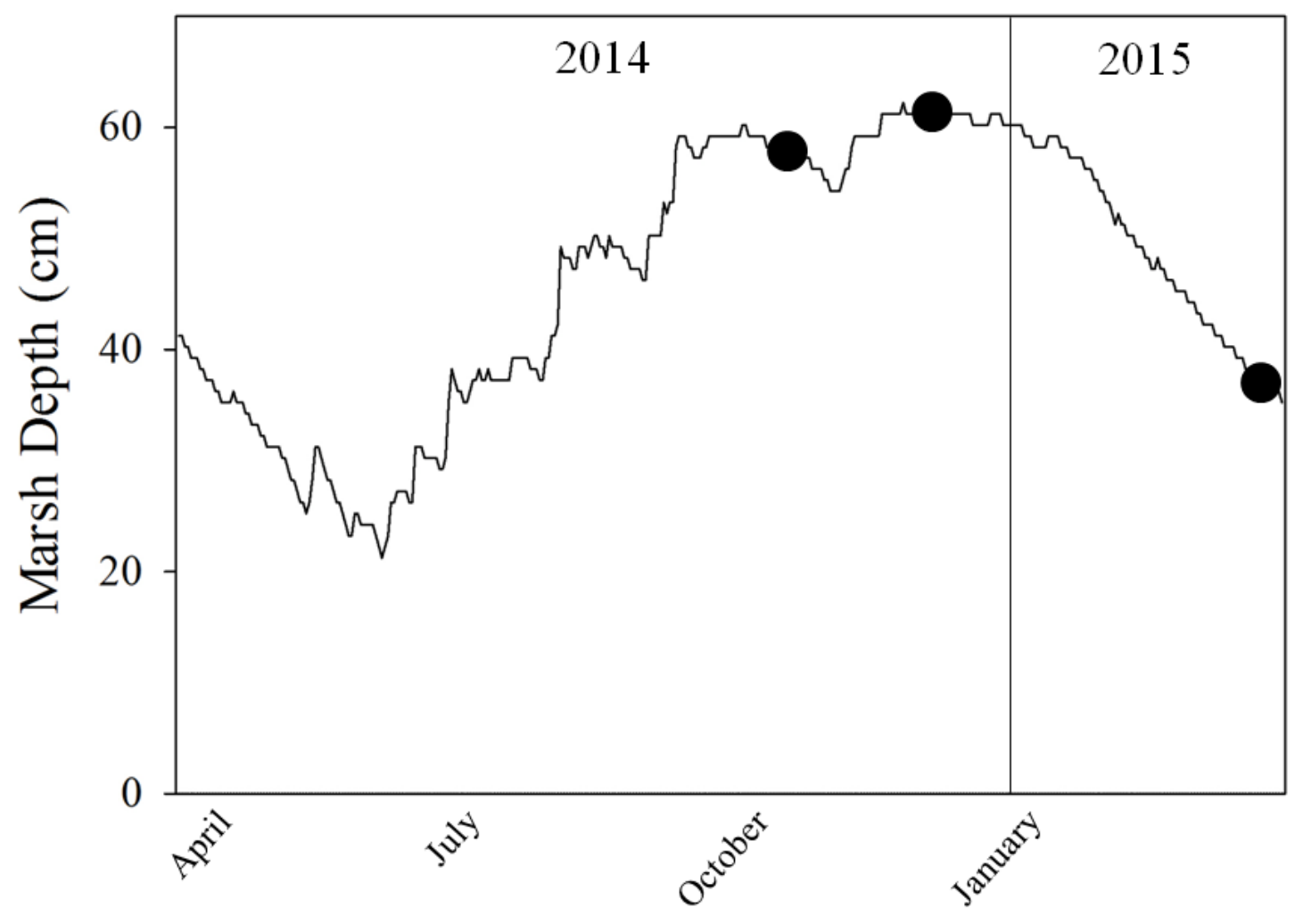


Figure 2
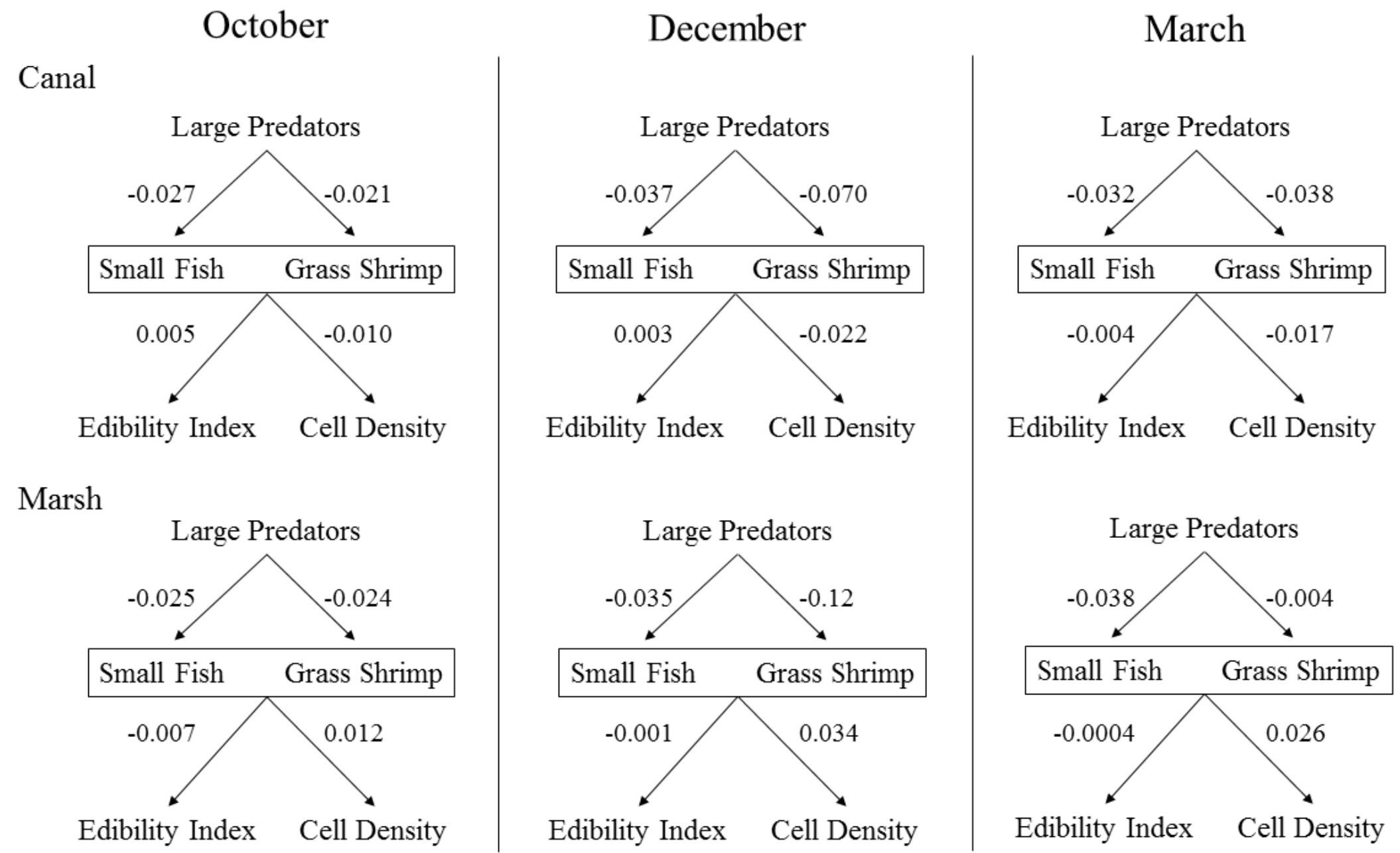
Figure 3

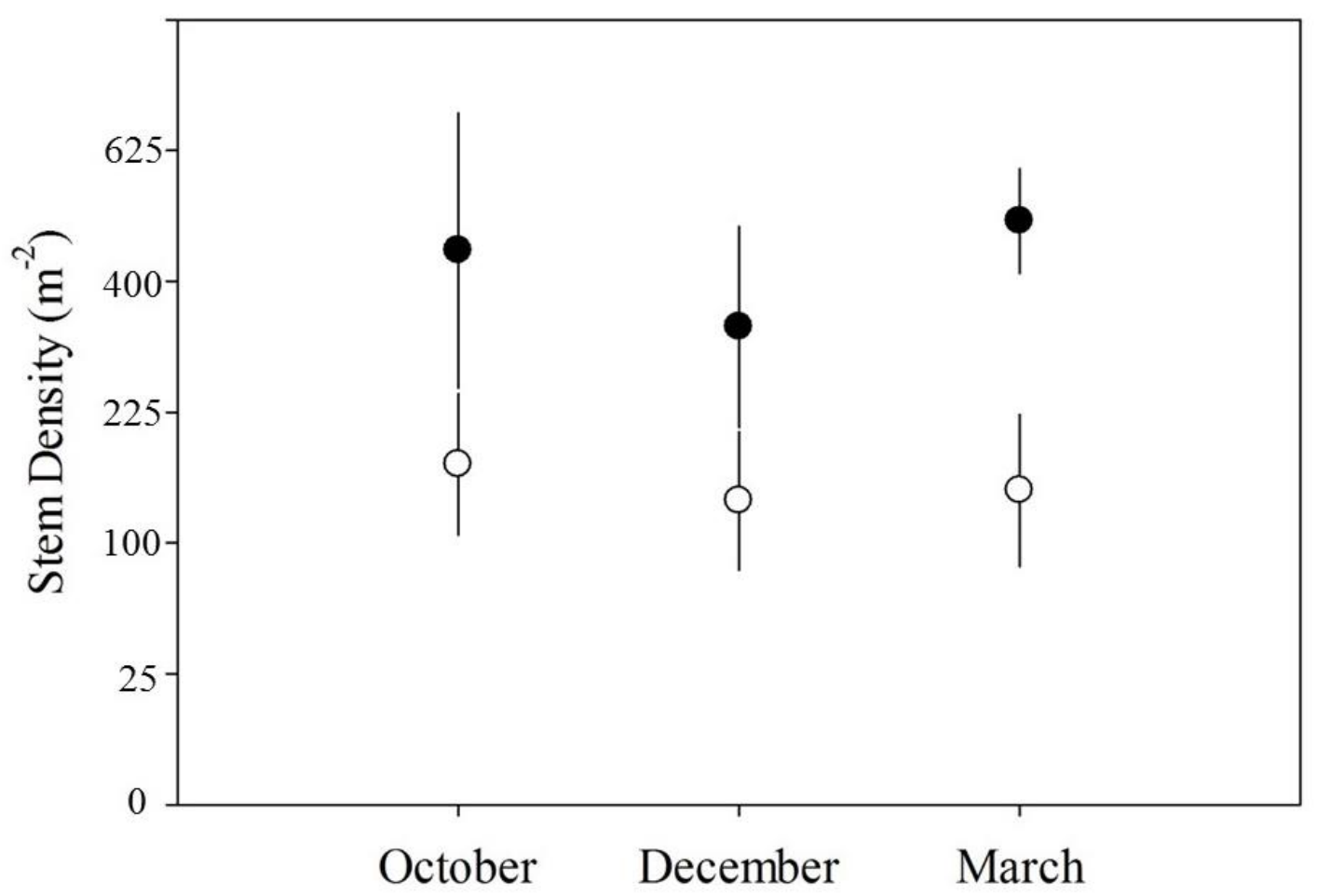


Figure 4

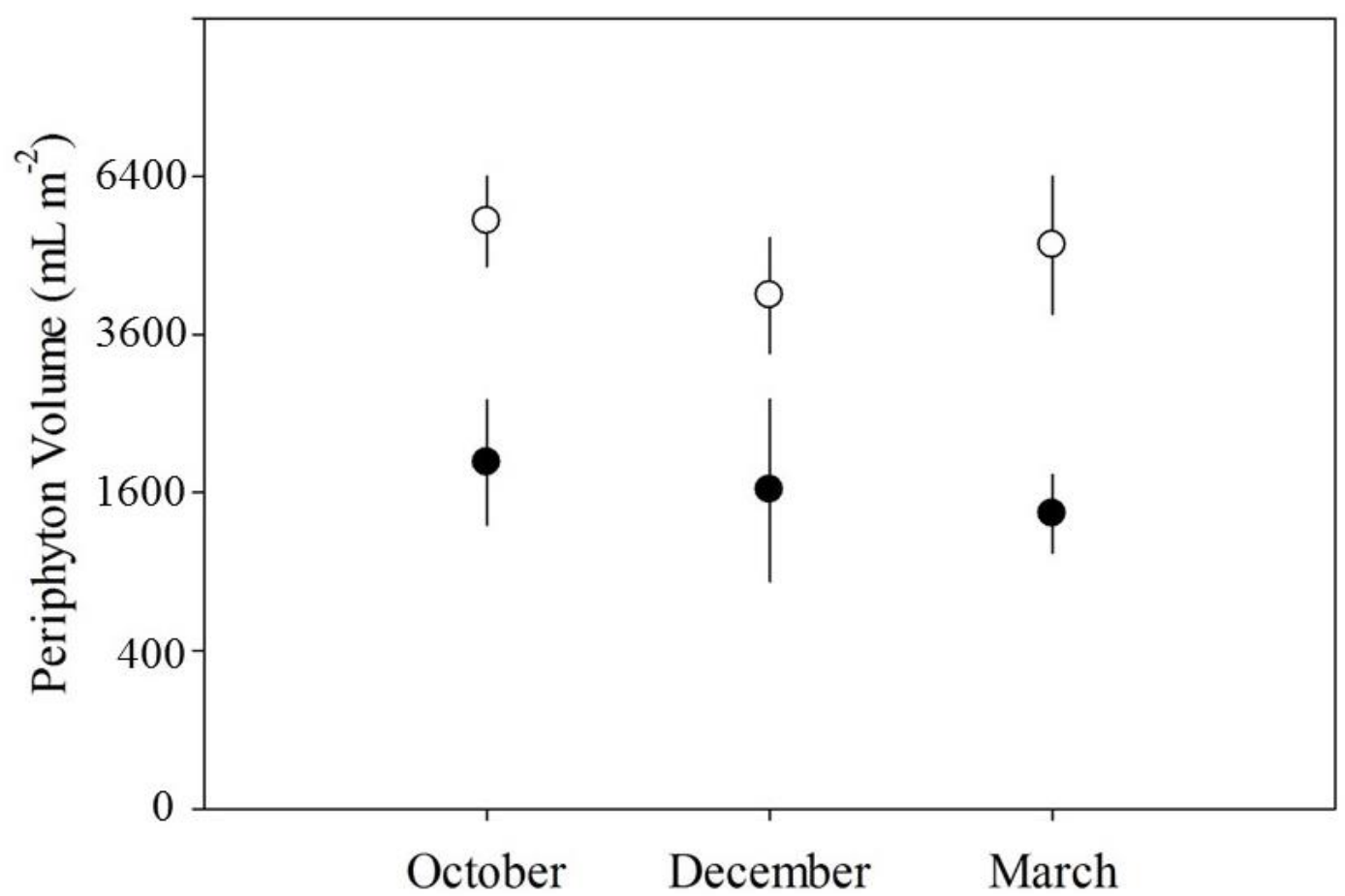




\section{Appendices Captions}

Appendix 1 - Pairwise comparisons of PERMANOVA results, separated by Canal and Marsh. TT denotes “Throw Trap”.

Appendix 2 - Results of SIMPER analyses. Species listed are Eastern Mosquitofish (Gambusia holbrooki), Least Killifish (Heterandria formosa), Sailfin Molly (Poecilia

latipinna), Bluefin Killifish (Lucania goodei), Golden Topminnow (Fundulus chrysotus), Everglades Pygmy Sunfish (Elassoma evergladei), and Bluespotted Sunfish (Ennacanthus gloriosus). TT denotes throw trap. Only the most relatively abundant species contributing to at least $50 \%$ of community dissimilarity were included. Appendix 3A \& B - Concentrations (\%) of phosphorus in Canal (filled circles) and Marsh (open circles) sites. Error bars represent 95\% confidence intervals. 


\section{Appendices}

Appendix 1

\begin{tabular}{lccc}
\hline TREATMENT $\times$ MONTH & T-STATISTIC & DF & P-VALUE \\
\hline Canal October & & & \\
Exclosure vs Control & 0.72 & 4,10 & 0.60 \\
Exclosure vs TT & 3.64 & 4,10 & $<0.01$ \\
Control vs TT & 2.47 & 4,10 & $<0.01$ \\
\cline { 2 - 4 } Canal December & & & \\
Exclosure vs Control & 0.82 & 4,10 & 0.64 \\
Exclosure vs TT & 2.33 & 4,10 & $<0.01$ \\
Control vs TT & 1.81 & 4,10 & 0.02 \\
Canal March & & & \\
Exclosure vs Control & 0.82 & 4,10 & 0.64 \\
Exclosure vs TT & 2.44 & 4,10 & $<0.01$ \\
Control vs TT & 1.86 & 4,10 & $<0.01$ \\
Marsh October & & & \\
Exclosure vs Control & - & - & - \\
Exclosure vs TT & 4.11 & 4,10 & $<0.01$ \\
Control vs TT & 4.62 & 4,10 & $<0.01$ \\
Marsh December & & & \\
Exclosure vs Control & 0.93 & 4,10 & 0.48 \\
Exclosure vs TT & 2.80 & 4,10 & $<0.01$ \\
Control vs TT & 1.92 & 4,10 & 0.03 \\
Marsh March & & & \\
Exclosure vs Control & 0.72 & 4,10 & 0.64 \\
Exclosure vs TT & 2.68 & 4,10 & $<0.01$ \\
Control vs TT & 1.98 & 4,10 & $<0.01$ \\
\hline
\end{tabular}


Appendix 2

\begin{tabular}{|c|c|c|c|}
\hline $\begin{array}{c}\text { Habitat } \times \text { Treatment by } \\
\text { Species }\end{array}$ & Exp Cage Abundance & TT Abundance & $\begin{array}{c}\text { Species } \\
\text { Contribution }(\%)\end{array}$ \\
\hline \multicolumn{4}{|l|}{ October Canal } \\
\hline Sailfin Molly & 5.0 & 1.3 & 21.4 \\
\hline Eastern Mosquitofish & 8.6 & 4.4 & 20.9 \\
\hline Bluefin Killifish & 1.6 & 4.7 & 17.8 \\
\hline \multicolumn{4}{|l|}{ December Canal } \\
\hline Eastern Mosquitofish & 3.2 & 7.0 & 17.3 \\
\hline Bluefin Killifish & 4.2 & 1.3 & 14.7 \\
\hline Golden Topminnow & 7.3 & 5.4 & 13.0 \\
\hline Sailfin Molly & 1.1 & 4.2 & 12.8 \\
\hline \multicolumn{4}{|l|}{ March Canal } \\
\hline Sailfin Molly & 6.3 & 0.0 & 18.7 \\
\hline Everglades Pygmy Sunfish & 0.0 & 5.7 & 16.8 \\
\hline Bluespotted Sunfish & 1.2 & 4.7 & 12.4 \\
\hline Eastern Mosquitofish & 6.9 & 4.8 & 11.0 \\
\hline \multicolumn{4}{|l|}{ October Marsh } \\
\hline Least Killifish & 4.0 & 9.1 & 19.1 \\
\hline Bluefin Killifish & 2.1 & 6.6 & 16.8 \\
\hline Sailfin Molly & 6.4 & 2.5 & 16.2 \\
\hline \multicolumn{4}{|l|}{ December Marsh } \\
\hline Bluefin Killifish & 4.2 & 8.9 & 18.6 \\
\hline Sailfin Molly & 5.6 & 1.8 & 17.7 \\
\hline Golden Topminnow & 0.5 & 4.4 & 14.8 \\
\hline \multicolumn{4}{|l|}{ March Marsh } \\
\hline Least Killifish & 3.9 & 9.7 & 20.8 \\
\hline Bluespotted Sunfish & 1.0 & 5.3 & 15.3 \\
\hline Sailfin Molly & 4.1 & 1.8 & 13.8 \\
\hline Eastern Mosquitofish & 7.0 & 6.7 & 12.6 \\
\hline Canal versus Marsh & Canal Abundance & Marsh Abundance & \\
\hline Sailfin Molly & 3.4 & 4.5 & 17.8 \\
\hline Least Killifish & 8.8 & 6.4 & 16.3 \\
\hline Bluefin Killifish & 3.3 & 5.1 & 15.6 \\
\hline Eastern Mosquitofish & 6.7 & 7.6 & 13.8 \\
\hline
\end{tabular}


Appendix 3

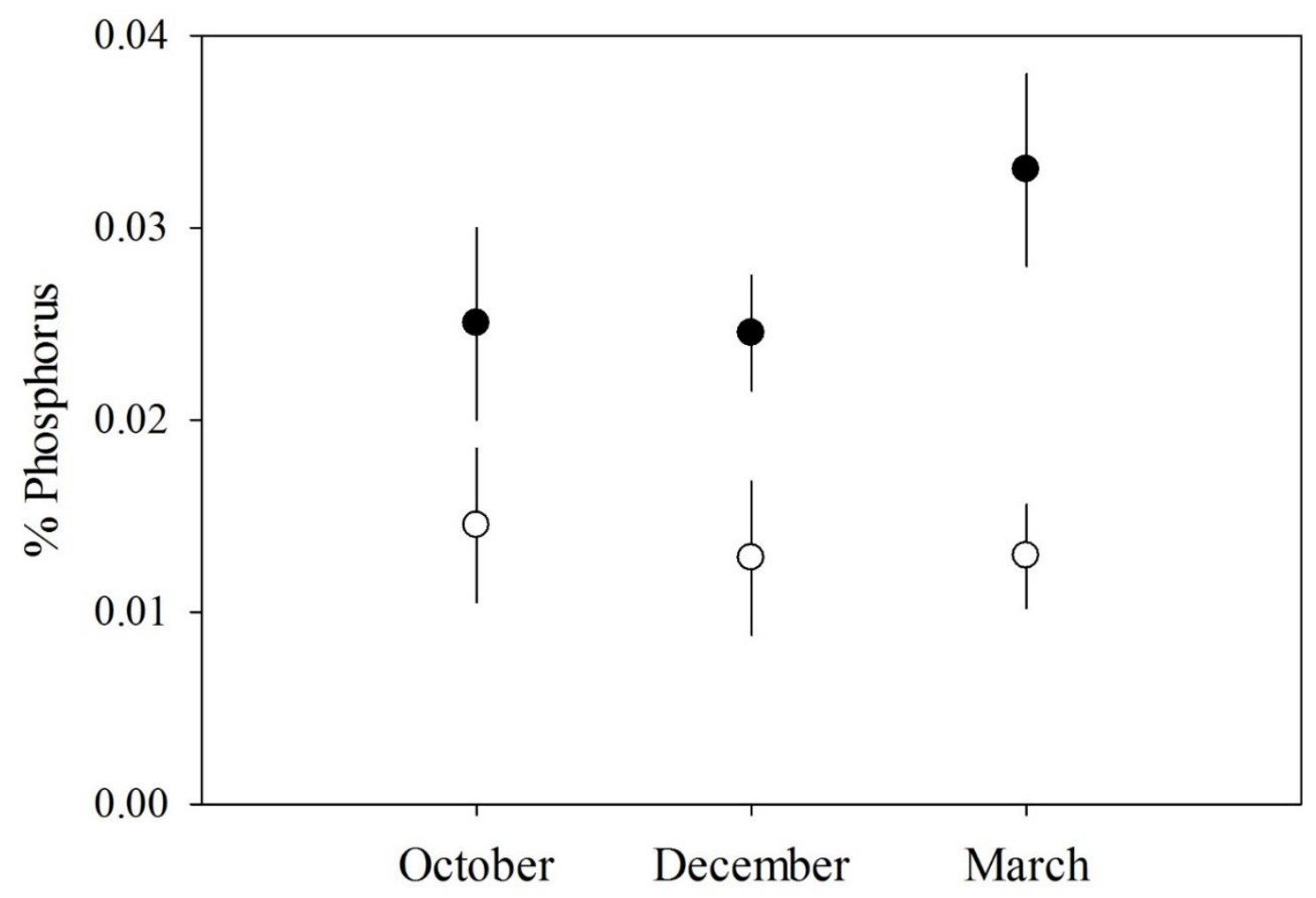


CHAPTER V

\section{CONCLUSIONS AND FUTURE DIRECTIONS}


Alterations of hydroscape structure and configuration can have large impacts on habitat quality and connectivity in dynamic freshwater systems (Cucherousset et al. 2007, Maloney, Parkos et al. 2011). To successfully survive hydroscape variation and seasonal changes in a hydroscape (Trexler et al. 2005, Goss et al. 2014), animals incorporate adaptive movement behaviors that in turn affect population and community dynamics. Documenting these responses will be important for guiding future restoration and conservation efforts in flowing-water systems (Poff et al. 1997, Lytle and Poff 2004, King et al. 2009).

Metacommunity research has largely been limited to invertebrate communities (Cottennie et al. 2003) or simulation exercises (Sokol et al. 2015). Expanding the metacommunity framework (Leibold et al. 2004) to applied situations of ecosystem restoration and management are critical for scientifically-informed conservation strategies to work. My dissertation reports an experimental examination of the effects of hydroscape structure on vertebrate communities. This study incorporates a large-scale physical model (DPM; DPMST 2010) that allowed me to determine how fish behavior, populations, and communities were affected by the alteration of the hydroscape. DPM involved filling in a canal that represented the only deep-water habitat in the area, as well as the degradation of a levee to allow two separated water units to be hydrologically connected for the first time in decades, providing alteration in hydroscape structure ideal for answering questions of biological response to changing conditions.

In Chapter II, I determined the effects of hydroscape alteration on small fishes of the Everglades, using a BACI (Before/After-Control/Impact) design to assess the effects of DPM on small fish behavior, abundance, and community structure. DPM effects on 
species-specific behaviors, such as directional movements and speed, were largely limited to species with strong responses to drought conditions, both positive (Flagfish Jordanella floridae) and negative (Bluefin Killifish - Lucania goodei) (Trexler et al. 2005). Density of small fishes was greatest adjacent to the canal-fill treatments, though behavioral traits of activity and directionality were not documented to change. Composition of communities were altered across the study area by DPM, particularly in sites near the canal fill treatments and adjacent to the degraded levee. However, there was no evidence that two communities previously separated by the earthen levee were approaching convergence after being hydrologically reconnected. These results show metacommunity processes can be affected by hydroscape alteration, even if spatial separation between communities is not great, and that effects of increasing connectivity may require more than two years to be completed, if they homogenize landscapes at all.

A BACI design was also used for Chapter III, examining the effects of hydroscape alteration on large fishes. Largemouth Bass and Bowfin were implanted with radio transmitters and relocated on a weekly basis in canal and marsh habitats to determine the effects of DPM on individual behaviors. Large fish abundance was also examined using airboat-mounted electroshocker transects and dual-frequency sonar (DIDSON). I also investigated the effects of the regional hydroscape, beyond DPM, on large fish behavior, abundance, and community structure. Multi-model selection also revealed that Largemouth Bass and Bowfin step lengths and mean weekly distance from the canal were best explained by the BACI predictor variables, as well as environmental variables such as marsh water depth, photoperiod, and temperature. However, magnitude of behaviors (such as distance moved in a 24 hour period) were often not affected by 
hydroscape alteration from DPM, though Bowfin did exhibit decreased daily movement rates in canal-fill areas compared to unfilled stretches of canal. Hydroscape alterations from DPM had few effects on large fish abundance or community structure, though some were observed. Canal-fill treatments tended to have higher abundances of Largemouth Bass and sunfish (Lepomis spp.) than were observed in the unfilled treatment. Beyond DPM, hydroscape configuration did affect large fish behavior, abundance, and community structure. Mean marsh water depth was often the best predictor variable determining large-fish movement rates and mean distance from the canal, though several predictor variables could contribute to behavior. Daily movement rates were highest when individuals were moving across the marsh-canal ecotone (either direction) than when just movements were begun and ended in one habitat type. Abundances of large fish were always higher in canal edge habitats compared to marsh sites, and community composition was always dissimilar between canal and marsh sites, but not within marsh sites. By increasing the aerial coverage of vegetated habitat similar to the canal edge, DPM canal-fill treatments increased the area of habitat with high density of large fish, including recreational species.

Chapter IV explicitly examined the effects of hydroscape configuration on the trophic interactions of two size classes of consumers and the food web generally. The chapter sought to explain why small fishes are found in higher densities at sites adjacent to canals, even though predators are often found in higher abundances in these areas (this study, Rehage and Trexler 2006; Ruehl and Trexler 2015). Using 1-m² predator exclosure and control (open) cages placed in sites adjacent to a canal as well as sites several hundred meters into a marsh, I determined that small fishes behaved as though 
predation risk was highest at sites near a canal versus the marsh interior, though detection of these behaviors was weak. Grass shrimp (Palaemonetes paludosus) responded as though predation risk was greater in sites near the canal compared to marsh sites. Beyond predation risk, other differences were observed between site types. Elemental phosphorus was highest in sites adjacent to the canal, possibly offering better foraging opportunities for small consumers (Gaiser et al. 2004, Trexler et al. 2015). There also were localized differences in habitat structure between the site types. Emergent vegetation was denser in sites adjacent to the canal, but amount of periphyton was greatest in marsh sites. These results indicate that trophic dynamics can be influenced by a multitude of factors, including predation risk, local habitat structure, and nutrient quality, all of which are influenced by hydroscape configuration.

Hydroscape structure, including both dynamic (changing water depth) and static (the presence of a canal) can have large impacts on animal behavior, abundance, and community structure. This dissertation supports the growing body of evidence that hydroscape structure can play important roles in ephemeral wetland function and that anthropogenic modifications can impact ecosystem processes (Ogston et al. 2014, Parkos et al 2014, Dittrich et al. 2016). It also provides evidence on how restoration efforts can have important implications for the behaviors of individuals, in turn scaling up to affect metacommunity processes. This dissertation represents one of the most comprehensive examinations of aquatic, vertebrate metacommunities and how they are affected by the configuration of the hydroscape. This is also the first study examining the movement behaviors of Bowfin (Amia calva), a poorly-studied species that is a common piscivore in many freshwater systems in eastern North America. Future research should continue to 
examine the effect of hydroscape structure on metacommunity structure and behaviors in the DPM footprint. As time moves further away from DPM construction, the affected area continues to get colonized by vegetation and sediment continues to consolidate, it may further affect biological processes. Careful monitoring will further expand the body of knowledge on how hydroscape alteration can affect biological processes.

\section{Literature Cited}

Cucherousset J, Carpentier A, Paillisson JM (2007) How do fish exploit temporary water throughout a flooding episode? Fish Manag Ecol 14:269-276

Decomp Physical Model Science Team (DPMST) (2010) The Decomp Physical Model Science Plan. 52pp. Located in Documentum at: Cabinets/Project Teams/Decomp/DecompPhysical Model (DPM)/Environmental Assessment/Final Dec 2009/Print/Science Plan

Dittrich J, Dias JD, Bonecker CC, Lansac-Toha FA, Padial AA (2016) Importance of temporal variability at different spatial scales for diversity of floodplain aquatic communities. Freshw Biol 61:316-327

Gaiser EE, Scinto LJ, Richards JH, Jayachandran K, Childers DL, Trexler JC, Jones RD (2004) Phosphorus in periphyton mats provides the best metric for detecting lowlevel P enrichment in an oligotrophic wetland. Water Res 38:507-516

Goss CW, Loftus WF, Trexler JC (2014) Seasonal fish dispersal in ephemeral wetlands of the Florida Everglades. Wetlands 34:147-157

King AJ, Tonkin Z, Mahoney J (2009) Environmental flow enhances native fish spawning and recruitment in the Murray River, Australia. Riv Res App 25:12051218

Leibold MA, Holyoak M, Mouquet N, Amarasekare P, Chase JM, Hoopes MF, Holt RD, Shurin JB, Law R, Tilman D, Loreau M (2004) The metacommunity concept: a framework for multi-scale community ecology. Ecol Lett 7:601-613

Lytle DA, Poff NL (2004) Adaptation to natural flow regimes. TREE 19:94-100

Ogston L, Gidora S, Foy M, Rosenfeld J (2014) Watershed-scale effectiveness of floodplain habitat restoration for juvenile coho salmon in the Chilliwack River, Columbia. Can J Fish Aq Sci 72:479-490 
Parkos JJ III, Ruetz CR III, Trexler JC (2011) Disturbance regime and limits on benefits of refuge use for fishes in a fluctuating hydroscape. Oikos 120:1519-1530

Parkos JJ III, Trexler JC (2014) Origins of functional connectivity in a human-modified wetland landscape. Can J Fish Aq Sci 71:1418-1429

Poff NL, Allan JD, Bain MB, Karr JR, Prestegaard KL, Richter BD, Spark

RE,Stromberg JC (1997) The natural flow regime. BioScience 47:769-784

Rehage JS, Trexler JC (2006) Assessing the net effect of anthropogenic disturbance on aquatic communities in wetland: community structure relative to distance from canals. Hydrobiologia 569:359-373

Sokol ER, Brown BL, Carey CC, Tornwall BM, Swan CM, Barrett JE (2015) Linking management to biodiversity in built ponds using metacommunity simulations. Ecol Model 296:36-45.

Trexler JC, Gaiser EE, Kominoski JS, Sanchez JL (2015) The role of periphyton mats in consumer community structure and function in calcareous wetlands: lessons from the Everglades. Pages 155-179 in Entry JS, Gottlieb AD, Jayachandran K, Ogram A (editors). Taylor and Francis, Oxfordshire, UK

Trexler JC, Loftus WF, Perry S (2005) Disturbance frequency and community structure on a twenty-five year intervention study. Oecologia 145:140-152 
VITA

\section{MICHAEL ROSS BUSH}

$2002-2008$

B.S., Fisheries and Wildlife

University of Minnesota - Twin Cities

Minneapolis, MN

$2008-2010$

National Audubon Society

2010-2017

Doctoral Candidate

Florida International University

Miami, Florida

\section{PUBLICATIONS, TECHNICAL REPORTS, AND PRESENTATIONS}

Stroud, JT, MR Bush, MC Ladd, RJ Nowicki, AA Shantz, JL Sweatman (2015) Is a community still a community? Reviewing definitions of key terms in community ecology. Ecology and Evolution. DOI: 10.1002/ece3.1651

Boucek R, C Barrientos, MR Bush, DA Gandy, C Hartman, KL Wilson, JM Young (in press in Environmental Biology of Fishes) Water column primary productivity, not temperature, best predicts condition of a temperate freshwater fish occurring at its equatorial range

Rosen B et al. (2013) The Decomp Physical Model (DPM) 2013 Annual Report: Pre-flow baseline monitoring of the Water Conservation Area (WCA) 3

Decompartmentalization and Sheet Flow Enhancement Project. US Geological Survey

Rosen B et al. (2015) The Decomp Physical Model (DPM) 2015 Annual Report: Pre-flow (baseline) and high-flow monitoring of the Water Conservation Area (WCA) 3 Decompartmentalization and Sheet Flow Enhancement Project. US Geological Survey

Sklar F et al. (2015) Everglades Research and Evaluation (Chapter 6) in South Florida Environmental Report 2015. South Florida Water Management District 
Bush MR, S Bornhoeft, JC Trexler. Ecotone proximity, threat of predation, and community structure in a dynamic wetland. Society for Freshwater Science, Milwaukee, WI, May 2015 (Oral presentation)

Bush MR, S Bornhoeft, J Gatto, JC Trexler. Effects of flow and connectivity on Everglades aquatic consumers: evaluating three hypotheses. Greater Everglades Ecosystem Restoration Conference, Coral Springs, FL, April 2015 (Oral presentation)

Bush MR, S Bornhoeft, JC Trexler. Effects of landscape structure on aquatic animal communities and behavior. Florida Coastal Everglades Mid-term Review III, Miami, FL, March 2015 (Poster presentation)

Bush MR. The role of landscape changes on fishes of the Everglades. Corkscrew Swamp Sanctuary, Naples, FL, February 2015 (Invited public oral presentation)

Bush MR and JC Trexler. Variable movement strategies of small fishes in a dynamic wetland. Joint Aquatic Sciences Meeting, Portland, OR, May 2014 (Oral presentation)

Bush MR and JC Trexler. Variation in movement strategies of small fishes in a dynamic wetland. $98^{\text {th }}$ Annual Meeting of the Ecological Society of America, Minneapolis, MN, August 2013 (Oral presentation)

Bush MR and JC Trexler. Landscape factors and environmental cues affecting movement decisions by large predators in an aquatic ecosystem. $97^{\text {th }}$ Annual Meeting of the Ecological Society of America, Portland, OR, August 2012 (Oral presentation)

Bush MR and JC Trexler. Effects of canals and levees on fish movement. 96 ${ }^{\text {th }}$ Annual Meeting of the Ecological Society of America, Austin, TX, August 2011 (Poster presentation)

Bush MR and SE Liston. Non-indigenous fishes of Big Cypress National Preserve. $1^{\text {st }}$ Annual Big Cypress Research Symposium, Ochopee, FL, October 2009 (Poster presentation) 